\title{
The molecular determinants of methicillin-resistance and virulence of Staphylococcus aureus : a cross- border study in Europe
}

Citation for published version (APA):

Deurenberg, R. H. C. A. (2005). The molecular determinants of methicillin-resistance and virulence of Staphylococcus aureus : a cross-border study in Europe. [Doctoral Thesis, Maastricht University]. Universiteit Maastricht. https://doi.org/10.26481/dis.20050929rd

Document status and date:

Published: 01/01/2005

DOI:

10.26481/dis.20050929rd

Document Version:

Publisher's PDF, also known as Version of record

Please check the document version of this publication:

- A submitted manuscript is the version of the article upon submission and before peer-review. There can be important differences between the submitted version and the official published version of record.

People interested in the research are advised to contact the author for the final version of the publication, or visit the DOI to the publisher's website.

- The final author version and the galley proof are versions of the publication after peer review.

- The final published version features the final layout of the paper including the volume, issue and page numbers.

Link to publication

\footnotetext{
General rights rights.

- You may freely distribute the URL identifying the publication in the public portal. please follow below link for the End User Agreement:

www.umlib.nl/taverne-license

Take down policy

If you believe that this document breaches copyright please contact us at:

repository@maastrichtuniversity.nl

providing details and we will investigate your claim.
}

Copyright and moral rights for the publications made accessible in the public portal are retained by the authors and/or other copyright owners and it is a condition of accessing publications that users recognise and abide by the legal requirements associated with these

- Users may download and print one copy of any publication from the public portal for the purpose of private study or research.

- You may not further distribute the material or use it for any profit-making activity or commercial gain

If the publication is distributed under the terms of Article 25fa of the Dutch Copyright Act, indicated by the "Taverne" license above, 
The molecular determinants of methicillin-resistance and virulence of

Staphylococcus aureus

A CROSS-BORDER STUDY IN EUROPE

Ruud H. Deurenberg 
Copyright $\odot 2005$ Ruud H. Deurenberg, Kerkrade, The Netherlands

Production: Datawyse B.V., Maastricht, The Netherlands

ISBN $90-90197-44-3$ 
The molecular determinants of

methicillin-resistance and virulence of

Staphylococcus aureus

A CROSS-BORDER STUDY IN EUROPE

\section{PROEFSCHRIFT}

Ter verkrijging van de graad van doctor aan de Universiteit Maastricht, op gezag van de Rector Magnificus Prof. Mr. G.P.M.F. Mols, volgens het besluit van het College van Decanen

in het openbaar te verdedigen op donderdag 29 september 2005 om 12:00 uur

door

Ruud Hubert Catherina Antonius Deurenberg geboren te Heerlen op 15 mei 1970 
Promotor

Prof. Dr. C.A. Bruggeman

Co-promotors

Dr. E.E. Stobberingh

Dr. C. Vink

\section{Beoordelingscommissie}

Prof. Dr. J.F. Glatz (voorzitter)

Prof. Dr. E.M. van den Berg-Loonen

Prof. Dr. G.d. Dinant

Prof. Dr. J.A.A. Hoogkamp-Korstanje

Prof. Dr. M.M. leven (Universitair Ziekenhuis Antwerpen, België) 
For those Il love

I"m always living alone An ancient cave is my home

See the look in my eyes They think I'm a mysterious man Cause people do all they can To avoid evil eyes (Keyyak - Mertinn) 
CONTENTS

Chapter 1 Aims of the study \& Outline of the thesis

Chapter 2 The molecular evolution of methicillin-resistant Staphylococcus aureus

Chapter 3 Rapid detection of Panton-Valentine leukocidin from clinical isolates of Staphylococcus aureus strains by real-time PCR

Chapter 4 Different clonal complexes of methicillin-resistant Staphylococcus aureus are disseminated in the Euregio Meuse-Rhine

Chapter 5 The prevalence of the Staphylococcus aureus tst gene among community- and hospital-acquired strains and isolates from Wegener's Granulomatosis patients

Chapter 6 Molecular characterisation of methicillin-resistant Staphylococcus aureus bloodstream isolates from Croatia

Chapter 7 Ciprofloxacin resistance is not a marker for methicillin-resistant Staphylococcus aureus in The Netherlands

Chapter 8 General discussion \& Summary

Dankwoord

Curriculum vitae 


\begin{tabular}{|c|c|}
\hline $\mathrm{APC}$ & Antigen-Presenting Cell (APC) \\
\hline$b p$ & base pair \\
\hline CA-MRSA & Community-Acquired Methicillin-Resistant Staphylocaccus aureus \\
\hline $\mathrm{CC}$ & Clonal Complex \\
\hline $\operatorname{cor}$ & cassette chromosome recombinase \\
\hline CFU & Colony Forming Unit \\
\hline CNS & Coagulase-Negative Staphylococci \\
\hline dNTP & deoxyribonucleotide triphosphate \\
\hline EMR & Euregio Meuse-Rhine \\
\hline ET & Exfoliative Toxin \\
\hline EU & European Union \\
\hline HA-MRSA & Hospital-Acquired Methicillin-Resistant Staphylococcus aureus \\
\hline $\mathrm{MHC}$ & Major Histocompatibility Complex \\
\hline MIC & Minimal Inhibitory Concentration \\
\hline MLST & Muttilocus Sequence Typing \\
\hline MRCNS & Methicillin-Resistant Coagulase-Negative Staphylococci \\
\hline MRSA & Methicillin-Resistant Staphylococcus aureus \\
\hline MSSA & Methicillin-Sensitive Staphylacoccus aureus \\
\hline NCCLS & National Committee for Clinical Laboratory Standards \\
\hline NT & Not Typeable \\
\hline PBP & Penicillin Binding Protein \\
\hline PCR & Polymerase Chain Reaction \\
\hline PFGE & Pulsed-Field Gel Electrophoresis \\
\hline PVL & Panton-Valentine lleukocidin \\
\hline $\mathrm{SAg}$ & Superantigen \\
\hline ScCmec & Staphylococcal Cassette Chromosome mec \\
\hline $\mathrm{SD}$ & Standard Deviation \\
\hline SE & Staphylacoccal Enterotoxin \\
\hline SLV & Single Locus Variant \\
\hline ST & Sequence Type \\
\hline TAE & Tris-Acetate-EDTA \\
\hline TST & Toxic Shock Syndrome \\
\hline TSST-1 & Toxic Shock Syndrome Toxin-1 \\
\hline UPGMA & Unweighted Pair Group Matching Analysis \\
\hline WG & Wegener's Granulomatosis \\
\hline
\end{tabular}




\section{CHAPTER 1}

AIMS OF THE STUDY \& OUTLINE OF THE THESIS 


\section{AIMS OF THE STUDY}

Since its discovery in the 1880s, Staphylococcus aureus has emerged as a potential pathogenic Gram-positive bacterium that can cause various diseases, ranging from skin infections to post-operative wound imfections. Shortly after the introduction of methicillin in 1959, methicillin-resistant S. aureus (MRSA) strains have been isolated in the United Kingdom. Subsequently, several MRSA clones, which differ in their genetic background, disseminated worldwide. The pathogenicity of $S$. aurous can be attributed to the production of virulence factors, such as Panton-Valentine leukocidin (PVL) and superantigens (SAgs), like Toxin Shock Syndrome Toxin-1 (TSST-1).

Any strategies to contain the dissemination of MRSA, either in the community, the hospital, at national or international level, require knowledge about the MRSA clones that are disseminated. Cross-border patient mobility and free access to health care facilities within the European Union (EU) in general, and the border regions in particular, are important issues for patients, doctors, hospitals, sickness funds and the health care insurance companies. Cross-border transfer of patients may have an important impact on the dissemination and prevalence of MRSA, in particular in cases where patients are transferred from countries with a relatively high prevalence to a country with a low prevalence.

The aims of this study were the molecular characterisation of $S$. aureus strains from several European countries (Belgium, Croatia, Germany and The Netherlands) with respect to the resistance to methicillin and the presence of the virulence factors PVL and TSST-1, and to test the usefulness of ciprofloxacin resistance as a predictive marker for MRSA in The Netherlands.

\section{OUTLINE OF THE THESIS}

This thesis describes the characterisation of MRSA isolates from the Euregio Meuse-Rhine (EMR), the border region of Belgium, Germany and The Netherlands, and Croatia using several typing techniques, such as. Pulsed-Field Gel Electrophoresis (PFGE), SCCmec typing and Multilocus Sequence Typing (MLST). Furthermore, the presence of the virulence factors PVL and TSST-1 was investigated. In chapter 2 a review of the literature is presented. This review includes the construction of Staphylocaccal Cassette Chromosome mec ( $\mathrm{SCC} m e c)$, the molecular evolution of both hospital-acquired (HA-MRSA) and community-acquired MRSA (CA-MRSA), the biology of virulence factors, such as PVL and TSST-1, the worldwide prevalence of HA-MRSA and CA-MRSA, and the risk factors associated with colonisation of HA-MRSA and CA- 
MRSA. Since CAMMSA isolates often harbour PVL, a real-time PCR method was developed for the detection of PVL, using clinical isolates of S. aureus strains, without prior DNA isolation. Furthermore, the specificity, reproducibility, and detection limit of this assay were investigated and a study was performed to investigate the prevalence of PVL among both community-acquired (CA) and hospital-acquired (HA) S aureus bloodstream isolates from The Netherlands (Chapter 3). This real-time PCR assay was used to investigate the prevalence of PVL in the EMR. Furthermore, the clonal dissemination of MRSA isolates was investigated using PFGE. SCCmec typing and MLST were used to investigate which MRSA clones are present in the EMR. Finally, the relation between the antibiotic susceptibility pattern and the SCCmec type was investigated (Chapter 4). Since TSST-1 is another important $S$. aureus virulence factor, another real-time PCR was developed for the tst gene, encoding TSST-1. The specificity, reproducibility, and detection limit were evaluated. Furthermore, the prevalence of the tst gene in $\mathrm{CA}$ and $\mathrm{HA} S$. aureus strains, and isolates from Wegener's Gramulomatosis patients from The Netherlands was investigated. Furthermore, the clonal relationship between the tst-positive strains was investigated with PFGE (Chapter 5). This real-time PCR, together with the real-time PCR assay for PVL, was used to investigate the prevalence of PVL and TSST-1 among Croatian MRSA bloodstream isolates. Furthermore, these strains were characterised using the antibiotic susceptibility pattern and PFGE. SCCmeo typing and MLST were used to investigate which MRSA clones are present in Croatia (Chapter 6). Since most of the MRSA strains studied were resistant to ciprofloxacin, a study was performed to investigate if ciprofloxacin resistance of $S$. aureus is a biological marker for MRSA in The Netherlands. Finally, the prevalence of the high-level mupirocin gene ileS-2 was irnestigated with PCR among the $S$, aureus isolates from The Netherlands (Chapter 7). At the end, a general discussion and summary of the study is given (Chapter $\mathbf{8}$ ). 


\section{CHAPTER 2}

\section{The molecular evolution of methicillin-resistant Staphylococcus aureus}

Ruud H. Deurenberg, Cornelis Vink, Smilja Kalenic, Alexandler W. Friedrich, Cathrien A. Bruggeman and Ellen E. Stobberingh

Journal of Antimicrabial Chemotherapy. 2005. In preparation 


\section{ABSTRACT}

Staphylococcus aureus is a potential pathogenic bacterium that can cause various diseases. S. aureus has a strong adaptive power to antibiotics. Since the introduction of methicillin in 1959, MRSA strains have been isolated, and several hospital-acquired MRSA (HA-MRSA) clones have disseminated worldwide. The prevalence of HA-MRSA ranges from $0.6 \%$ in The Netherlands to $66.8 \%$ in Japan. Resistance to methicillin is caused by the mecA gene, which is situated on a mobile genetic element, the Staphylococcal Cassette Chromosome mec (SCCmec). To date, five different SCCmec types (I to $\mathrm{V}$ ) have been distinguished. All these SCCmec elements carry genes encoding fior resistance to $\beta$-lactam antibiotics as well as genes for the regulation of expression of mecA. Additionally, SCCmec types II and III carry non- $\beta$-lactam antibiotic resistance genes on integrated plasmids and transposons. SCCmec have been acquired at least twenty times by different lineages of $S$. aureus. Although most MRSA strains are hospital-acquired, community-acquired strains (CA-MRSA) have also been repoited recently. Worldwide, the prevalence of CA-MRSA is $0.5 \%$. Several risk factors have been identified for colonisation with CA-MRSA and HA-MRSA. S. aureus can produce several virulence factors, such as Panton-Valentine leukocidin (PVL), which, together with SCCmec type IV, is suggested to be a marker for CA-MRSA. Furthermore, s. aureus can produce several superantigens (SAgs), such as staphylococcal endotoxins (SEs) and toxic shock syndrome toxin-1 (TSST-1), causing several diseases, like food poisoning and toxin shock syndrome (TSS).

\section{INTRODUCTIION}

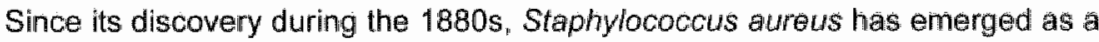
potential pathogenic Gram-positive bacterium that can cause vartous diseases, ranging from minor infections of the skin to post-operative wound infections, bacteraemia, infections associated with foreign bodies and necrotising pneumonia. Until the introduction of penicillin, the mortality rate of patients infected with $S$. aureus was about $80 \%$. In the early 1940 s, 5 . aureus infections were treated with penicillin, but in 1942 the first strains resistant to this antibiotic were isolated, first in hospitals, and later in the community. Since 1960 around $80 \%$ of all $S_{\text {. }}$ aureus strains were resistant to penicillin. These resistant strains produced a plasmidmencoded enzyme, penicillinase, which hydrolysed penicillin. $S$. aureus has shown a strong adlaptive power to antibiotics, first to methicillin, a semi-synthetic derivate of penicillin, through the acquisition of a mobile genetic element ( $\mathrm{SCC} m e c$ ), and recently to wancomycin through the acquisition of the vanA gene $(53,54)$. 


\section{STAPHYLOCOCCAL CAsSETTE CHROMOSOME MEC}

The resistance of $S$ aureus to methicillin is caused by the presence of the mecA gene, which encodes the $78-\mathrm{kDa}$ penicillin binding protein (PBP) $2 \mathrm{a}$, which thas transpeptidase activity. Normally, $\beta$-lactam antibiotics bind to PBPs in the cell wall, resulting in the disruption of the synthesis of the peptidoglycan layer. Consequently, the bacterium dies. Since $\beta$-lactam antibiotics cannot bind to PBP2a, synthesis of the peptidoglycan layer is not disrupted and cell wall synthesis continues. Consequently. the bacterium survives and becomes resistant to $\beta$-lactam antibiotics. The mecA gene is regulated by both the repressor $\mathrm{Mecl}$ and the transmembrane $\beta$-lactam-sensing signal-transducer MecR1, which are both divergently transcribed. In the absence of a B-lactam antibiotic, Mecl represses the transcription of both mecA and mecR1-mecl, but in the presence of a $\beta$-lactam antibiotic, MecR1 is auto-catalytically cleaved and a metalloprotease domain. that is located in the cytoplasmic part of MecR1, becomes active. The metalloprotease cleaves $\mathrm{Mecl}$ bound to the operator region of mecA, which allows transcription of mecA and production of PBP2a to occur (5). Both mecl and mecR 1 can be truncated by the insertion sequences $1 S 431$ or IS1272 and this result in a de-repression of the mecA gene (44).

The $2.1-\mathrm{kb}$ mecA gene is lacated on a mobile genetic element, which is designated the Staphylococcal Cassette Chromosome mec (SCCmec) (39). Currently, five main types of SCCmec (type I to $\mathrm{V}$ ) are distinguished, ranging in size from 20.9 to $66.9 \mathrm{~kb}$ (Figure 1). SCCmec types I, II and III (34.3,53.0 and $66.9 \mathrm{~kb}$, respectively) are associated with hospitall-acquired MRSA (HA-MRSA), whereas types IV and V (20.9 to 24.3 and $28 \mathrm{~kb}$, respectively) are associated with community-acquired MRSA (CAMRSA) (16, 36, 37, 38). SCCmec types I, IV or $V$ exclusively encode for resistance to B-lactam antibiotics. By contrast, SCCmec types II and III determine multi-resistance as these cassettes carry both integrated plasmids (e.g. pUB110, pl258 and/or pT181) and transposon Tn554 containing drug resistance genes. Integrated plasmid pUB110 carries the ant $\left(4^{\prime}\right)$ gene, responsible for resistance to aminoglycosides. pl258 codes for resistance to penicillins and heavy metals. Plasmid pT181 codes for tetracycline resistance, while transposon Tin 554 carries the ermA gene, which is responsible for inducible MLS resistance (Figure 1) $(39,48)$. SCCmec also carries insertion sequences, such as IS431 and IS1272, and they have a key role in the insertion of the above mentioned plasmids and transposon. Also situated on SCCmec are the genes responsible for the regulation of the transcription of mecA: $\triangle$ mecR1 (on SCCmec types I. IV and V), mecR1 and med (on SCCmec types II and III) (16, 37, 38, 39). These genes are situated in mec complexes and four mec complexes have been identified: 

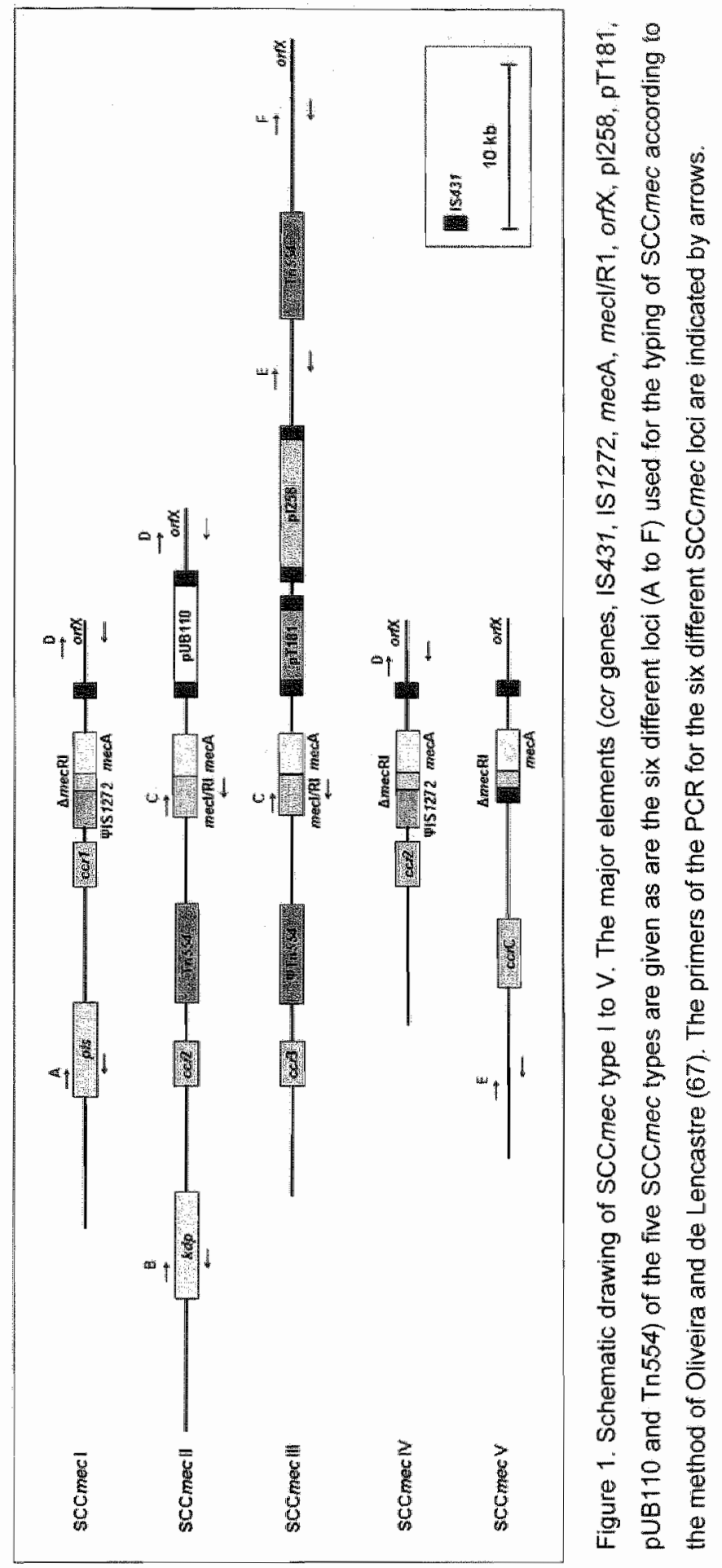
class A: med-mecR1-mecA-1S431 (in ScCmec types II and III); class B: IS1272$\Delta m e c R 1-m e c A-4431$ (in SCCmec types I and IV), class C: IS431- $\triangle$ mecR1-mecAIS431 (in SCCmec type V) and class D: $\triangle$ mecR1-mecA-IS431 (in methicillin-resistant S. caprae) $(37,38,44)$.

For integration into and excision from the chromosome at a specific site (attBscc), genes encoding cassette chromosome recombinases (ccr) are located within the SCCmec elements. These genes are designated ccrAl and ccrB1 (in SCCmec type 1), ccrA2 and corB2 (in SCCmec types II and IV), ccrA3 and cCrB3 (in SCCmec type III), ccrA4 and corB4 (in SCCmec type IV of MRSA strain HDE288) and CCrC (in sccmec type $V)(16,36,38,44,68)$. The regions bordering the mec and ccr complexes, integrated plasmids and transposons are designated the $J$ (junkyard) regions (Figure 1) (38).

SCCmec was probably transferred from other staphylococcal species to $S$. aureus, but the origin of SCCmec is still unknown. S. epidermidis could be a source of SCCmec, since it has been shown that it harbours SCCmec type I to IV (104). It has also been demonstrated that an epidemic methicillin-susceptible S. aureus (MSSA) and, subsequently, an isogenic MRSA strain were isolated from a neonate who had never been in contact with MRSA. The mecA gene was identical to that of a $S$. epidermidis strain isolated from the same patient. It was concluded that the isolated MRSA strain had emerged in wivo by horizontal transfier of mecA between staphylococcal species (103). In a further study, a PBP homologue with $87.8 \%$ amino acid homology with PBP2a was identified in $S$. sciuri strains and this could be a precursor of PBP2a in MRSA. These strains were all susceptible to methicillin, but upory growth of the strains in the presence of methicillin, they became resistant to methicillin through an increase in the rate of transcription of the mecA homologue, due to a point mutation in the promoter. Furthermore, upon introduction of this mecA homologue into MSSA, it became resistant to methicillin and could thus be classified as MRSA (106).

The first MRSA strain (NCTC10442) isolated in 1961 in the United Kingdom (UK) harboured SCCmec type $\|$ and this Archaic clone spread around the world in the 1960s. In 1982, an MRSA strain (N315) with SCCmec type II was discovered in Japan and this New York/Japan clone spread worldwide "followed in 1985 by the discovery of an MRSA strain (82/2082) harbouring SCCmec type III in New Zealand. MRSA strains harbouring SCCmec IV spread around the world in the 1990s and at the beginning of the 21 st century the first MRSA strain (WIS) with SCCmec type $V$ was isolated in Australia $(38,97,98)$. 


\section{THE EVOLUTION OF HOSPITAL-ACQUIRED MRSA}

Methicillin was first introduced in 1959, but two years later, in 1961, MRSA strains, harbouring SCCmec type I, were isolated in the UK. Since then, MRSA has disseminated to other European countries in the 1960s, and thereafter, in the 1970s, to Australia, Japan and the USA. Currently MRSA is a major cause of nosocomial infections worldwide. The worldwide spread of MRSA is driven by the dissemination of a number of clones with a specific genetic background adapted to virulence and the hospital environment (Table 1) $(11,17,18,24,26,34,45,58,64,69,73,89,99)$. HAMRSA is characterised by SCCmec type I, II or III and most of the HA-MRSA strains have a multi-resistant pattern, although a recent report showed that SCCmec type IV can also be associated with HA-MRSA (83).

Multilocus sequence typing (MLST) is an excellent tool to irvestigate the clonal evolution of MRSA. MLST investigates the DNA sequence of highly conserved DNA regions $( \pm 500 \mathrm{bp}$ ) from seven $S$. aureus housekeeping genes, i.e. arcC, aroE glpF, $g m k, p t a_{n}$ tpi and yqiL. Different sequences are thus assigned as distinct alleles for each housekeeping gene and each isolate is defined by the alleles of the seven housekeeping genes. This results in an allelic profile or Sequence Type (ST). For example, the Iberian clone has the MLST profile 3-3-1-12-4-4-16 and ST247 (http://www.mist.net). Currently, the MRSA nomenclature is based on the ST and the SCCmec type, i.e. ST247-MRSA-I is the Iberian clone harbouring SCCmec type I. Furthermore, clonal complexes (CCs) can be defined with the software package BURST (Based Upon Related Sequence Types) to analyze evolutionary events (http://wmw.mlst.net). S. aureus strains are grouped within one $\mathrm{CC}$ when 5 of the 7 housekeeping genes have the same sequence and the ancestor of each $\mathrm{CC}$ is the ST with the largest number of single locus variants (SLVs). Sub group founders can be described as SLVS or double locus variants (DLVS) of a founder of a CC that has become prevalent in a population and may be diversified to produce its own set of SLV and DLVs $(23,24,25,90)$.

Two opposing theories have been suggested to describe the relationship between the first MRSA isolated and recent MRSA clones. The single-clone theory suggested that all MRSA clones have a common ancestor and that SCCmec was introduced only once in $S$. aureus (46). The multi-clone theory suggested that SCCmec was introduced several times into different genetic $S$ aureus lineages and this hypothesis is supported by studies of Musser et al using multilocus enzyme electrophoresis (MLEE), Fitzgerald et al using DNA micro-array analyses, and Enright ef al using MLST $(24,27,60)$. In the latter study, it was reported that five clonal 


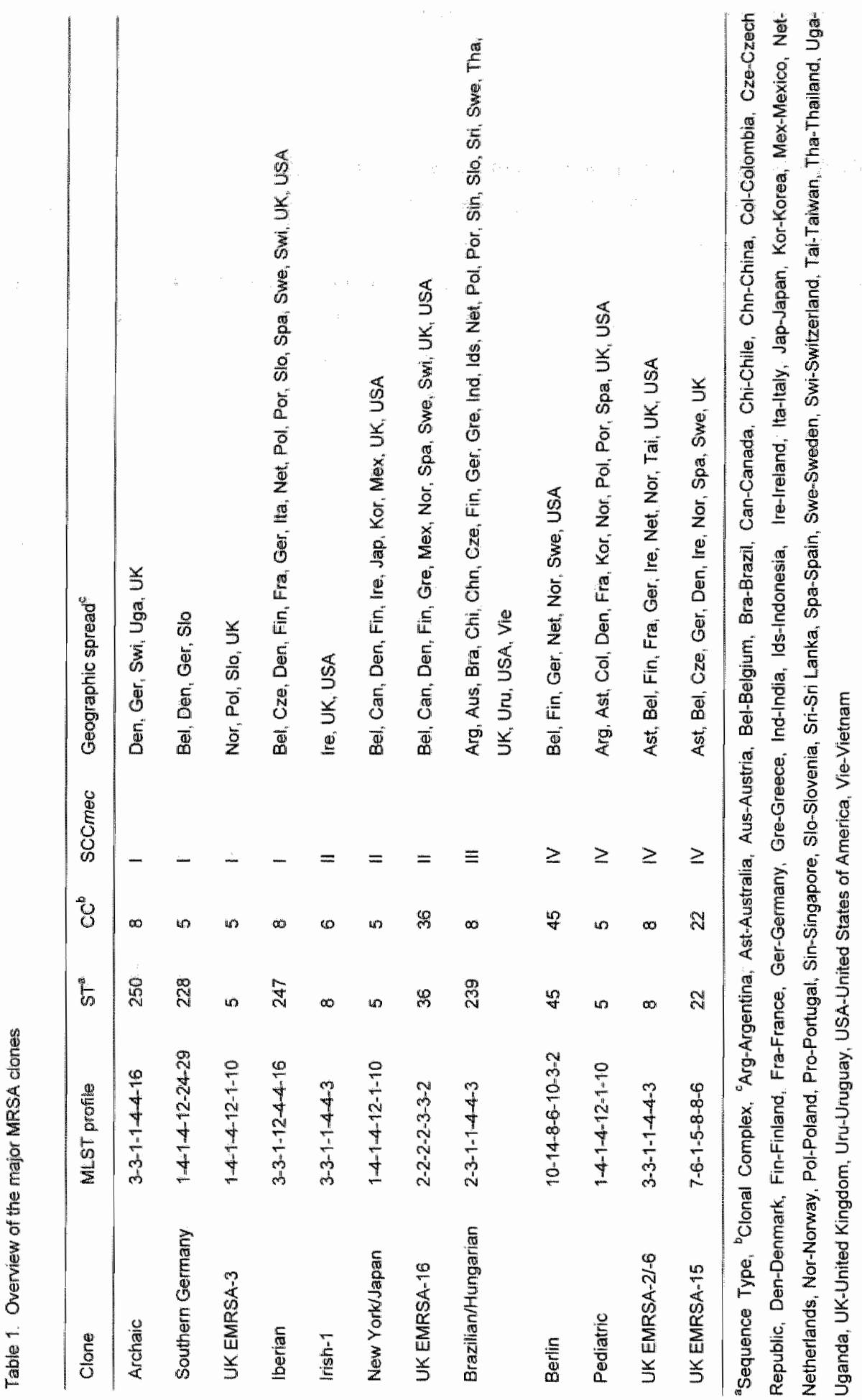


complexes were found among 359 MRSA strains isolated in 20 countries between 1961 and 1999 and that strains with the same ST harboured different SCCmec types (24).

To investigate the relationship between MSSA and MRSA, a study was performed by Crisostomo et al. They reported that ST250 was found predominantly among MSSA strains isolated in Denmark in the 1950s. It was concluded that ST250 could be the ancestor of the first MRSA strain isolated in the UK in 1961 (14). Enright et al further investigated MSSA and MRSA strains from the UK. A high level of genetic similarity was found between MSSA (ST30) and MRSA (ST36). The difference between ST30 and ST36 is a point mutation in the pta gene. It was concluded that ST36-MRSA-I) (EMRSA-16) has emerged from ST30-MSSA through ST36-MSSA upon acquisition of SCCmec type II (23).

To further investigate the evolution of MRSA, SCCmec typing, together with MLST and BURST analyses was applied on 359 MRSA and 553 MSSA strains isolated between 1961 and 1999 from 20 countries worldwide. It was shown that the major MRSA clones, defined as groups of isolates from more than one country with the same ST and SCCmec type, belonged to one of five clonal complexes (CC5, 8, 22, 30, and 45). As shown in table 1, different SCCmec types have been acquilred by $S$. aureus strains with the same genetic background, i.e. ST5-MSSA has acquired SCCmec types I to IV, to form ST5-MRSA-I to IV. Furthermore, it was shown that ST8-MSSA in CC8 is the ancestor of the first MRSA, as ST250-MRSA-I was derived from ST250-MSSA, which arose from ST8-MSSA through a point mutation in the yqil gene. ST8-MSSA is a common cause of epidemic MSSA disease and it has acquired SCCmec types I and IV. Derived from ST250 by a point mutation at the gmk locus is ST247-MRSA-I, the Iberian clone. This is one of the major MRSA clones currently isolated in European hospitals. Another major MRSA ST within CC8 was ST239 (ST239-MRSA-1I), which corresponds to the Brazilian clone. It is derived from ST8-MRSA-III by recombination in the arcC gene. If was further shown that $\mathrm{CC} 5,22,36$ and 45 were all derived from epidemic lineages that have acquired SCCmec, since they differed from each other and from ST8 at six or seven loci (table 1). Furthermore, these MLST analyses showed that some of the first vancomycin-intermediate $S$. aureus (VISA) isolates have emerged from ST5-MRSA-11, a pandemic MRSA clone known as the New York/Japan clone (24). A recent study confirmed that multiple lineages of $S$. aureus harbour different $S C \mathrm{C} m e C$ types and that both CA-MRSA and HA-MRSA strains were found among hospitalized patients in Australia (12).

Another study of 147 geographically diverse MRSA strains showed that MRSA has emerged at least twenty times upon acquisition of SCCmec and that the acquisition 
of SCCmec by MSSA was four times more common than the replacement of one SCCmec with another fype. Interestingly. SCCmec type $\mathrm{N}$ was found in twice as many MRSA clones than other SCCmec types. This suggested that most cllones arise by acquisition of SCCmec type $\mathrm{W}$ in $\mathrm{S}$ aureus $(79)$

Recently, two studies were published in which clonal evolution within one hospital was described. ST30-MRSA-IV was present in a Mexican hospital between 1997 and 2000, but this clone was replaced by ST5-MRSA-11 in 2001 and was dominating in 2002 (99). Another study in Spain showed that between 1998 and 2002, ST247-MRSA-I was replaced by ST36-MRSA-Il (73). Besides the major clones shown in table 1. MRSA strains are also isolated in single hospitals (minor clones) or from single patients (sporadic isolates) (17). Although most of the MRSA strains are isolated in hospitals, community-acquired strains have recently emerged.

\section{THE EMERGE OF COMMUNITY-ACQUIRED MRSA}

The first CA-MRSA strain was reported in Western Australia in 1993 from hospitalised patients who lived in remote communities (96). During the $1990 \mathrm{~s}_{\text {" }} \mathrm{CA}$ MRSA strains spread worldwide (98). Interestingly, CA-MRSA strains are isolated from patients who have no or few risk factors associated with MRSA colonisation. It was found that CA-MRSA is both genotypically and phenotypically different from HA-MRSA. In contrast to HA-MRSA, CA-MRSA strains are largely susceptible to antibiotics other than $\beta$-lactam antibiotics. Pulsed-Field Gel Electrophoresis (PFGE) analyses have shown that CA-MRSA belongs to a single clonal type and that this clone is unrelated to clones isolated in hospitals $(33,62)$. Moreover, SCCmec types $N$ and $V$ are associated with CA-MRSA $(16,38,39)$. Furthermore, many CA-MRSA strains harbour PVL and several clones, as shown by MLST, are disseminated worldwide (98). However, MRSA strains harbouring SCCmec type IV have also been associated with nosocomial infections $(65,83)$. This could suggest that MRSA strains harbouring SCCmec type IV are adapted to both the hospital and the community environment. This is probably due to the smaller size of SCCmec type IV, which facilitates easier transfer between staphylococcal species, compared to other SCCmec types (80). One report described two CA-MRSA strains harbouring SCCmec type II (11).

Okuma of al investigated the origin of CA-MRSA, e.g. whether CA-MRSA strains are HA-MRSA with SCCmec type IV, or MSSA that have acquired SCCmec type IV in the community. For this study, a total of 23 CA-MRSA isolates from Australia and the USA was investigated by MLST. They found that the two main STs were ST1 and ST30. S. aureus with STI is normally found in the community, but it was not 
associated with CA-MRSA until this study was performed. ST30 is usually only found in MSSA, but only a few HA-MRSA with this ST were found, but they did not harbour SCCmec type IV. This study showed that CA-MRSA strains are truly novel acquisitions of SCCmec type IV in the community (66). Furthermore, it was shown that CAMRSA has greater clonal diversity than HA-MRSA, since seven CCs (CC1, 5, 8, 22, 30, 45, and 298) were found among the 23 strains investigated, compared to five CCs among 359 HA-MRSA strains $(24,66)$. The emerge of SCCmec type IV in virulent strains with a ST1 and ST30 background is very worrying. since these strains also harbour the genes coding for PVL $(31,98)$.

Later on, another study by Aires de Sousa et al (1) raised the possibility that some CA-MRSA strains may actually originate in hospitals. This study showed interesting similarities between CA-MRSA and HA-MRSA strains. A total of 41 HAMRSA strains that differed from the major pandemic clones by PFGE pattern, meCA and Tn554 polymorphism, as well as epidemic behaviour were selected from an international strain collection. MLST, spa typing, and SCCmec typing showed extensive diversity among these sporadic isolates, both in the genetic background and the SCCmec type. Nevertheless, the isolates could be grouped into restricted CCs (CC5, $8,22,30,45$, and 91) by BURST, which showed that most sporadic MRSA isolates evolved from pandemic MRSA clones. Several of these HA-MRSA strains resembled CA-MRSA isolates in properties that include a limited multi-resistance pattern, faster growth rate, diversity of the genetic background, and carriage of SCCmec type IV (1)

CA-MRSA strains from Europe differ from Australian and US strains in their PFGE pattern "MLST profile (ST1 in US isolates, ST30 in Australian isolates, and ST80 in European isolates), and SCCmec type (98). European CA-MRSA harbour ccrAB2. the class B mec complex, but they could not be typed with SCCmec type IV specific primers. Furthermore, they harboured the farl gene, encoding for resistance to fusidic acid and have a unique spa type (r07-r23-r12-r34-r34-r33-r34). This clone is spread through Finland, France, Germany, Norway, and Scotland (22, 105). All three CA MRSA clones carry the genes for the production of PVL, lukF.PV and lukS-PV. SCCmec type $V$ was present in Australian CA-MRSA strains with ST5, 45 and 152 (12).

A worrying trend is the transmission of MRSA from humans to pets as was described recently. An MRSA strain with a novel SCCmec type was isolated from a dog and the owner, who worked in a nursing home. This study showed that the spread of MRSA from health care facilities to the community could occur trough pets (97). 


\section{VIRULENCE FACTORS}

The ability of $\mathfrak{S}$. aurecis to cause infections is mainly attributed to the production of virulence factors, such as Panton-Valentine leukocidin (PVL) and the family of the superantigens (SAgs). The genes for the production of these virulence factors are mainly situated on genomic islands (GIS) and both MSSA and MRSA can harbour these virulence genes. It is believed that the genes for the production of SAgs were aciquired from Streptococcus pyogenes, another human pathogen producing different SAgs (74).

\section{Panton Valentine leukocidin}

Panton-Valentine leukocidin (PVL) is a $S$. aureus-specific exotoxin that belongs to the family of bicomponent synergohymenotropic toxins $(32,92)$. It is encoded by two contiguous and cotranscribed genes, designated lukF-PV and lukS-PV (77), which produce proteins of 32 and $38 \mathrm{kDa}$ respectively. Like all other leukocidins, PVL kills leukocytes by creating pores in the cell membrane. Purified PVL was reparted to induce severe inflammatory lesions when injected intradermally in rabbits, leads into capillary dilation, infiltration of polymorphonuclear cells, and skin necrosis $(77,101)$.

The genes encoding $P V L_{\text {, which }}$ are carried on a bacteriophage, are found in only a subset of $S$. aureus isolates. Prévost et al reported that PVL was harboured by fewer than $5 \%$ of the isolates in a general hospital (77). In accordance with the aforementioned activities of purified PVL, PVL-positivity of S. aureus strains was found to be associated with primary skin infections such as furunculosis, and severe necrotizing pneumonia $(31,49)$. The clinical importance of PVL was further demonstrated in a study of $S$. aureus infections which occurred between 1986 and 1998 in France. This study revealed eight cases of community-acquired pneumonia caused by PVL-positive $S$, aureus strains, six of which with a fatal outcome. The patients involved were all immunocompetent children and young adults; and each of them presented with a preceding influenza-like syndrome before developing pneumonia (31).

Furthermore, Vandenesch et al performed a study in which the presence of 24 virulence factors and SCCmec in 117 CA-MRSA isolates from a large number of countries worldwide was investigated. This investigation showed that CA-MRSA was characlerized by SCCmec type IV and that PVL was a stable genetic marker for CAMRSA (98). The relationship between CA-MRSA, SCCmec type IV and PVL (ST1MRSA-IV) was confirmed by a study by Shukla et al in the USA (89). However, another 
study by O'Brien et al in Australia did not find a relationship between CA-MRSA ScCmec type IV and PVL (64).

\section{Superantigens}

The pathogenicity of $S$. aureus can in part be attributed to the production of pyrogenic toxins. Because secretion of these toxins causes excessive stimulation of $T$ lymphocytes, they are called superantigens (SAgs) (57). To date, several different SAgs have been identified in $S$. aureus, i.e. staphylococcal enterotoxins (SE) A to $U$, exfoliative toxins (ET) $A$ and $B$, and toxic shock syindrome toxin-1 (TSST-1) $(2,43,74)$. However, only a small number of SAgs is produced by each $S$. aureus strain. Several studies have shown that SAgs play a role in food poisoning, toxic shock syndrome (TSS), scarlet and rheumatic fever, arthritis, multiple sclerosis, diabetes, sudden infant death syndrome (SIDS) and Kawasaki syndrome $(29,52)$.

The potency of SAgs lies in their ability to efficiently induce $T$-cell proliferation and activation (10,000-fold more efficiently than other antigens) by bridging the antigen-presenting cells (APC) and T-cell receptors (TCRs) through binding the major histocompatibility complex (MHC) class II on APCs and specific variable regions on the $\beta$-chain (TCR VB) of both CD4 and CD8 antigen receptors. Consequently, a T-helper 1 type response is mounted, which results in the massive release of interleukins and proinflammatory cytokines, such as tumour necrosis factor-a (TNF-a), interleukin-2 (IL-2) from the APCs and interferon- $y$ (INF- $y)$ from the T-cells $(20,21,28,47,72)$. Furthermore, SAgs are capable of inducing cytotoxicity towards target cells (74).

The genes responsible for the production of SAgs are situated on plasmids, on prophages, or on S. aureus pathogenicity islands (SaPl). Currently, seven SaPIs have been identified. These seven SaPls can be classified into four groups, depending on their integrase homology and insertion site. In addition, it has been found that no more than one SaPI is present in an $S$. aureus strain. The SaPIs are packed into phage heads; and are integrated into the chromosome of $S$. aureus. This implies that they can move with a high frequency between $S$. aureus strains $(6,50,51)$.

The SAgs that have been structurally characterized share three-dimensional folds, despite their low amino acid sequence similarity. It is assumed that SAgs have a common ancestor and that horizontal transfer, together with vertical evolution are responsible for the diversity among SAgs. The structure of SAgs shows conserved twodomain architecture ( $N$ - and $\mathrm{C}$-terminal domains) and a long solvent-accessible o-helix spanning the centre of the molecule. The $N$-terminal domain is characterized by the presence of hydrophobic residues in solvent-exposed regions and the C-terminal 
domain comprises a four-stranded B-sheet capped by a long a-helix $(70,85,91,93)$. Zinc ions are important for the three-dimensional stability of most SAgs, as well as their fumclion, and their ability to bind MHC class: II (7.4). Both SEB and TSST-1 do not bind zinc $(76,93)$.

Staphylococcal enterotoxins $A, B, C 1$ to $C 3, D, E, G$ to $R$ and $U$ are 24.8 to 31.2 $\mathrm{kDa}$ polypeptides and are mainly responsible for food poîsoning. SEH however, plays a role in TSS. These enterotoxins belong to a family of heat stabile enterotoxins and show 50 to $85 \%$ homology in their predicted amino acid level. Furthermore, SEA is a potent gastrointestinal toxin, while Inthalation of SEB can induce pathophysiological changes, which include widespread systernic dlamage and septic shock $(29,30,52,74$, 78).

The exfoliative toxins (ET) $A(26.9 \mathrm{kDa})$ and $B(27.3 \mathrm{kDa})$ are responsible for staphylococcal scalded-skin syndrome (SSSS), an exfoliative dermatitis of infants and children, that is characterized by the formation of large bullae without inflammatory cell infiltrate and the separation of extended areas of the epidermis at the stratum granulosum leaving the keratinocytes intact. ETA is chromosomal encoded, whereas ETB is plasmid encoded. These proteins share a $40 \%$ homology $(40,41,107)$.

TSST- 1 is a $29.1 \mathrm{kDa}$ protein that is encoded by the $t$ st gene. This gene is present in up to $20 \%$ of the $S$. aureus strains $(29,52)$. The release of TSST- 1 into the bloodstream may give rise to a variety of severe clinical conditions, such as TSS, SIDS, and Kawasaki syndrome. TSS is characterized by high fever, erythematous rash formation, hypotension and major oxygen involvement, which may lead to multi organ failure. Without the appropriate therapy, a lethal shock may develop within 24 hours after the onset of symptoms $(20,54,57)$. Although most cases (two thirds) of TSS are associated with tampon use, an increasing number of cases are related to localized infectlons, surgical complications and insect bites (54). Musser et al showed that the majority of female patients affected with TSS had a single S. aureus clone well adapted to colonization in the genital tract $(61)$. TSS is usually treated with proper drainage of surgical wounds, a high dose of a $\beta$-lactam antibiotic and an $y$-globulin (3). Nevertheless, TSS still has a lethality rate of about $30 \%(29)$.

\section{Prevalence AND RISK FActors}

A high prevalence of MRSA in hospitals has been associated with higher patient mortality and higher health care costs. The SENTRY study indicated that the prevalence of MRSA in hospitals worldwide between 1997 and 1999 was $22.4 \%$ in Australia, $66.8 \%$ in Japan, $34.9 \%$ in Latin America, $40.4 \%$ in South America, $32.4 \%$ in 
the USA, and $263 \%$ in Europe $(4,19)$. The prevalence of MRSA between countries in Europe varies. The prevalence of MRSA in the northern countries $10.6 \%$ in the Scandinavian countries and The Netherlands) is lower than in most other European countries (up to 44.7\%). This low prevalence of MRSA in North Europe is attributed to a low antibiotic pressure and screening of "high-risk' patients for MRSA before they enter a hospital (Search-and-Destroy) (95). Risk factors for MRSA colonisation include previous exposure to one or more antibiotics, prolonged duration of therapy, stay in an intensive care unit or a burn unit, severe underlying illness, invasive procedures, surgical wounds or burns and contact with patients colonised with MRSA $(7,8,15,42$, $71,102)$. It has also been shown that if a patient, who receives antibiotic treatment, acquired MRSA, it survived and proliferated more easily than MSSA, because it had a selective advantage (86).

Furthermore, more effective disinfection procedures and hand hyglene guidelines would partly help to prevent spread of MRSA in a hospital environment (75). Strict implementation of the above rules in Denmark 25 years ago, when the prevalence of MRSA was as high as 30\%, have decreased the MRSA prevalence to less than $1 \%$ and this low percentage has been maintained since then (81).

A least eight definitions are known for CA-MRSA $(63,84)$, but the Center for Disease Control and Prevention (CDC) defines C.A-MRSA as strains isolated within 48 hours of admission to a hospital. The prevalence of CA-MRSA is still llow worldwide. but a recent report indicates that the prevalence of CA-MRSA is increasing (84). Several studies have been performed and they showed that the prevalence of CAMRSA is lower than $0.5 \%$. In a study among 500 children and their guardians in New York, one child was colonised with MRSA. This corresponded with a CA-MRSA prevalence of $0.2 \%$. This child, which had been hospitalised several times within the last year, was found to be colonised with an MRSA strain identified as the predominant clone found in hospitals in New York (87). A further study in the San Francisco area among 833 homeless and marginally housed adults showed that 23 adults were colonized with MRSA (2.8\%), but further investigation showed that only 2 of the 23 adults had no risk factors for MRSA colonization, so that the prevalence of CA-MRSA was as low as $0.24 \%$ (9). A study performed in Portugal showed that among 3,525 healthy and young individuals, without risk factors for MRSA colonization, only 7 were colonized with CA-MRSA $(0.2 \%)$. Of the seven CA-MRSA strains, five were identified as either the Brazilian, Iberian, or Pediatric clone, which are endemic in Portuguese hospitals (82). Furthermore, Salgado et al performed a global analysis of 57 studies on CA-MRSA prevalence among both hospitalised patients and community members, and reported that most persons with CA-MRSA had at least one risk factor for MRSA. This 
study suggested that he prevalence of CA-MRSA among persons without risk factors is $0.24 \%(84)$. A recent study showed that the prevalence of CA-MRSA in Europe is 0.03 to $1.5 \%$ (95). The high rates of MRSA colonisation among Australian aboriginals or Native Americans is probably associated with risk factors for spread in the community, such as skin infections and use of broad-spectrum antibiotics $(33,56)$. In other studies, a number of risk factors associated with CA-MIRSA colonisation were identffed. These included gastrointestinal disease, recent transmission to a hospital and injection drug use. Furthermore; it was shown that recent medication tends also to be a risk factor for CA-MRSA colonisation $(10,55)$.

Any strategy to contain the spread of MRSA, either in the community, in a hospital, at national or at international level, requires a throughout knowledge how MRSA is disseminate ${ }_{i}$ the number of clones that are spread and the relatedness of these clones to each other. Today, the epidemiology of MRSA is investigated with PFGE, SCCmec typing, and MLST (17). First, the PFGE patterns are analyzed with Dice comparison and unweighted pair group matching analysis (UPGMA) settings according to the scheme of Tenover et al (94). The position tolerance is set at 1 to $2 \%$ and isolates with a similarity index of 0.80 or more are cllassified as a clonal group. A small selection of strains from the major clonal groups is then further investigated by MLST and SCCmec typing $(12,73)$.

\section{FUTURE PROSPECTS}

Rapid and accurate molecular characterisation of MRSA, based on the SCCmec type and the investigation of the genetic background by MLST, is still a labour intensive task. Two methods are described in the literature to investigate the type of SCCmec. The first method of Oliveira ef al is a multiplex PCR method, where mecA and six different loci on SCCmec are amplified with PCR (67). The second method by Ito $t$ al characterise the SCCmec type based on the combination of the mec complex and the ccr genes $(38,39)$. The first method is used in most studies, and the method of Ito et al is now used when the SCCmec type cannot be determined with the method of Oliveira et al. However, the two methods gave different results when typing ScCmec (88). A general and international agreement should be reached to define known and future SCCmec types, and than one method should be developed and used in future studies. This method should be evaluated on all major MRSA clones as investigated by MLST (24). Since MLST is very labour intensive, a novel molecular typing method for the investigation of the dissemination of MRSA should be developed, that brings with it the speed of spa typing and the accuracy of MLST. This method should ideally be a 
combination of MLST, SCCmec typing and should also include the determination of $\mathrm{S}$.

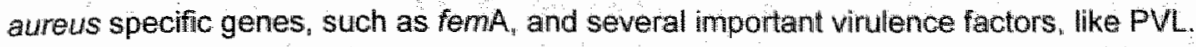

The worldwide emerge of CA-MRSA is a threat to both the community and the hospital environment, since these strains are known to be more virulent than HA-MRSA strains. First, a clear definition for CA-MRSA, instead of at least eight definitions that are now available $(63,84)$, must be implemented in research. Second, studies to investigate the prevalence of CA-MRSA and their genetic background should be started. MLST analyses are necessary to investigate if these strains have for example a ST8O background, the common CA-MRSA background found in Europe. Furthermore, in these studies, the presence of a larger panel of virulence factors should be investigated by real-time PCR. This study should also focus on determining the risk factors for CA-MRSA infection. Another intriguing question concerning CAMRSA is the possible relation between SCCmec type IV (and V) and PVL, since reports are conflicting as to whether there is a relation between SCCmec type IV and PVL $(11,64,98)$. This should be performed with a real-time PCR assay, combining the S. aureus specific femA gene, the resistance gene mecA, ccrAB2, $\triangle$ mecR1 (in combination specific for SCCmec type IV) and PVL. CA-MRSA strains with a different genetic background as investigated by MLST should be studied $(24,98)$.

There are still a number of intriguing questions unanswered concerning the molecular evolution of MRSA. One of the most intriguing is the origin of SCCmec. In this respect; it is noteworthy that Hanssen et al studlied 39 methicillin-resistant coagulase-negative staphylococci (MRCNS), and 22 had a novel SCCmec type (35). These novel SCCmec types could give us more information about the possible transfer of SCCmec between CNS species and $S$. aureus. Moreover, other sludies found novel SCCmec types $(88,97,100)$, or SCC elements without meCA, which could be a reservoir for antibiotic resistance islands, in $S$. aureus $(13,59)$. Further studies should also investigate the role of pets and farm animals in the transfer of SCCMec, $i . e$. is SCCmec formed in animals in MRCNS or MRSA and transferred to humans, or are humans the source of CNS or S. aureus strains carrying SCCmeC?

It has been suggested that MRSA is more pathogenic than MSSA, but little evidence has been brought forward, except that CA-MRSA, harbouring SCCmec type IV and PVL, have caused necrotising pneumonia in young adults. However, a relation between resistance and virulence cannot be ruled out, since it has been shown that sub-inhibitory concentrations of antibiotics influence the expression of wirulence factors. 


\section{REFERENCES}

1. Aires de Sousa, M. and H. de Lencastre. 2003. Evolution of sporadic isolates of methicillin-resistant Staphylococcus aureus (MRSA) in hospitals and their similarities to Hsolates of community-acquired MRSA. J. Clin Microbiol 41.3806-3815.

2. Banks, M.C., N.S. Kamel, J.B. Zabriskie, D.H. Lanone, D. Ursea, and D.N. Posnett. 2003. Staphylococcus aureus express unique superantigens depending on the tissue source. J. Infect. Dis 187 77-86.

3. Barry, W. L. Hudgins, S.T. Donta and E.L. Pesanti. 1992. Intravenous immunoglobulin therapy for toxic shock syndrome. JAMA 267:3315-3316.

4. Bell, J.M., and J.D. Turnidge. 2002. High prevalence of oxacillin-resistant Staphylococcus aureus isolates from hospitalized patients in Asia-Pacific and South Africa: results from SENTRY antimicrobial surveillance program, 1998-1999. Antimicrob. Agents Chemother. 46:879-881.

5. Berger-Bachi, $\mathbf{B}_{\text {s, }}$ and $\mathbf{S}$. Rohrer. 2002. Factors influencing methicillin resistance in staphylococci. Arch. Microbiol. 178:165-171.

6. Betley, M.J., D.W. Borst, and L.B. Regassa. 1992. Staphylococcal enterotoxins, toxic shock syndrome toxin and streptococcal pyrogenic exotoxins: a comparative study of their molecular biology. Chem. Immunol. 55:1-35.

7. Boyce, J.M., M. Landry, T.R. Deetz, and H.L. DuPont. 1981. Epidemiologic studies of an outbreak of nosocomial methicillin-resistant Staphylococcus aureus infections. Infect. Control. 2:110-116.

8. Boyce, J.M., R.L. White, W.A. Causey, and W.R. Lockwood. 1983. Burn units as a source of methicillin-resistant Staphy/ococcus aureus infections. JAMA 249:2803-2807.

9. Charlebois, E.D., D.R. Bangsberg, N.J. Moss, M.R. Moore, A.R. Moss, H.F. Chambers, and F. Perdreau-Remington. 2002. Popullation-based community prevalence of methicillin-resistant Staphylococcus aureus in the urban poor of San Francisco. Clin. Infect. Dis. 34:425 433

10. Charlebois, E.D., F. Perdreau-Remington, B. Kreiswirth, D.R. Bangsberg, D. Ciccarone, B.A. Dlep, V.L. Ng, K. Chansky, B. Edlin, and H.F. Chambers. 2004. Origins of community strains of methicillin-resistant Staphylococcus aureus. Clin. Infect. Dis. 39:47-54.

11. Chung, M. G. Dickinson, H. De Lencastre, and A. Tomasz. 2004. International clones of methicillin-resistant Staphylococcus aureus in two hospitals in Miami. Florida. J. Clin. Microbiol. 42:542-547.

12. Coombs, G.W., G.R. Nimmo, J.M. Bell, F. Huygens, G. O"Brien F, M.J. Malkowski, J.C. Pearson, A.J. Stephens, and P.M. Giffard. 2004. Genetic diversity among community methicillin-resistant Staphylococcus aureus strains causing outpatient infections in Australia. J. Clin. Microbiol. 42:4735-4743. 
13. Corkill, J.E., J.J. Anson, P. Griffiths, and C. Anthony Hart 2004. Detection of elements of the staphylococcal cassette chromosome (SCC) in a methicilin-susceptible (meoA gene negative) homalogue of a fucidin-resistant MRSA. J. Antumicrob. Chemother. 54:229-231.

14. Crisostomo, M.I., H. Westh, A. Tomasz, M. Chung, D.C. Oliveira, and H. de Lencastre. 2001. The evolution of methicillin resistance in Staphylococcus aureus: similarity of genetic backgrounds in historically early methicillin-susceptible and resistant isolates and contemporary epidemic clones. Proc. Natl. Acad. Sci. USA. 98:9865-9870.

15. Crossley, K, D. Loesch, B. Landesman, K. Mead, M. Chern, and R. Strate, 1979. An outbreak of infections caused by strains of Staphylococcus aureus resistant to methicilin and aminoglycosides. II. Clinical studies. J. Infect. Dis. 139:273-279.

16. Daum, R.S., T. Ito, K. Hiramatsu, F. Hussain, K. Mongkolrattanothai, M. Jamkllang; and S. Boyle-Vavra. 2002. A nove methicillin-resistance cassette in community-acquired methicillin-resistant Staphylococcus aureus isolates of diverse genetic backgrounds. J. Infect. Dis. 186:1344-1347.

17. de Sousa, M.A., and H. de Lencastre. 2004. Bridges from hospitals to the laboratory: genetic portraits of methicillin-resistant Staphylococcus aureus clones. FEMS Immunot: Med. Microbiol. 40:101-111.

18. Denis, O., A. Deplano, C. Nonhoff, R. De Ryck, R. de Mendonca, S. Rottiers, R. Vanhoof, and M.J. Struelens. 2004. National surveillance of methicillin-reststant Staphylococcus aureus in Belgian hospitals indicates rapid diversification of epidemic clones. Antimicrob. Agents Chemother, 48:3625-3629.

19. Diekema, D.J., M.A. Pfaller, F.J. Schmitz, J. Smayevsky, J. Bell, R.N. Jones, and M. Beach. 2001. Survey of infections due to staphylococcus species: frequency of occurrence and antimicrobial susceptibility of isolates collected in the United States, Canada, Latin America, Europe, and the Western Pacific region for the SENTRY Antimicrobial Surveillance Program, 1997-1999. Clin. Infect. Dis. 32:S114-S132.

20. Dinges, M.M., P.M. Orwin, and P.M. Schlievert. 2000. Exotoxins of Staphylococcus aureus. Clin. Microbiol. Rev. 13:16-34.

21. Dohlsten, M., G. Hedlund, H.O. Sjogren, and R. Carlsson. 1988. Two subsels of human CD4+T helper cells differing in kinetics and capacities to produce interleukin 2 and interferon-gamma can be defined by the Leu-18 and UCHL1 monoclonal antibodies. Eur. J. Immunol. 18:1173-1178.

22. Dufour, P., Y. Gillet, M. Bes, G. Lina, F. Vandenesch, D. Floret, J. Etienne, and $H_{.}$ Richet. 2002. Community-acquired methicillin-resistant Staphylococcus aureus infections in France: emergence of a single clone that produces Panton-Valentine leukocidin. Clin. Infect. Dis. 35:819-824.

23. Enright, M.C., N.P. Day, C.E. Davies, S.J. Peacock, and B.G. Spratt. 2000. Multhlocus sequence typing for characterization of methicillin-resistant and methicillin-susceptible clones of Staphylococcus aureus. J. Clin. Microbiol. 38:1008-1015. 
24. Enright, M.C. D.A. Robinson, G. Randle, E.J. Feil. H. Grundmann, and B.G. Spratt. 2002. The volutionary history of methicillin-resistant Staphylococcus aureus (MRSA). Proc. Natl Acad. Sici. USA, 99:7687-7692.

25. Enright, M.C., and B.G. Spratt. 1999. Multilocus sequence typing. Trends Microbiol. 7:482-487.

26. Faria, N.A., D.C. Oliveira, H. Westh, D.L. Monnet, A.R Larsen, R. Skov, and H. de Lencastre. 2005. Epidemiology of emerging methicillin-resistant Staphylococcus aureus (MRSA) in Denmark a nationwide study in a country with low prevalence of MRSA infection. J. Clin. Microbiol. 43:1836-1842.

27. Fitzgerald, J.R., D.E. Sturdevant, S.M. Mackie, S.R. Gill, and J.M. Musser. 2001. Evolutionary genomics of staphylococcus aureus: insights into the origin of methicillinresistant strains and the toxic shock syndrome epidemic. Proc. Natl. Acad. Sci. USA. 98:8821-8826.

28. Fleischer, B., and $H$. Schrezenmeler "4988. T cell stimulation by staphylococcal enterotoxins. Clonally variable response and requirement for major histocompatibility complex class II molecules on accessory or target cells. J. Exp. Med. 167:1697-1707.

29. Fraser, J., V. Arcus, P. Kong, E. Baker, and T. Proft. 2000. Superantigens-powerful modifiers of the immune system. Mol. Med. Today 6:125-132.

30. Fueyo, J.M., M.C. Mendoza, M.R. Rodicio, J. Muniz, M.A. Alvarez, and M.C. Martín. 2005. Cytotoxin and pyrogenic toxin superantigen gene profiles of Staphylococcus aureus associated with subclinical mastitis in dairy cows and relationships with macrorestriction genomic profiles. J. Clin. Microbicl. 43:1278-1284.

31. Gillet, Y., B. Issartel, P. Vanhems, J.C. Fournet, G. Lina, M. Bes, F. Vandenesch, Y. Piemont "N. Brousse, D. Floret, and II. Etienne. 2002. Association between Staphylococcus aureus strains carrying gene for Panton-Valentine leukocidin and highly lethal necrotising pneumonia in young immunocompetent patients. Lancet 359:753-759.

32. Gravet, A., D.A. Colin, D. Keller, R. Girardot, H. Monteil, and G. Prevost. 1998. Characterization of a novel structural member, LukE-LukD, of the bi-component staphylococcal leucotoxins family. FEBS Lett. 436:202-208.

33. Groom, A.V., D.H. Wolsey, T.S. Naimi, K. Smith, S. Johnson, D. Boxrud, K.A. Moore, and J.E. Cheek. 2001. Community-acquired methicillin-resistant Staphylococcus aureus in a rural American Indian community. JAMA 286:1201-1205.

34. Hanssem, A.M., A. Fossum, J. Mikalsen, D.S. Halvorsen, G. Bukholm, and J.U. Sollid. 2005. Dissemination of community-acquired methicillin-resistant Staphylococcus aureus clones in northern Norway: sequence types 8 and 80 predominate. J. Clin. Microbiol. 43:2118-2124.

35. Hanssen, A.M., G. Kjeldsen, and J.U. Sollid. 2004. Local variants of staphylococcal cassette chromosome mec in sporadic methicillin-resistant Staphylococcus aureus and methicillin-resistant coagulase-negative staphylococci: ewidence of horizontal gene transfer? Antimicrob. Agents Chemother. 48:285-296. 
36. Hiramatsu, K., L. Cui, M. Kuroda, and T. Ito. 2001. The emergence and evolution of methicillin-resistant Staphylococcus auraus. Trends Microbiot. 9:486-493.

37. Ito, T., Y. Katayama, K. Asada, N. Mori, KK. Tsutsumimoto $\mathrm{C}$. Tiensasitom, and K. Hiramatsu. 2001. Structural comparison of three types of staphylococcal cassette chromosome mec integrated in the chromosome in methicilin-riesistant Staphylococcus aureus. Antimicrab. Agents Chemother. 45:1323-1336.

38. Ito, T., X.X. Ma, F. Takeuchi, K. Okuma, H. Yuzawa and K. Hiramatsu. 2004. Novel type $V$ staphylococcal cassette chromosome mec driven by a novel cassette chromosome recombinase, $a c r C$. Antimicrob. Agents Chemother, 48:2637-2651.

39. Ito, T., K. Okuma, X.X. Ma H. Yuzawa, and K. Hiramatsu. 2003. Insights on antibiotic resistance of Staphylococcus aureus from its whole genome: genomic island SCC. Drug Resist. Updat. 6:411-52.

40. Jackson, M.P., J. DeSena, J. Lednicky, B. McPherson, R. Haille, R.G. Garrison, and M. Rogolsky. 1983. Isolation and characterization of a bacteriophage factor that confers competence for genetic transformation to an exfoliative toxin-producing strain of Staphylococcus aureus, Infect. Immun. 39:939-947.

41. Jackson, M.P., and J.J. landolo. 1986. Cloning and expression of the exfoliative toxin $B$ gene from Staphylococcus aureus. J. Bacteriol. 166:574-580.

42. Jernigan, J.A., M.G. Titus, D.H. Groschel, S. Getchell-White, and B.M. Farr. 1996. Effectiveness of contact isolation during a hospital outbreak of methicillin-resistant Staphylococcus aureus. Am. J. Epidemiol. 143:496-504.

43. Johnson, W.M., S.D. Tyler, E.P. Ewan, F.E. Ashton, D.R. Pollard, and K.R. Rozee. 1991. Detection of genes for enterotoxins, exfoliative toxins, and toxic shock symdrome toxin 1 in Staphylococcus aureus by the polymerase chain reaction. J. Clin. Microbioll. 29:426-4310.

44. Katayama, Y., T. Ito, and K. Hiramatsu. 2001. Genetic organization of the chromosome region surrounding mecA in clinical staphylococcal strains: role of 15431-mediated mecl deletion in expression of resistance in mecA-carrying. low-level methicillin-resistant Staphylocaccus haemolyticus. Antimicrob. Agents Chemather. 45:1955-1963.

45. Ko, K.S., J.Y. Lee, J.Y. Suh, W.S. Oh, K.R. Peck, N.Y. Lee, and J.H. Song. 2005. Distribution of major genotypes among methicillin-resistant Staphylococcus aureus clones in Asian countries. J. Clin. Microbiol. 43:421-426.

46. Kreiswirth, B., J. Kornblum," R.D. Arbeit, W. Eisner, J.N. Maslow, A. McGeer, D.E. Low, and R.P. Novick. 1993. Evidence for a clonal origin of methicillin resistance in Staphylococcus aureus. Science 259:227-230.

47. Langford, M.P., G.J. Stanton, and H.M. Johnsion. 1978. Biological effects of staphylacoccal enterotoxin $A$ on human peripheral lymphocytes. Infect. Immun. 22:62-68.

48. Leclercq, R. 2002. Mechanisms of resistance to macrollides and lincosamides nature of the resistance elements and their clinical implications. Clin. Infect. Dis. 34:482-492. 
49. Lina, C., Y. Piemont, F, Godail-Gamot, M. Bes, M.O. Peter, V. Gauduchon, $F$. Vandenesch, and $d$. Etienne. 1999. Involvement of Panton-Valentine leukocidinproducing staphylococcus awras im primary skin infections and pneumonia. Clin. Infect. Dis. 29:1128-1132.

50. Lindsay, J.A., and M.T. Holden. 2004. Staphylococcus aureus: superbug. super genome? Trends Microbiol 12:378-385.

51. Lindsay, J.A., A. Ruzin, H.F. Ross, N. Kurepina, and R.P. Novick. 1998. The gene for toxic shock toxin is carried by a family of mobile pathogenicity islands in Staphylococcus aureus. Mol Microbio' 29:527-543:

52. Llewelyn, $M_{.}$and $J_{\text {. Cohen. }}$ 2002. Superantigens: microbial agents that corrupt immunity. Lancet Infect. Dis. 2:156-162.

53. Lowy, F.D. 2003. Antimicrobial resistance: the example of Staphylococcus aureus. $\mathbb{N}$. Clin. invest. 111:1265-1273.

54. Lowy, F.D. 1998. Staphylococcus aureus infections. N. Engl. J. Med. 339:520-532.

55. Lu, P.L. L.C. Chin, C.F. Peng, Y.H. Chiang, T.P. Chen, L. Ma, and L.K. Siu. 2005. Risk factors and molecular analysis of community methicillin-resistant Staphylococcus aureus carriage. ل. Clin. Microbiol. 43:132-139.

56. Maguire, G.P., A.D. Arthur, P.J. Boustead, B. Dwyer, and B.J. Currie. 1998. Clinical experience and outcomes of community-acquired and nosocomial methicillin-resistant Staphylococcus aureus in a northern Australian hospital. J. Hosp. Infect. 38:273-281.

57. Marrack, P., and J. Kappler. 1990. The staphylococcal enterotoxins and their relatives. Science 248:705-711.

58. Melter, O., M. Aires de Sousa, P. Urbaskova, V. Jakubu, H. Zemlickova, and H. de Lencastre. 2003. Update on the major clonall types of methicillin-resistant Staphylococcus aureus in the Czech Republic. J. Clin. Microbiol. 41:4998-5005.

59. Mongkolrattanothai, K., S. Boyle, T.V. Murphy, and R.S. Daum. 2004. Novel nonmecA-containing staphylococcal chromosomal cassette composite island containing pbp4 and tagF genes in a commensal staphylococcall species: a possible reservoir for antibiatic resistance islands in Staphylococcus aureus. Antimicrob. Agents Chemother. 48:18231836.

60. Musser, J.M.n and V. Kapur. 1992. Clonal analysis of methicillin-resistant Staphylococcus aureus strains from intercontinental sources: association of the mec gene with divergent phylogenetic lineages implies dissemination by horizontal transfer and recombination. $\mathrm{J}$. Clin. Microbiol. 30:2058-2063.

61. Musser, J.M., P.M. Schllievert, A.W. Chow, P. Ewan, B.N. Kreiswirth, V.T. Rosdahi, A.S. Naidu, W. Witte, and R.K. Selander. 1990. A single clone of Staphylococcus aureus causes the majority of cases of toxic shock syndrome. Proc. Natl. Acad. Sci. USA. 87:225229 . 
62. Naimi, T.S., K.H. LeDell, D.J. Boxrud, A.V. Groom, C.D. Steward, S.K. Johnson, J.M. Besser, C. O'Boyle, R.N. Danila, J.E. Cheek, M.T, Osterholm, K.A. Moore, and K.E. Smith. 2001. Epidemiology and clonality of community-acquired methicillin-lesistarit Staphylococcus aureus in Minnesota, 1996-1998. Clin. Infect. Dis. 33990-996.

63. Naimi, T.S., K.H. LeDell, K. Como-Sabetti, S.M. Borchardt, D.J. Boxrud, J. Etienne, S.K. Johnson, F. Vandenesch, S. Fridkin, C. O'Boyle, R.N. Danila, and R. Lynfield. 2003. Comparison of community- and health care-associated methicillin-resistant Staphylococcus aureus infection. JAMA 290:2976-2984.

64. O'Brien, F.G., T.T. Lim, F.N. Chong, G.W. Coombs, M.C. Enright, D.A. Rabinson, A. Monk, B. Said-Sallim, B.N. Kreiswirth, and W.B. Grubb, 2004. Diversity among community isolates of methicillin-resistant Staphylococcus aureus in Australia. J. Clin. Microbiol. 42:3185-3190.

65. O"Brien, F.G., J.W. Pearman, M. Gracey, T.V. Riley, and W.B. Grubb. 1999. Community strain of methicillin-resistant Staphylococcus aureus involved in a hospital outbreak. J. Clin. Microbiol. 37:2858-2862.

66. Okuma, K., K. Iwakawa, J.D. Turnidge, W.B. Grubb, J.M. Bell, F.G. O'Brien, G.W. Coombs, J.W. Pearman, F.C. Tenover, $M_{*}$ Kapl, C. Tiensasitorn, T. Ito, and $K_{*}$ Hiramatsu. 2002. Dissemination of new methicillin-resistant Staphylococcus daureus clones in the community. J. Clin. Microbiol. 40:4289-4294.

67. Oliveira, D.C., and H. de Lencastre. 2002. Multiplex PCR strategy for rapid identification of structural types and variants of the mec element in methicillin-resistant Staphylococcus aureus. Antimicrab. Agents Chemother. 46:2155-2161.

68. Oliveira, D.C., A. Tomasz, and H. de Lencastre. 2001. The evolution of pandemic clones of methicillin-resistant Staphylococcus aureus: identification of two ancestral genetic backgrounds and the associated mec elements. Microb. Drug Resist. 7:349-361.

69. Oliweira, D.C., A. Tomasz, and IH. de Lencastre. 2002. Secrets of success of a human pathogen: molecular evolution of pandemic clones of methicilin-resistant Staplybococous aureus. Lancet Infect. Dis. 2:180-189.

70. Papageorgiou, A.C., K.R. Acharya, R. Shapiro, E.F. Passalacqua, R.D. Brehm, and H.S. Tranter. 1995. Crystal structure of the superantigen enterotoxin $\mathrm{C2}$ from Staphylococcus aureus reveals a zinc-binding site. Structure 3:769-779.

71. Peacock, J.E., F.J. Marsik, and R.P. Wenzel. 1980. Methicillin-resistant Staphylococcus aureus: introduction and spread within a hospital. Ann. Intern. Med. 93:526-532.

72. Peavy, D.L., W.H. Adler, and R.T. Smith. 1970. The mitogenic effects of endoloxin and staphylococcal enterotoxin B on mouse spleen cells and human peripheral lymphocytes. J. Imminol. 105:1453-1458.

73. Perez-Roth, E., F. Lorenzo-Diaz, N. Batista, A. Moreno, and S. Mendez-Alvarez. 2004. Tracking methicillin-resistant Staphylococcus aureus clones during a 5-year period (1998 to 2002) in a Spanish hospital. J. Clin. Microbiol. 42:4649-4656. 
74. Petersson, $K_{s}, G$. Forsberg, and $\mathrm{B}$. Walse. 2004 Interplay between superantigens and immunoreceptors. Scand. I. Immunol. 59:345-355.

75. Pittet, D., S. Hugonnet, S. Harbarth, P. Mourouga, V. Sauvan, S. Touveneau, and T.V. Perneger. 2000. Effectiveness of a hospitai-wide programme to improve compliance with hand hyglene, Infection Control Programme Lancet 356:1307-1312.

76. Prasad, G.S., C.A. Earhart, D.L. Murray, R.P. Novick, P.M. Schlievert, and D.H. Ohlendorf. 1993. Structure of toxic shock syndrome toxin 1. Biochemistry 32:1376113766.

77. Prevost, G., P. Couppie, P. Prevost, S. Gayet, P. Petiau, B. Cribier, H. Montell, and Y. Piemont. 1995. Epidemiological data on Staphylococcus aureus strains producing synergohymenotropic toxins. J. Med. Microbiol. 42:237-245.

78. Proft, T., and J.D. Fraser. 2003. Bacterial superantigens. Clin. Exp. Immunol. 133:299306.

79. Robinson, D.A.1 and M.C. Enright. 2003. Evolutionary models of the emergence of methicillin-resistant Staphylococcus aureus. Antimicrob. Agents Chemother. 47:39263934

80. Robinson, D.A., and M.C. Enright. 2004. Multilocus sequence typing and the evolution of methicillin-resistant Staphylococcus aureus, Clin. Mïcrobiol. Infect. 1092-97.

81. Rosdahl, V.T., and A.M. Knudsen. 1991. The decline of methicillin resistance among Danish Staphylococcus aureus strains. Infect. Control Hosp. Epidemiol. 12:83-88.

82. Sa-Leao, R., I.S. Sanches, II. Couto, C.R. Alves, and H. de Lencastre. 2001. Low prevalence of methicillin-resistant strains among Staphylococcus aureus colonizing young and healthy members of the community in Portugal. Microb. Drug Resist. 7:237-245.

83. Saiman, L., M. O'Keefe, P.L. Graham, F. Wu, B. Said-Sallim, B. Kreiswirth, A. LaSala, P.M. Schllievert, and P. Della-Latta. 2003. Hospital transmission of community-acquired methicillin-resistant Staphylococcus aureus among postpartum women. Clin. Infect. Dis. $37: 1313-1319$

84. Salgado, C.D., B.M. Farr, and D.P. Calfee. 2003. Community-acquired methicillinregistant Staphylococcus auraus: a meta-analysis of prevalence and risk factors. Clin. Infect. Dis. 36:131-139.

85. Schad, E.M., I. Zaitseva, V.N. Zaitsev, M. Dohlsten, T. Kalland, P.M. Schlievert, D.H. Ohlendorf, and L.A. Svensson. 1995. Crystal structure of the superantigen staphylococcal enteratoxin type A. EMBO J. 14:3292-3301.

86. Shaplro, M., T.R. Townsend, B. Rosner, and E.H. Kass. 1979. Use of antimicrobial drugs in general hospitals. II. Analysis of patterns of use. J. Infect. Dis. 139:698-706.

87. Shopsin, B., B. Mathema, J. Martinez, E. Ha, M.L. Campo, A. Fierman, K. Krasinski, J. Kornblum, P. Alcabes, M. Waddington, M. Riehman, and B.N. Kreiswirth. 2000. Prevalence of methicillin-resistant and methicillin-susceptible Staphylocaccus aureus in the community. J. Infect. Dis. 182:359-362. 
88. Shore, A., A.S. Rossney, C.T. Keane, M.C. Enright, and D, C. Coleman, 2005 Seven novel variants of the staphylococcal chromosomal cassette mec in methicillin-resistant Staphylococcus aureus isolates from lreland. Antimicrob Agents Chemother. 49:20702083 .

89. Shukla, S.K., M.E. Stemper, S.V. Ramaswamy, J.M Conradt, R. Reich, E.A. Graviss, and K.D. Reed. 2004. Molecular characteristies of nosocomial and native American community-associated methicillin-resistant Staphylococcus aureus clones from rural Wisconsin. J. Clin. Microbiol, 42.3752-3757.

90. Spratt, B.G., W.P. Hanage, B. Li, D.M. Aanensen, and E.J. Feil. 2004. Displaying the relatedness among isolates of bacterial species - the eBURST approach. FEMS Microbiol. Lett. 241:129-134.

91. Sundstrom, M., L. Abrahmsen, P. Antonsson, K. Mehindate, W. Mourad, and M. Dohlsten. 1996. The crystall structure of staphylococcal enterotoxin type $\mathrm{D}$ reveals $\mathrm{Zn}{ }^{2+4}$. mediated homodimerization. EMBO J. 15:6832-6840.

92. Supersac, G., G. Prevost, and $Y$. Piemont. 1993. Sequencing of leucocidin $\mathbb{R}$ from Staphylococcus aureus PB3 suggests that staphylococcal leucocidins and gammahemolysin are members of a single, two-component family of toxins. Infect. Immun. 61:580-587.

93. Swaminathan, S., W. Furey, J. Pletcher, and M. Sax. 1992 Crystal structure of staphylococcal enterotoxin $B_{1}$ a superantigen. Nature 359:801-806.

94. Tenover, F.C., R.D. Arbeit, R.V. Goering, P.A. Mickelsen, B.E. Murray, D.H. Persing, and B. Swaminathan. 1995. Interpreting chromosomal DNA restriction patterns produced by pulsed-field gel electrophoresis: criteria for bacterial strain typing. J. Clin. Microbiol. 33:2233-2239.

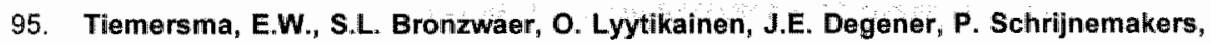
N. Bruinsma, J. Monen, W. Witte, H. Grundman, and European Antimicrobiall Resistance Surveillance System Participants. 2004. Methicillinuresistant Staphylococcus aureus in Europe, 1999-2002. Emerg. Infect. Dis, 10:1627-1634.

96. Uldo, E.E., J.W. Pearman, and W.B. Grubb. 1993. Genetic analysis of community isolates of methicillin-resistant Staphylococcus aureus in Western Australia. J. Hosp. Infect. 25:97-108.

97. van Duijkeren, E., M.J. Wolfhagen, A.T. Box, M.E. Heck, W.J. Wannet, and A.C. Fluit. 2004. Human-to-dog transmission of methicillin-resistant Staphylococcus aurous. Emerg. Infect. Dis. 10:2235-2237.

98. Vandenesch, F., T. Naimi, M.C. Enright, G. Lina, G.R. Nimmo, H. Heffernan, N. Liassine, M. Bes, T. Greenland, M.E. Reverdy, and J. Etienne. 2003. Communityacquired methicillin-resistant Staphylococcus aureus carrying Panton-Valentine leukocidin genes: worldwide emergence. Emerg. Infect. Dis. 9:978-984. 
99. Velazquez-Meza, M.E, M. Aires De Sousal, G. Echaniz-Aviles, F. Solorzano-Santos, G. Hranda-Nowales; J Silva-Sanchez, and $\mathbb{H}$. De Lencastre. 2004. Surveillance of methicilin-resistant Staphylococcus aureus in a pediatric hospital in Mexico City during a 7-year period (1997 to 2003): clonal evolution and impact of infection control. J. Clin. Microbial $42: 3877-3880$.

100. Wannet, W.J., E. Spalburg, M.E. Heck, G.N. Pluister, R.J. Willems, and A.J. De Nealing. 2004. Widespread dissemination ini The Netherlands of the epidemic Berlin methicillin-resistant Staphylococcus aureus clone with low-level resistance to oxacillin. $\mathrm{J}$. Clin. Microbiol: 42:3077-3082:

101. Ward, P.D., and W.H. Tumer. 1980. Identification of staphylococcal Panton-Valentine leukocidin as a potent dermonecrotic toxin. Infect. Immun. 28:393-397.

102. Ward, T.T., R.E. Winn, A.I. Hartstein, and D.L. Sewell. 1981. Observations relating to an inter-hospital outbreak of methicilin-resistant Staphylococcus aureus: role af antimicrobial theirapy in infection control. Infect. Control 2:453-459.

103. Wielders, C.L., M.R. Vriens, S. Brisse, L.A. de Graaf-Miltenburg; A. Troelstra, A. Fleer, F.J. Schmitz, J. Verhoef, and A.C. Fluit. 2001. Evidence of in-vivo transfer of mocA DNA to Staphylococcus aureus. Lancet 357:1674-1675.

104. Wisplinghoff, H., A.E. Rosato, M.C. Enright, M. Noto, W. Craig, and G.L. Archer. 2003. Related clones containing SCCmec type IV predominate among clinically significant Staphylococcus epidermidis isolates. Antimicrob. Agents Chemother. 47:3574-3579.

105. Witte, W., C. Cuny, B. Strommenger, C. Braulke, and D. Heuck. 2004. Emergence of a new community acquined MRSA strain in Germany. Euro Surveill. 9:1-2.

105. Wu, S.W., H. de Lencastre, and A. Tomasz. 2001. Recruitment of the mecA gene homologue of Staphyococcus sciuri into a resistance determinant and expression of the resistant phenotype in Staphytococcus aureus. J. Bacteriol. 183:2417-2424.

107. Yoshizawa, Y., J. Sakurada, S. Sakurai, K. Machida, I. Kondo, and S. Masuda. 2000. An exfoliative toxin A-converting phage isolated from Staphylococcus aureus strain ZM. Migrabiol Immunal. 44:189-191. 


\section{CHAPTER 3}

Rapid detection of Panton-Valentine leukocidin from clinical isolates of Staphylococcus aureus strains by real-time PCR

Ruud H. Deurenberg, Cornelis Vink, Christel Driessen, Michèle Bes, Nancy London, Jerome Etienne, and Ellen E. Stobberingh

FEMS Microbiology Letters. 2004. 240:225-228 


\section{ABSTRACT}

To allow rapid identification of Panton-Valentine leukocidin (PVL)-producing Staphylococcus aureus strains, a real-time PCR assay for detection of PVL was developed. This assay is convenient, since it can be applied directly on bacterial suspensions and does not require previous DNA purification. Furthermore, the assay was found to be highly reproducible, robust and specific, since positive results were generated exclusiwely with PVL-positive S. aureus strains, and neither with PVL-negative strains nor staphylococcil other than $S$. aureus.

INTRODUCTION

Staphylococcus aureus is a potential pathogenic micro-organism that can cause various diseases like pneumonia, toxic shock syndrome (TSS) and wound infections (1). Panton-Valentine leukocidin (PVL) is a $S$. aureus-specific exotoxin that belongs to the family of bicomponent synergohymenotropic toxins $(4,10)$. PVL can be harboured in both methicillin-susceptible $S$. aureus (MSSA) and methicillin-resistant $S$ a aureus (MRSA) strains. It is encoded by two contiguous and cotranscribed genes, designated lukF-PV and lukS-PV (8). Like all other leukocidins, PVL kills leukocytes by creating pores in the cell membrane. Purified PVL was reported to induce severe inflammatory lesions when injected intradermally in rabbits "leading to capillary dilation, infiltration of polymorphonuclear cells, and skin necrosis $(8,13)$.

The genes encoding PVL, which are carried on a bacteriophage, are found in only a subset of $S$. aureus isolates. Prévost et al. reported that PVL was harboured by fewer than $5 \%$ of the isolates in a general hospital (8). In accordance with the aforementioned activities of purified PVL, PVL-positivity of S, aureus strains was found to be associated with primary skin infections, such as furunculasis, and severe necrotizing pneumonia $(3,6)$. The clinical importance of PVL was further demonstrated in a study of $S$. aureus infections which occurred between 1986 and 1998 in France. This study revealed eight cases of community-acquired pneumonia caused by PVLpositive S. aureus strains, six of which with a fatal outcome. The patients involved were all immunocompetent children and young adults, and each of them presented with a preceding influenza-like syndrome before developing pneumonia. (3).

Furthermore, during the last years infections caused by community acquired MRSA (CA-MRSA) have been an emerging phenomenon worldwide. Vandenesch et al performed a study in which the presence of 24 virulence factors and the methicillin resistance determinant (SCCmec) in 117 CA-MRSA isolates from a large number of 
countries worldwide was investigated. This investigation showed that CA-MRSA was characterized by SCCmec type IV and that PVL is a stable genetic marker for CAMRSA (11).

To investigate the prevalence of PVL-producing $S$. aureus isolates in our hospital and the community, and to allow monitoring of patients for PVL-producing strains, we developed a real-time PCR (TaqMan) assay for the rapid detection of $P V L$. Rapid detection of PVL in clinical isolates of MSSA and MRSA may have consequences for the antibiotic therapy prescribed.

\section{MATERIALS AND METHODS}

\section{Bacterial isolates}

One-hundred characterized S. aureus strains consisting of 51 PVL-negative $(30$ PVL-negative MSSA and 21 PVL-negative MRSA) and 49 PVL-positive (23 PVLpositive MSSA and 26 PVL-positive MRSA) $S$. aureus isolates as tesited with conventional PCR (6) were used to investigate the specificity of the assay. These strains included different $S$. aureus clones spreading around the world from countries like Australia (MRSA with sequence type (ST) 30 and 93), China (MRSA with ST30), France (MSSA with ST1,22, 25, 26, 30,80, 121 and 188 and MRSA with ST8 and 80), the Netherlands (MRSA with ST8, 22, 37, 59 and 377), Spain (MSSA with ST121), Switzerland (MRSA with ST5), Tahiti (MSSA with ST1 and 181) and the United States of America (MRSA with ST1, 8 and 59) $(11,12)$.

To test the potential cross-reactivity with other staphylococcal species, 20 clinical Staphy/ococcus epidermidis isolates ( 5 methicillin-susceptible [MSSE] and 15 methicillin-resistant $S$. epidermidis isolates [MRSE]), $3 S$. capitis, $1 \mathrm{~S}$. chromogenes, 1 S. cohnii, $4 \mathrm{~S}$. heremolyticus, $1 \mathrm{~S}$. hominis, $1 \mathrm{~S}$. sciuri and $1 \mathrm{~S}$. wameri clinical isolates were used.

To investigate the presence of PVL in clinical isolates from our hospital, a total of $106 \mathrm{~S}$. aureus isolates from blood cultures, obtained between 1999 and 2003, were tested. We included both community acquired (CA) $S$. aureus isolates (isolated within 48 hours after patient admission to the hospital) and hospital acquired (HA) S. aureus isolates (isolated after 72 hours of admission).

MRSA Cluster 28 was used as the reference strain for PVL (12). For the identification of the strains, the catalase and coagulase activity was tested, followed by further identification with the API Staph identification system (Biomerieux, Boxtel, The Netherlands). 


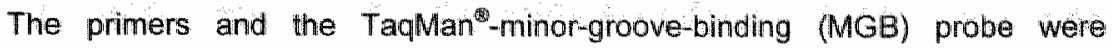
designed on the basis of the published sequences of PVL (GenBank accession number AB006796 (5)), using the computer programme Primer Express 2:0 (Applied Biosystems [ABI], Nieuwerkerk ald ljssel, The Netherlands). The sequences of the forward and reverse primer were 5'-GCTGGACAAAACTTCTTGGAATAT-3" (PVL-FP: corres-ponding to position 2666-2690 of the PVL sequence (5)) and 5-GAT AGGACACCAATAAATTCT GGATTG-3" (PVL-RP, corresponding to position 2749 2723 of the PVL sequence (5)), respectively (Sigma-Genasys, Cambridge, United Kingdom). The sequence of the $\mathrm{V} \| \mathrm{C}$-labelled $\mathrm{MGB}$ probe was $5^{4}$ AAAATGCCAGTGTTATCCA-3" (PVL-PR, corresponding to position 2694-2712 of the PVL sequence (5)) (ABI, Nieuwerkerk a/d ljssel, The Netherlands). The specificity of the primer and probe sequences were confirmed by screening of sequence databases using BLAST (http://www.ncbi.nlm.nih.gov/blast).

\section{TaqMan assay for $P V L$}

The assay conditions, such as primer and probe concentrations, were optimized according to the guidelines from both the Primer Express 2.0 software programme and the manual (Protocol) of the TaqMan Universal PCR Master Mix (ABI, Nieuwerkerk a/d ljssel, The Netherlands). The following reaction conditions were used: $0.6 \mu \mathrm{M}$ of PVL-FP, $0.6 \mu \mathrm{M}$ of PVL-RP, $175 \mathrm{nM}$ of MGB probe, $1 \times$ TaqMan Universal PCR Master Mix (ABI, Nieuwerkerk a/d ljssel, The Netherlands) and $20 \mu \mathrm{l}$ of purified genomic DNA (isolated from a 1 McFarland suspension using the WizardQ Genomic DNA Purification Kit (Promega, Leiden. The Netherlands) (7)) or $20 \mu \mathrm{l}$ of a 0.5 to 1 McFarland suspension (1.5 to $3 \times 10^{8}$ colony forming units $\left.\llbracket \mathrm{CFU} / / \mathrm{ml}\right)$ of the isolates in a total volume of $50 \mu \mathrm{l}$. After amplification $\left(2 \mathrm{~min}\right.$ at $50^{\circ} \mathrm{C}$, $10 \mathrm{~min}$ at $95^{\circ} \mathrm{C}$, followed by 42 cycles of $15 \mathrm{sec}$ at $95^{\circ} \mathrm{C}$ and $60 \mathrm{sec}$ at $60^{\circ} \mathrm{C}$ ) using the $\mathrm{ABI}$ PRISM 7000 Sequence Detection System, Ct (threshold cycle) values were calculated.

\section{RESULTS AND DISCUSSION}

\section{Determination of the detection limit of the PVL real-time PCR assay}

Initially, the PVL TaqMan assay was tested using both purified bacterial DNA as well as bacterial suspensions as input material. Since the assay performed similarly 
using either of both types of material (data not shown), we optimized the assay using bacterial suspensions directly in the reaction mixtures. To assess the detection limit of the assay, four ten-fold dilutions were made of a 11 McFarland suspension of a PVLpositive S: aureus strain. Then, each of the dilutions was kested directly in the PCR assay. As shown in Figure 1a, the four dilutions generated Ct values ranging from 19.5 to 33.5 . The standard curve that was derived from these values (Figure 1 b) showed a near optimal slope of -3.5 indicating that the assay was optimal over a broad dynamic range. Thus, a signal with suspensions of at least $30 \mathrm{CFU} / \mu \mathrm{l}$, which corresponds to a 10,000 fold dilution of a 1 McFarland suspension could be detected.
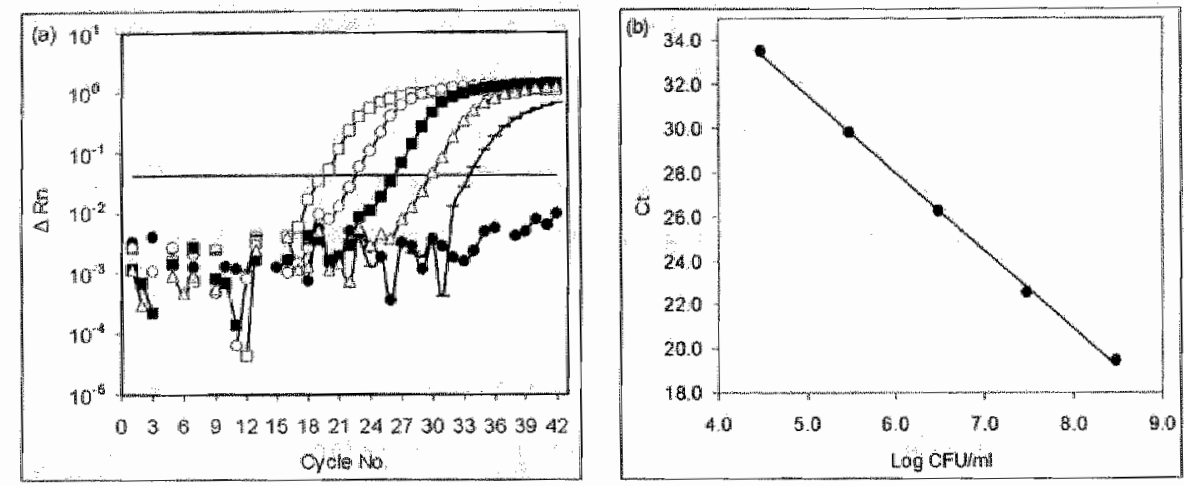

Figure 1. (a) PCR amplification curves of serial dilutions of a PVL-positive $S$. aureus strain. The strengths of the suspensions ranged from $3 \times 10^{4}$ to $3 \times 10^{8} \mathrm{CFU} / \mathrm{ml}(1$ McFarland). $\Delta R n$ indicates the normalized fluorescent reporter value, subtracted from the background value. No Template Count (NTC) (-๑); $3 \times 10^{8} \mathrm{CFU} / \mathrm{ml}(-\square-) ; 3 \times 10^{7}$ $\mathrm{CFU} / \mathrm{ml}(-\mathrm{O}) ; 3 \times 10^{6} \mathrm{CFU} / \mathrm{ml}(-\mathrm{m}) ; 3 \times 10^{5} \mathrm{CFU} / \mathrm{ml}\left(-\Delta^{-}\right) ; 3 \times 10^{4} \mathrm{CFU} / \mathrm{ml}\left(-{ }_{-}\right) ;$ Threshold (-). (b) Standard curve generated with the $\mathrm{Ct}$ values from the amplification curves shown in (a).

Specificity of the assay

To determine the specificity of the assay, a large panel of PVL-positive and PVL-negative $S$. aureus isolates was tested. The PVL-positive strains produced $\mathrm{Ct}$ values between 17.46 and 23.76 (mean=20.23, $S D=1.72)$, whereas all $P V L$-negative strains did not generate detectabie signals. Potential cross-reactivity with staphylococcal species other than $S$. aureus was also tested in the assay. None of these 32 isolates generated positive results in the assay (data not shown). These data indicate that the PVL real-time PCR assay was highly specific. 
The reproducibility of the PCR assay was tested with six PVLpositive S. aureus strains in five independent runs. The strains used included MRSA Cluster 28 and five independent MRSA strains from the Netherlands. In the five PCR runs mean Ct values were found of $19.00(S D=0.35), 21.43(S D=0.46), 19.40 \quad(S D=0.32), 18.77(S D=0.35)$, $19.02(S D=0.40)$ and 20.32 ( $S D=0.09)$, respectively. This shows that the real-time $P V L$ PCR was highly reproducible.

Investigation of PVL in clinical isolates

Two of the $63(3.2 \%) C A: S$. aureus isolates were positive for PVL and generated $\mathrm{Ct}$ values of 22.4 and $19.2_{n}$ respectively. None of the $43 \mathrm{HA} \mathrm{S}$. aureus isolates were positive for PVL. The percentage of PVL-positive strains corresponded to the results found by Prévost et al. in a French study, who found a percentage of less than $5 \%$ among isolates from a general hospital (8).

\section{CONCLUSUON}

In conclusion, a real-time PCR assay was developed for the detection of $S$. aureus strains producing PVL. This assay generated results at least two times faster than the conventional PCR methods previously used for the detection of PVL. The assay was very convenient, since it can be applied directly on bacterial suspensions and does not require previous DNA purification. Furthermore, the assay was found to be highly reproducible, specific and robust. Since PVL-carrying $S$, aureus strains pose an upcoming problem worldwide, both in the hospital and in the community, the availlability of a rapid, real-time PVL PCR assay will help to identify PVL-harbouring $S$. aureus strains and thus contribute to the prevention of the spread of such strains. Moreover, infections with PVL positive strains could warrant, like pyrogenic exotoxin producing Streptococcus pyogenes, a combination therapy of a penicillin and clindamycin. This combination proved to be more effective than penicillin alone for severe group A streptococci infections ( 9 )

\section{ACKNOWLEDGEMENTS}

We would like to thank Dr. W. Wannet from the National Institute of Public Health and Environment (RIMM) in Bithoven, the Netherlands for making MRSA Cluster 28 strain available 
as well ar a part of the panel of PVL-positive and PVL-negative strains. Alexandra Heinzmann Is thanked for excelsut technical assistance

\section{REFERENCES}

1. van den Broek, P.J, 2003. Staphylococcus aureus, a successful pathogen. Ned. Tijdschr. Geneaskd 147:1045-1048

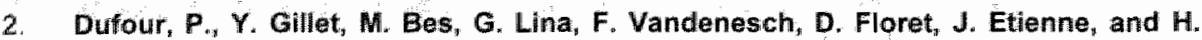
Richet. 2002. Community-acquired methicillin-resistant Staphylococcus aureus infections in France: emergence of a single clone that produces Panton-Valentine leukocidin. Clin. Infect. Ois. 35:819-824.

3. Gillet, $Y_{*}$ B. Issartel ${ }_{t}$ P. Vanhems, J.C. Fournet ${ }_{\|}$G. Lina, M. Bes, F. Vandenesch, $Y$. Piemont, N. Brousse, D. Floret, and J. Etienne. 2002. Association between Staphylococcus aurous strains carrying gene for Panton-Valentine leukocidin and mighly lethal necrotising pneumonia in young immunocompetent patients. Lancet. 359:753-759.

4. Gravet, A., D.A. Colin, D. Keller, R. Girardot, H. Monteil, G. Prevost, and R. Giradot. 1998. Characterization of a nowell structural member, LukE-LukD, of the bi-component staphylococcal leucotoxins family. FEBS Lett. 436:202-208.

5. Kaneko, J., T. Kilmura, Y. Kawakamil, T. Tomita, and Y. Kamio. 1997. Panton-Valentine leukocidin genes in a phage-like particle isolated from mitomycin C-treated Staphylococcus aureus V8 (ATCC 49775). Biosci. Biotechnol. Biachem. 61:1960-1962.

6. Lina, G., Y. Piemont, F. Godail-Gamot, M. Bes, M.O. Peter, V. Gauduchon, F. Vandenesch, and J. Etienne. 1999. Involvement of Panton-Valentine leukocidinproducing Staphylococcus aureus in primary skin infections and pneumonia. Clin. Infect. Dis. 29:1128-1132.

7. Miller, S.A., D.D. Dykes, and H.F. Polesky. 1988. A simple salting out procedure for extracting DNA from human mucleated cells. Nucleic Aoids Res. 16:1215.

8. Prevost, G., P. Couppie, P. Prevost, S. Gayet, P. Petiau, B. Cribier, H. Monteil, and Y. Plemont. 1995. Epidemiological data on Staphylococcus aureus strains producing synergohymenotropic toxins. J. Med. Microbial 42:237-245.

9. Stevens D.L. 1999. The flesh-eating bacterium: what"s next? J. Infect. Dis. 179:S3665374

10. Supersac, G., G. Prevost, and Y. Piemont. 1993. Sequencing of leucocidin R from Staphylocaccus aureus P83 suggests that staphylococcal leucocidins and gamma. hemolysin are members of a single "two-component family of toxins. Infect. Immun. 61:580-587.

11. Vandenesch, F., T. Naiml, M.C. Enright, G. Lina, G.R. Nimmo, H. Heffernan, N. Liassine, M. Bes, T. Greenland, M.E. Reverdy, and J. Etienne. 2003. Communityacquired methicillin-resistant Staphylococcus aureus carrying Panton-Valentine leukocidin genes: worldwide emergence. Emerg. Infeet. Dis. 9:978-984. 
12. Wannet, W. 2003. Virulent MRSA strains containing the Panton Valentine Leukocidin gene in The Netherlands. Eurosurvellance Weekly 7:10.

13. Ward, P.D., and W.H. Turner. 1980. Identification of staphylococcal Panton-Valentine leukocidin as a potent dermonecrotic toxin. Infect. Immun. 28:393-397. 


\title{
CHAPTER 4
}

\section{Different clonal complexes of methicillin-resistant Staphylococcus aureus are disseminated in the Euregio Meuse-Rhine}

\author{
Ruud H. Deurenberg, Cornelis Vink, Guy J. Oudhuis, Jascha E. Mooij, Christel \\ Driessen, Guy Coppens, Jos Craeghs, Els de Brauwer, Sebastian Lemmen "Hans \\ Wagenvoort Alexander W. Friedrich, Jacques Scheres and Ellen E. Stobberingh
}

Antimicrabial Agents and Chemotherapy. 2005. Submitted 
The Euraglio Meuse-Rhine (EMR) is formed by the border regions of Belgium, Germany and The Netherlands. Cross-border health care requires infection control measures in particular since the prevalence of methicillin-resistant Staphyiococcus aureus (MRSA) differs between the three countries. To investigate the dissemination of MRSA in the EMR, 152 MRSA isolates were characterized by Pulsed-Field Gel Electrophoresis (PFGE); SCCmec typing and Multilocus Sequence Typing (MLST). PFGE revealed major clonal group $A, G, L$ and $Q$, suggesting dissemination of MRSA in the EMR. Group $A$ harboured mainly SCCmec type III and sequence types (STS) ST239 and ST241. The Imajority of the strains from group $\mathrm{G}$ harboured SCCmec type I and ST8 and ST247, whereas most strains from group L carried either SCCmec type IV or I. Within group L, ST8 and 228 were found, belonging to clonal complexes (CC) 8 and 5, respectively. Most strains from group $Q$ included SCCmec type II and were sequence typed as ST225. Both ST225MRSA-II and ST241-MRSA-IIII were novel findings in Germany. In addition, the SCCmec type of two isolates has not been described previously. One strain was classified as SCCmec type III, but harboured the p/s gene and the dcs region. Another strain was characterized as SCCmec type IV, but lacked the dcs region. In addition, one isolate harboured both scCmec type $V$ and Panton-Valentine leukocidin. Finally, the ScCmec type of the strains was found to be correlated with the antiblotic susceptibility pattern.

\section{INTRODUCTION}

Staphylococcus aureus is a potentially pathogenic bacterium that can cause various diseases, such as post-operative wound infections and necrotizing pneumonia (21). S. aureus has a strong adaptive power to antibiotics. Since the introduction of methicillin in 1959, methicillin-resistant S. aureus (MRSA) strailns have been isolated, first in the United Kingdom in 1961, and subsequently in other parts of the world. Although most of the MRSA strains are hospital-acquired (HA-MRSA), community acquired strains (CA-MRSA) have also recently been reported (4).

Resistance of MRSA strains to methicillin is determined by the presence of the mecA gene, which encodes the penicillin binding protein (PBP) 2a. The mecA gene is localized on a mobile genetic element, which is designated the Staphylococcal Cassette Chromosome mec (SCCmec) $(3,15,22)$. Currently, five main types of SCCmec (type I to V) are distinguished. SCCmec types I, II and III are associated with HA-MRSA, whereas types $\mathrm{N}$ and $V$ are associated with CA-MRSA $(13,16)$. SCCmeC types I. IV or $V$ exclusively encode resistance to $\beta$-lactam antibiotics. By contrast, 
SCCmec types III and III determine mult-resistance as these cassettes carry both integrated plasmid sequences (e.g. pT181 and pUB110) and transposons (e.g. Tn554) conitaining drug resistance genes. Besides the resistance genes on SCCmec. $S$ aureus can also carry drug resistance genes on other sites of its chromosome and on plasmids. Also situated on SCCmec are genes responsible for the regulation of the transcription of mecA: $\triangle$ mecR1 (on SCCmec types I, IV and V), mecR1 and mecl (on sccmec type II and III) $(14,15,16)$. For integration into and excision from the chromosome at a specific site (attBscc), genes encoding cassette chromosome recombinases $(\mathrm{Ccr})$ are located within the SCCmec elements. These genes are designated ccrA1 and ccrB1 (in SCCmec type 1), ccrA2 and ccrB2 (in SCCmec type II and IV), CorA3 and corB3 (in SCCmec type III) and ccrC (in SCCmec type V) $(7,13$, $16 \%$

The Euregio Meuse-Rhine (EMR) is a region consisting of the Belgian provinces of Limbourg and Liège, the German-speaking region of Bellgium, the region Aachen in Germany and the southern part of the Dutch province of Limbourg, with an area of $10.478 \mathrm{~km}^{2}$. Cross-border patient mobility and free access to health care facilities within the European Union (EU) in general, and the EMR in particular, is an important issue for patients, doctors, hospitals, sickness funds and the health care insurance companies. Each year many thousands of the 3.7 million inhabitants of the EMR crass the border to visit a medical specialist or a hospital on the other side of the border. In an official publication of the European Commission (Eurocommissioner David Byrne, Opening Speech Maastricht Conference on Cross-border Health Care, June 8th 2004, Maastricht, The Netherlands), the EMR was therefore recently mentioned as a model region for the EU in the field of cross-border health care and cross-border co-operation of hospitals and sickness funds. Nevertheless, an important issue of concern that is related to cross-border health care is the dissemination of multi-resistant bacteria. In this regard, it is interesting to note that the three countries forming the EMR differ considerably in the prevalence of MRSA isolated in hospitals $(23.6 \%, 13.8 \%$ and $0.6 \%$ in Belgium, Germany and The Netherlands, respectively) (32). Consequently, the cross-border transfer of patients may have an important impact on the dissemination and prevalence of MRSA, in particular in cases where patients are transferred from countries with a relatively high prevalence to a country with a low prevalence. Therefore, we investigated the dissemination of MRSA isolates between hospitals from the EMR during the lasit five years. The MRSA isolates were subjected to Pulsed-Field Gel Electrophoresis (PFGE), SCCmec typing, and Multilocus Sequence Typing (MLST) (2). As the presence of Panton-Valentine leukacidin (PVL) genes was suggested to be 
an important characteristic off CA-MRSA (33), the isolates were also subjected to a PVL-specific real-time PCR.

\section{MATERIALs ANd Methods}

\section{Clinical isolates}

One hundred and fifty-two isolates of MRSA from individual patients isolated between December 1999 and February 2004 from five geographically closely related hospitals in the EMR were included in the study (Table 1). These included two Belgium hospitals (Hospital East-Limbourg, Genk, a 822-bed general hospital, and General Hospital Vesalius, Tongeren, a 355-bed general hospital), one German hospital (Universitätsklinikum Aachen, a tertiary 1500-bed university hospital) and two Dutch hospitals (Atrium Medical Centre, Heerlen; a 811-bed general hospital and University Hospital Maastricht, a tertiary 680-bed university hospital). All strains were identified as S: aureus by catalase and coagulase testing. Methicillin resistance was determined by the disk diffusion test with oxacillin concentration disks, according to the guidelines of the National Committee for Clinical Laboratory Standards (NCCLS) (23) and by PCR amplification of the mecA gene (27).

\section{Reference strains}

MRSA strains COL, BK2464, ANS46, HDE288 and WIS were used as reference strains for SCCmec type I, II, III, IV and $\mathrm{V}$, respectively $(16,24) . S_{\text {i aureus }}$ strain 1206 was used as a positive control for the Tn554 PCR (35). For PFGE. reference strain $S$. aureus $P$ s 47 was used as a molecular weight marker, whereas MRSA strains BK2464, COL, HDE288, HU25 and PER34 were used as reference sitrains for the New York/Japan, Archaic, Pediatric, Brazilian and Iberian clonal type, respectively (25).

\section{Antimicrobial susceptibility testing}

Antimicrobial susceptibility testing was performed by micro-broth dilution according to the NCCLS guidelines (23) for the following antibiotics: amikacin, amoxicillin, cefazolin, ciprofloxacin, clindamycin, co-trimoxazol, doxycyclin, erythromycin, flucloxacillin, gentamicin, penicillin, rifampicin and vancomycin. 


\section{SCCmed lyping}

SCCmec typing was essentially carried out as described by Oliveira et al (24) in which mecA and six different loci on SCCmec (Figure 1) were amplified by PCR with the following modifications. PCR amplification of mecA sequences was carried out with primer mecA1 and mecA2 (Sigma Genosys, The Netherlands), resulting in a PCR product of 527 bp instead of 162 bp (27). PCR was performed in a volume of $50 \mu l$ containing $10 \mu \mathrm{l}$ of a $0.5 \mathrm{McF}$ artand suspension $\left(1.5 \times 10^{8} \mathrm{CFU} / \mathrm{ml}\right)$ of the MRSA strain, $0.2 \mathrm{mM}$ of each dNTP (Amersham Biosciences, The Netherlands), $1 \times$ PCR reaction buffer (Qiagen, The Netherlands), 1.25 U HotStarTaq (Qiagen, The Netherlands) and primers. The primer concentrations used were silmilar as previously described (24), except for those of the mecA primers, which were $0.6 \mu \mathrm{M}$ for both mecA1 and mecA2. The amplifications were performed on a GeneAmp PCR System Model 9600 (Applied Biosystems, The Netherlands) with the following programme: $15 \mathrm{~min}$ at $94^{\circ} \mathrm{C}$, followed by 30 cycles of $30 \mathrm{sec}$ at $94^{\circ} \mathrm{C}, 30 \mathrm{sec}$ at $53^{\circ} \mathrm{C}$ and $60 \mathrm{sec}$ at $72^{\circ} \mathrm{C}$, followed by a postextension step of 10 min at $72^{\circ} \mathrm{C}$. The PCR products were separated on $2 \%$ agarose glels in Tris-Acetate-EDTA (TAE) buffer, stained with ethidium bromide and visualized with UV light using a FluorChem ${ }^{\text {TMM }}$ Imaging System (Alpha Innotech Corporation, The Netherlands).

PCR for CorAB and corC.

Most of the primers used for amplification of ccrAB and corC were as described previousily $(12,16)$. Primer $\beta 2$, however, was replaced by a primer with the following sequence: 5 -ATTGCCTTGATAATAGCCTCT-3' (primer $\beta 2 \mathrm{a}$ ). The following reaction conditions were used: either $1.2 \mu \mathrm{M}$ of forward primer $32 \mathrm{a}$ or $0.4 \mu \mathrm{M}$ of forward primeir yF respectively, $0.4 \mu \mathrm{M}$ of either reverse primer $\alpha 2, \alpha 3$, $\alpha 4$, or $y R, 0.2 \mathrm{mM}$ of each dNTP, $1 \times$ PCR reaction buffer, $2.5 \mathrm{U}$ of HotStarTaq DNA Polymerase and $10 \mu \mathrm{ll}$ of a 0.5 to 1 McFarland suspension $\left(1.5\right.$ to $\left.3 \times 10^{8} \mathrm{CFU} / \mathrm{ml}\right)$ in a total volume of $50 \mu$. Amplification was performed on the GeneAmp PCR System Model 9600 using the following programme: $15 \mathrm{~min}$ at $95^{\circ} \mathrm{C}$, followed by 35 cycles of 1 min at $95^{\circ} \mathrm{C}$ " 1 min at $55^{\circ} \mathrm{C}$ and $1 \mathrm{~min}$ at $72^{\circ} \mathrm{C}$, followed by an extension step of $10 \mathrm{~min}$ at $72^{\circ} \mathrm{C}$. PCR products were analyzed by electrophoresis through $1 \%$ agarose gels as described above. 


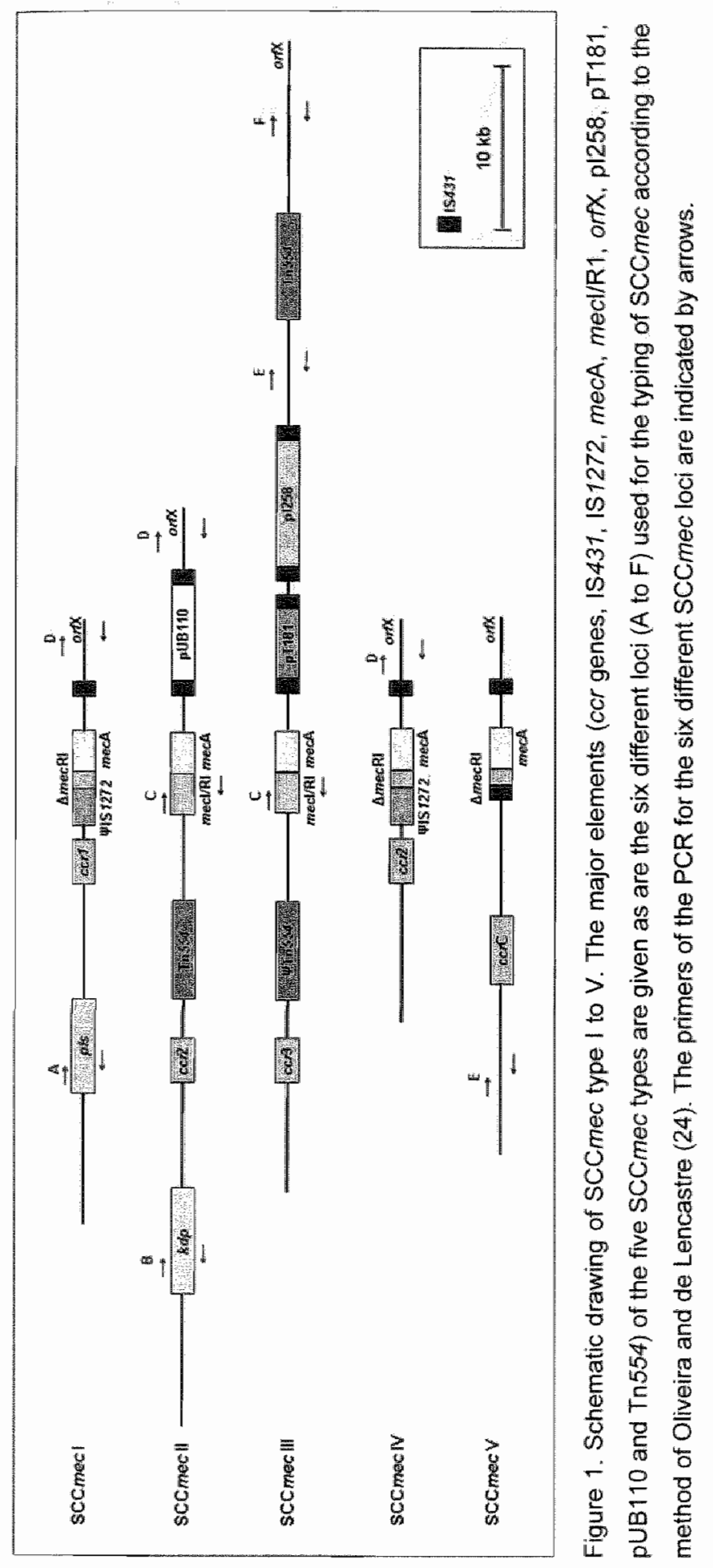


PCR for Tr554

The primers for Tn554 were used as described previously (17). The reaction conditions used were similar to those for the ccr PCR. Amplification was performed on the GeneAmp PCR System Model 9600 using the following programme: $15 \mathrm{~min}$ at $94^{\circ} \mathrm{C}$, followed by 34 cycles of 1 min at $94^{\circ} \mathrm{C}, 1 \mathrm{~min}$ at $63^{\circ} \mathrm{C}$ and $1 \mathrm{~min}$ at $72^{\circ} \mathrm{C}$, followed by an extension step of 10 min at $72^{\circ} \mathrm{C}$. PCR products were analysed by electrophoresis through $1 \%$ agarose gels as described above.

\section{Pulsed-Field Gel Electrophoresis (PFGE)}

PFGE was carried out essentially as described previously (12). The banding patters were visualized with UV light using a FluorChem ${ }^{\text {Th }}$ Imaging System. Subsequently "the patterns were analysed with Dice comparison and unweighted pair group matching analysis (UPGMA) settings with GelCompar II 3.5 (Applied Maths, SintMartens-Latem, Belgium) according to the scheme of Tenover et al (31). The position tolerance was set at $2.0 \%$ and isolates with a similarity index of 0.80 or more were classified as a clonal group $(6,26)$.

\section{Mutilocus Sequence Typing (MLST)}

It has previously been shown that MRSA strains from one major clonal group, as demonstrated by PFGE, have the same Sequence Type (ST), or STs that are related to a single Clonal Complex (CC) $(6,8,26,30)$. Therefore, two representative strains from each of the major clonal groups as obtained through PFGE $(6,8,26,30)$ were used for MLST (10). The primers used for MLST were identical to those described previously (10), with the exception of primers glpF-Dn and gmk-Up, which were replaced by primers glpF-Dna (5'-TGGTAAAATCGCATGTGCAATTC-3') gmk-Upa (5'ATCGTTTTATCAGGACCATC-3'), respectively. The PCR products were sequenced using an ALFexpress II automatic sequencer (Amersham Biosciences. The Netherlands). Finally, the ST was determined using the MLST database (http://www.mlst.net).

Real-time PCR for Panton-Valentine leukocidin (PVL)

PVL was detected with a real-time PCR method as described previously (9). 
The correlation between the SCCmec type and the antibiotic susceptibility pattern was determined with canonical discriminant analyses with the software package SPSS 11.0 .1 (SPSS Inc., The Netherlands). Canonical discriminant analyses are used for the investigation of one or more normally distributed interval independent variables (SCCmec types) and a categorical dependent variable (susceptibility pattern). This is a multivariate technique that considers the latent dimensions in the independent variables for predicting group membership in the categorical dependent variable.

\section{RESULTS}

Distribution of SCCmec types

The SCCmec type (Figure 1) could be determined for 148 of the $152(97.4 \%)$ clinical isolates of MRSA. Only four of the five different types of SCCmec were found (1 to IV; Table 1) with the method described by Oliveira of al (24). SCCmec types I and IV were predominant with $29 \%$ and $34 \%$, respectively, and types $I$ and $I I$ were less common with $12 \%$ and $23 \%$, respectively. The different SCCmec types were not distributed similarly among the three countries from the EMR. In Belgium, SCCmec type I and IV predominated, whereas in Germany the most common types were type II and III. In The Netherlands, the most frequently found types were type I, III and IV (Table 1).

The SCCmec type of four (DOM068, 083, 114 and 012) of the 152 MRSA isolates (3\%) could not be determined according to the method described by oliveira et al (24). DOM068 was found to contain $\operatorname{locil} A, C, D, E$ as well as $F$ (Table 2), which is uncommon to the prototypes of the five known SCCmec types, as shown in Figure 1. Another isolate, DOM083, was also found to have a unique SCCmec orgianization. possessing loci $C, D, E$ and $F$ (Table 2). The SCCmec structure of isolates DOMO68 and DOM083 was further characterized by determination of the presence of two other lloci from the SCCmec cassette, i.e. ccr and Tn554. Both strains were found to possess Tn554 as well as the carAB3 gene, indicating that their SCCmec cassettes most strongly resemble the type III cassette (Table 2).

The cassette of another strain. DOM114, was found to contain onlly a single locus from the six loci that were defined by Oliveira et al (24), i.e. locus. $E$ (Table 2). Since DOM114 was also found to possess the ccrC gene, its SCCmec cassette can be classified as type $V($ Table 2$)$. 


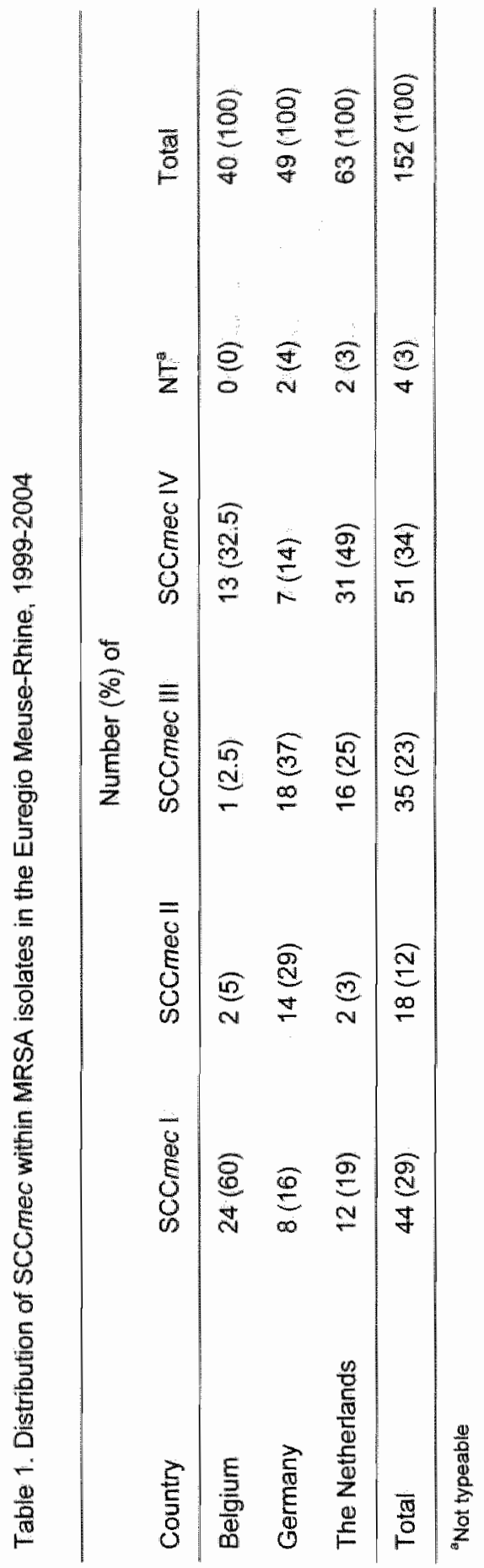


The fourth 'non-typeable' isolate, DOM012, lacked all six loci as defined by Oliveira et al. (24). However, this strain was found to contain the ccrAB2 gene, which is characteristic for both type II and type IV cassettes. Since the DOM012 cassette did not contain Tn554, it was classified as type IV (Table 2).

Table 2. Results of non-typeable ${ }^{\text {SC }}$ SCmec within MRSA isolates

\begin{tabular}{|c|c|c|c|c|c|}
\hline Codle $e^{a}$ & Country & Locus ${ }^{b}$ & $\mathrm{ccr}$ & $\operatorname{Tn} 554$ & SCCmec type \\
\hline DOMO12 & The Netherlands & - & CCRA2 & $=$ & IV \\
\hline DOMO68 & Germany & $A, C$ to & $\operatorname{ccr} A 3$ & + & III \\
\hline DOMOB3 & Germany & $C$ to $F$ & $\operatorname{CCr} A 3$ & + & III \\
\hline DOM114 & The Netherlands & $E$ & $\operatorname{cor} 0$ & - & V \\
\hline
\end{tabular}

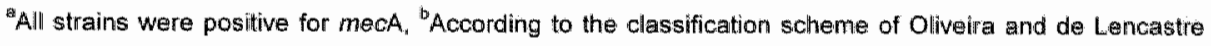
(24). The distribution of the six different loci among the SCCmec types are given in Figure 1.
}

\section{PFGE analyses}

Each of the MRSA strains was subjected to analysis by PFGE. On the basis of the PFGE patterns, a dendrogram was constructed (Figure 2). One of the isolates (DOM152) could not be typed due to repeated difficulties with the isolation of DNA from this strain. A total of 32 clonal groups (A to AF) were distinguished, of which four were major clonal groups ( $A, G, L$ and $Q$ ). Major clonal group $A$ was closely related to the clonal groups B, C, D and E. Taken together "these groups included 34 of the 152 MRSA isolates $(22 \%)$. A large majority of these 34 strains $(88 \%)$, isolated from both Germany and The Netherlands, harboured ScCmec type Ill.

The second major clonal group, group $G$, contained 26 of the 152 MRSA isolates $(17 \%)$ of which $21(81 \%)$ harboured SCCmec type I, and $5(19 \%)$ harboured SCCmec type IV. Most isalates from this group originated from Belgium and The Netherlands. Group $\mathrm{G}$ was also found to include reference strain $\mathrm{COL}$, representative for the Archaic clone, which is one of the six major MRSA clones spread worldwide (2). Clonal group $F$, which was related to group $G$, comprised only 4 isolates $(3 \%)$, three of which harboured SCCmec type IV and one strain harboured SCCmec type $V$. The reference strain for the Iberian clone (2). PER34, was linked to clonal group F.

The third major clonal group, group $L$, included 26 of the 152 MRSA isollates $(17 \%)$. Of these, $18(69 \%)$ contained SCCmec type IV $6(23 \%)$ contained SCCmec 


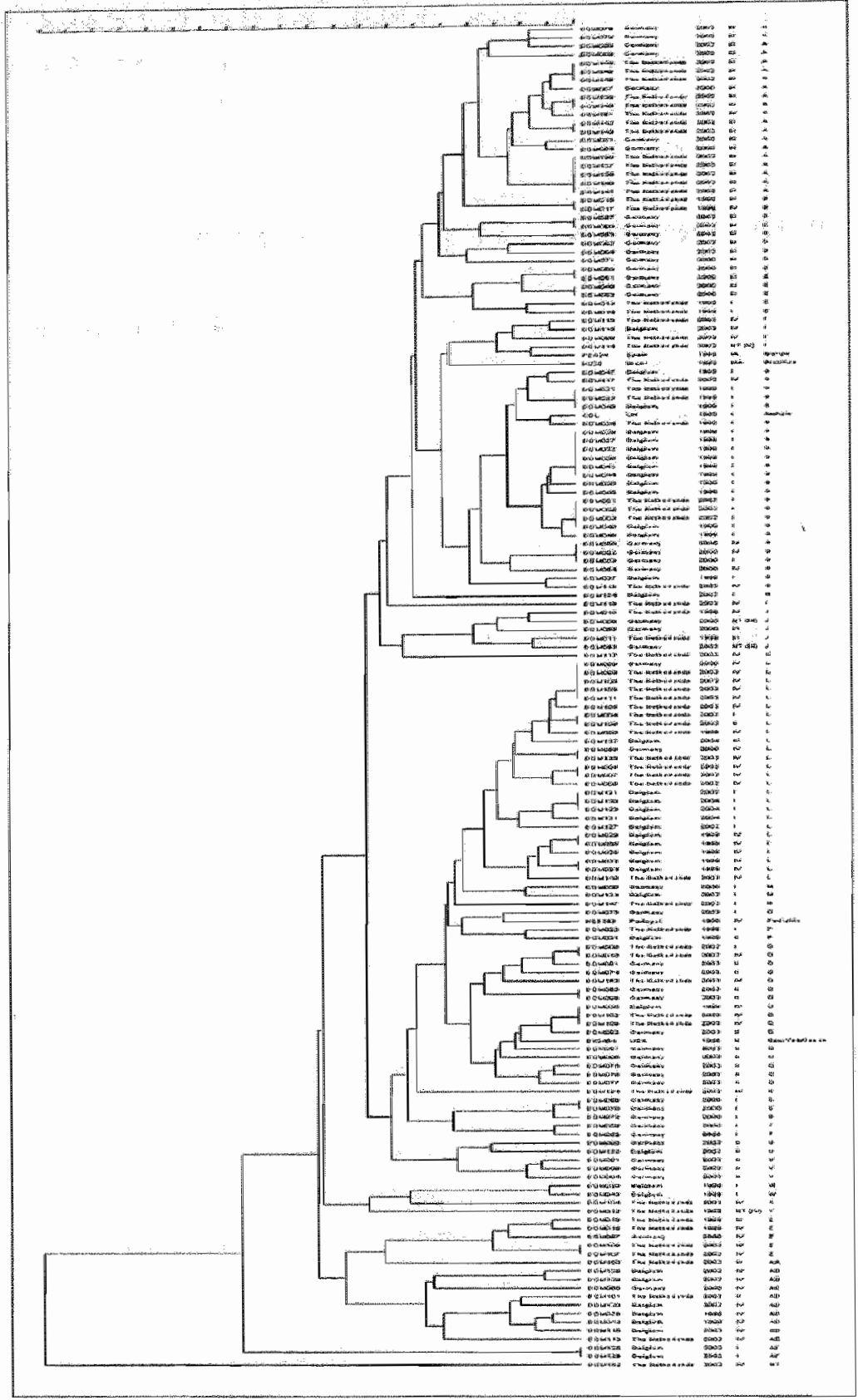

Figure 2. Dendrogram of the 152 clinical MRSA isolates and five reference clones. The five columns on the right represent MRSA isolate code, country of origin, year of isolation, SCCmec type and clonal group respectively. NT, Not typeable. 
type 1, $1(4 \%)$ contained SCCmec type H, and $1(4 \%)$ contained SCCmec type III Most of the strains were isolated in Belgium and The Netherlands. None of the reference strains were linked to this clonal group.

The fourth major group, group $Q$, contained 16 of the 152 MRSA isolates $(11 \%)$. Ten $(63 \%)$ of these carried SCCmec type II, whereas $5(31 \%)$ contained SCCmec N. and $1(6 \%)$ contained SCCmec type I. All except one of the strains from this group was ilsolated in either Germany or The Netherlands. Group $Q$ also included reference strain BK2464, which is a representative of the New York/Japan cllone (2).

\section{MLST analyses}

Two representative strains from each major clonal PFGE group were subjected to MLST. As shown in Table 3, MLST identified six different sequence types (ST8, 225, $228,239,241,247$ ) that belonged to two clonal complexes (CC5 and 8 ). In major

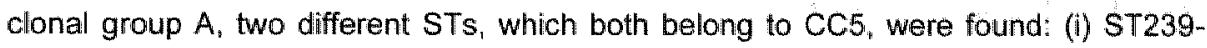
MRSA-III, a single locus variant (SLV) of ST8 and representative for the Brazilian clone, and (ii) ST241-MRSA-II, an SLV of ST239-MRSA-III (at loculs yqiL). The two STs that were found in major clonal group $G$ are different SLVs of a single ST, i.e. ST250; ST247-MRSA-I is an SLV at the gmk locus, and STB-MRSA-I is an SLV at the yqiL locus of ST250 (11). Interestingly, the strains from major clonal group L (DOM111 and DOM131) were typed as ST8-MRSA-IV and ST228-MRSA-I, respectively, which belong to different clonal complexes ( $\mathrm{CC} 8$ and 5 , respectively). Both strains from major clonal group Q were typed as ST225-MRSA- III, an SLV at the tpi locus of ST5 (11).

\section{Prevalence of PVL}

Only two (DOM103 and DOM114) of the 152 MRSA isolates (1.3\%) contained PVL. Although both strains were isolated in The Netherlands in 2003, they differed in both SCCmec type and PFGE type. Strain DOM103 was classified within major clonal group $L$, harbouring SCCmec type $W$, whereas strain DOM114 was classified within

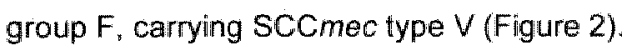

\section{Correlation between SCCmec type and antibiotics susceptibility pattern}

The antibiotic resistance pattern for the SCCmec types is presented in Table 4. Only the non $\beta$-lactam antibiotics are presented in this table, since all MRSA strains. 


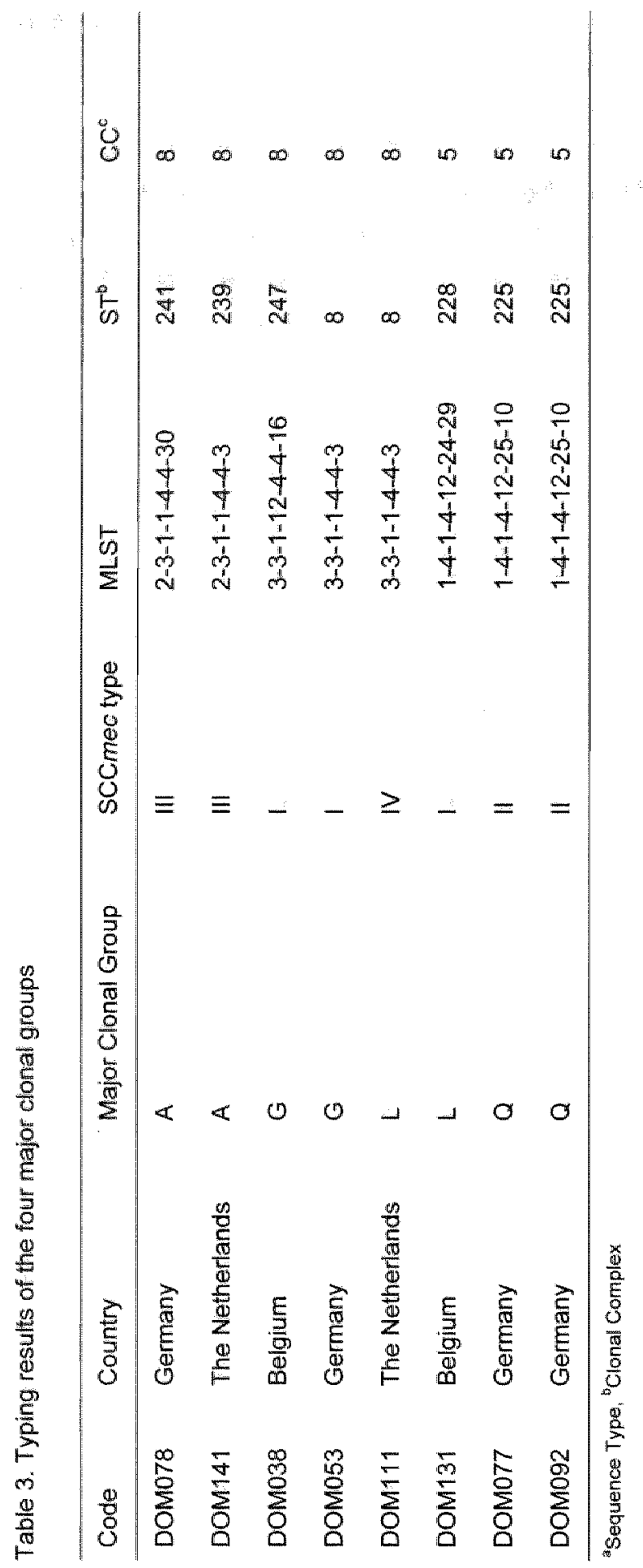


were resistant to the four $\beta$-lactam antibiotics tested, e.g. amoxicillin, cefazolim, flucloxacillin, and penicillin. To investigate if a correlation exists between the SCCmec type and the antibiotic susceptibility pattern of MRSA isolates, canonical discriminant analyses were performed. As shown in Figure 3 , the SCCmec types were centred around the four group centroids, indicating that the SCCmectype and the susceptibility pattern were indeed correlated. The antibiotic susceptibility pattern had a predictive value of $84.1 \%$ for SCCmec type I, $83.3 \%$ for SCCmec type $11.85 .7 \%$ for SCCmec type III and $86.3 \%$ for SCCmec type IV. As shown in Table 4 and Figure 3, the correlation is more pronounced for SCCmec type II, III and IV than for SCCmec type I.

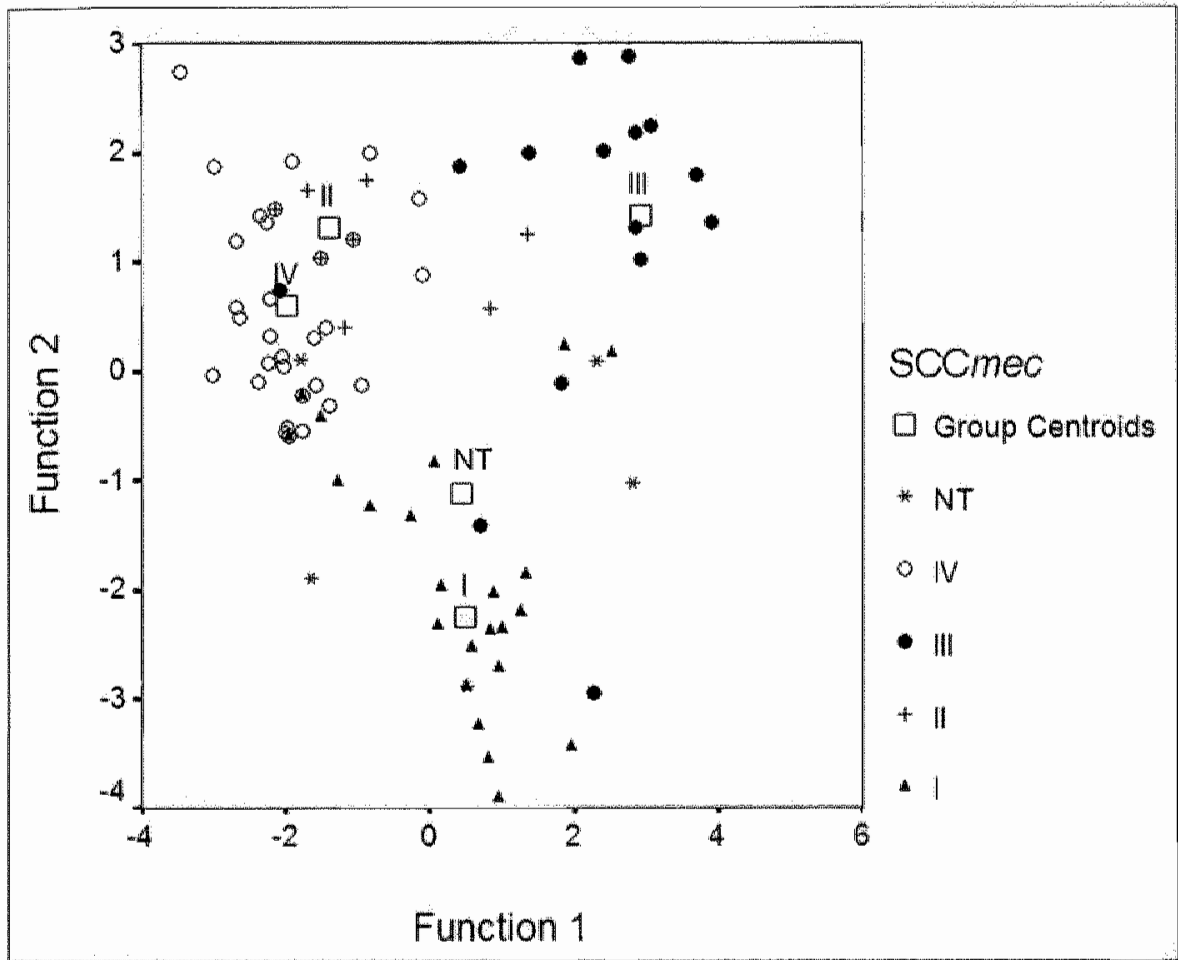

Figure 3. Statistical analyses of the SCCmec type and the antibiotic susceptibility pattern. The discriminant function 1 and function 2 are latent variables that are created as a linear combination of discriminating variables. $\mathbb{N} \mathbb{T}$, Not typeable. 


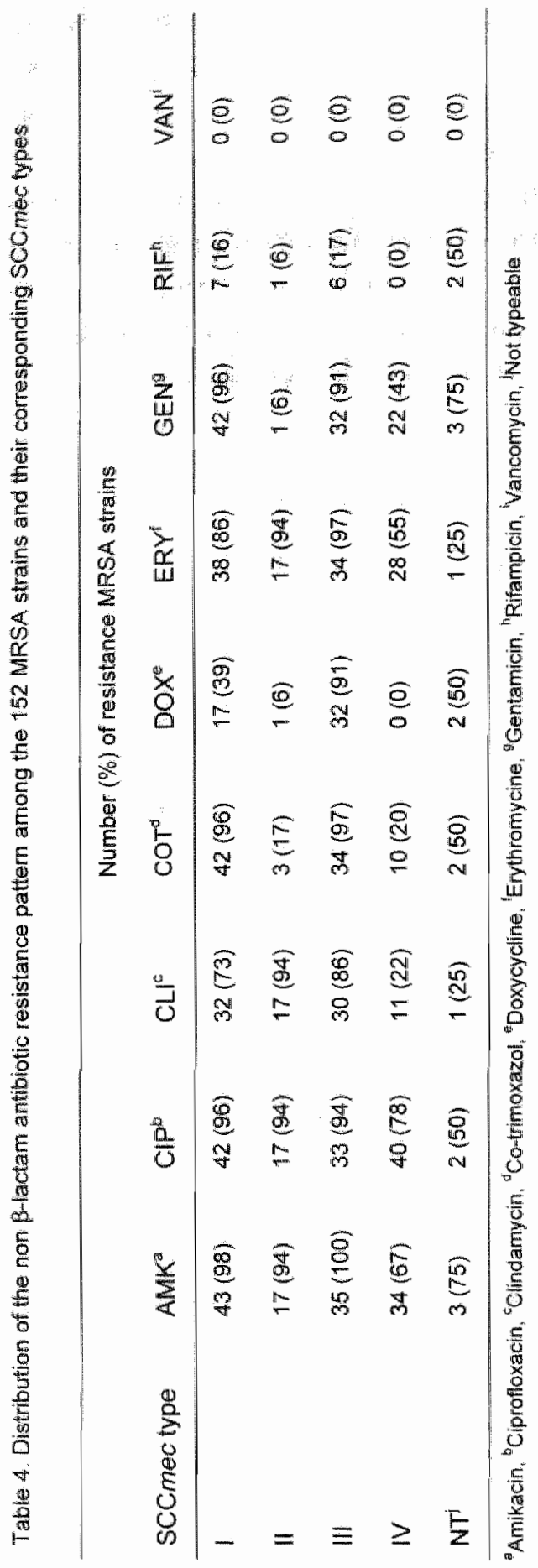




\section{Discussion}

Monitoring the dissemination of MRSA in the EMR is important, since known and novel MRSA clones may spread from country to country through cross-border patient care. In particular, the spread of MRSA harbouring either SCCmec type II or III" which encode multi-resistance, could pose a serious threall to health care facilities.

In this study, 152 MRSA strains were characterized, isolated in hospitals from the EMR between 1999 and 2004. Typing of the strains by PFGE revealed four major clonal groups, suggesting dissemination of MRSA in the EMR. The strains that were classified within major clonal group $A$ and within the closely related minor clonal groups $B$ to $E_{1}$ comprised $22 \%$ of all isolates. Two representative strains from group $A$ were also typed by MLST, and were classified as ST239-MRSA-III and ST241-MRSAIII. Both STs form part of CC8 (11). Although strains with the signature of ST239MRSA-III were previously found in both Germany and The Netherlands, this study is the first to repont the presence of ST241-MRSA-III in Germany (11).

The second major clonal group, group $G$, included MRSA strains harbouring mainly SCCmec type I (Figure 2). MLST of two representative clones from group $G$ revealed two different STs, which were classified within the same clonal complex (CC8), i.e. ST8-MRSA-I and ST247-MRSA-I. Both STs have previously been found in the countries from the EMR: ST8-MRSA-1 in Belgium and The Nietherlands, and ST247-MRSA-I in Belgium and Germany $(8,11,36)$.

MRSA strains from major clonal group $\mathbb{L}$ harboured mainly SCCmec types IV and 1. From this group, two strains with a different SCCmec type (IV and I) were selected for analysis by MLST. Thus, these strains were classified as ST8-MRSA-IV and ST228-MRSA-I, respectively. Interestingly, these STs belong to different cional complexes, i.e. CC8 and CC5, respectively. Although these CCs were more related to each other than they are to other CCS (20), the finding of strains from different MLST clonal complexes within a single PFGE clonal group was novel for $S$. aureus. Nevertheless, this finding was in line with previous reports that demonstrated the higher discriminatory power of MLST over PFGE for bacterial species other than S. aureus, such as Vibrio cholerae. Salmonella and Listeria monocytogenes $(18,19,29)$. Both ST8MRSA-IV and ST228-MRSA-I were found previously in the EMR countries: ST8-MRSA-IV in Germany and The Netherlands, and ST228-MRSA-I in Belgium and Germany $(11,36)$.

MRSA strains from the fourth major clonal group, group Q, harboured mainly SCCmec type 11. Two representatives from this group were both typed as ST225MRSA-II, an ST belonging to CC5. Although ST225-MRSA-II has previously been 
found in the USA (30), the finding of this ST in Germany is novel. Since ST225-MRSAII is a single-locus variant (SLV) at the tor locus of strain ST5-MRSA-II, which was previousty found in Belgium (8); ST225-MRSA-II may be derived from ST5-MRSA-11. Recent studies reported the finding of ST22-MRSA-IV and ST45-MRSA-IV in Belgium and ST45-MRSA-I and ST45-MRSA-IV in The Netherlands $(8,34)$. These STs, however "were not found in this study.

From four of the 152 MRSA isolates $(3 \%)$ the SCCmec type could not be determined using the method described by Oliveira ef al (24). The percentage of nontypeable SCCmec cassettes was low compared to other studies, in which 10 to $15 \%$ could not be typed $(5,12)$. Since two of the non-typeable MRSA strains (DOM068 and DOM083) were found to possess the ccrAB3 gene, they could be considered to be SCCmec type III strains. However; compared to the type III cassette prototype (Figure 1). strain DOM068 contained two additional loci, locus A (p/s gene) and D (dcs region). Strains with a similar organization of SCCmec loci as DOMO6B have not been reported yet. In contrast, a strain with an additional locus D as opposed to the type III prototype, as seen in strain DOM083, has previously been described by Aires de Sousa and coworkers (1).

Another non-typeable strain, DOM012, was found to contain only a single SCCmec locus apart from mecA. This locus, ccrAB2, was present in the protolype cassettes of both type II and IV. However, since strain DOM012 gene neither possessed mecl (locus C) nor Tn554, its cassette had a higher similarity with the cassette of type IV than with that of type II. Also the resistance to $\beta$-lactam antibiotics found was in line with SCCmec type IV. We therefore concluded that strain DOM012 carries a SCCmec type IV, but lacks locus D.

The low prevalence of PVL was in accordance with previous studies $(9,28)$. Both strains were very likely not related as they were classified within a different clonal group and harboured a different SCCmec type. DOM 114 is to our knowledge the first reported $P V L$-positive MRSA strain carrying SCCmec type $V$.

Although antibiotic resistance in $S$. aureus can also be determined by sequences other than SCCmec, a correlation of approximately $85 \%$ was found between the antibiotic susceptibility pattern and the SCCmec type. Rapid identification of the SCCmec type of MRSA isolates by PCR could therefore be useful to predict the antibiotic susceptibility pattern of isolates and, consequently, guide the choice of antibiotics used for treatment. Hence, the identification of the SCCmec type of clinical isolates might contribute to prevent the unnecessary use of vancomycin, which is only needed in case of MRSA isolates harbouring SCCmec type II or III. 
In summary, MRSA strains belonging to clonal complexes 5 and 8 were disseminated in the EMR and several new types were found: both ST225-MRSAII and ST241-MRSA-III were novel findings in the German part of the EMR. Furthermore. one strain was classified as SCCmec type III, but contained the p/s gene and the dcs region and another strain was characterized as SCCmec type $1 \mathrm{~W}$, but lacked the dos region. One isolate was found harbouring both SCCmec type $\mathrm{V}$ and PVL.

\section{ACKNOWLEDGMENTS}

The study has been partly performed within the framework of the Interreg-1ll project "Cross-border Health Care in the Euregio Meuse Rhine".

We thank Prof. H. De Lencastre and Dr. D.C. Oliweira from The Rockefeller University, New York, USA for providing the reference strains for SCCmec typing. Dr. T. Ito from the Juntendo University, Tokyo, Japan, for providing the reference strain (WIS) for SCCmeC V and Dr. W. Wannet from the National Institute of Public Health and Environment (RIVM) in Bilthowen, The Netherlands for MRSA. Cluster 28 strain. We are grateful to Monique Coomans and Alexandra Heinzmann for excellent technical assistance with the MIC determinations: Peter Terporten for the statistical analysis and Erik Beuken for help with the DNA sequencing.

\section{REFERENCES}

1. Aires de Sousa, M., and H. de Lencastre. 2003. Evolution of sporadic isolates of methicillin-resistant Staphylococcus aureus (MRSA) in hospitals and their similarities to isolates of community-acquired MRSA. J. Clin. Microbiol. 41:3806-3815.

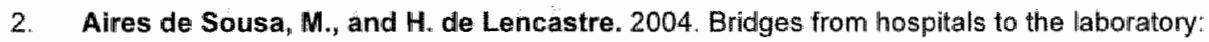
genetic portraits of methicilin-resistant staphylococcus aureus clones. FEMS Immunol. Med. Microbiol 40:101-111.

3. Berger-Bächi, B., and S. Rohrer. 2002. Factors influencing methicillin resistance in staphylococci. Arch. Microbiol. 178:165-171.

4. van den Broek, P.J. 2003. Staphylococcus aureus, a successful pathogen. Ned. Tijdschr. Geneeskd. 147:1045-1048.

5. Chung, M., G. Dickinson, H. De Lencastre, and A. Tomasz. 2004. International clones of methicillin-resistant Staphylococcus aureus in two hospitals in Miami, Florida. J. Clin. Microbiol. 42:542-547

6. Coombs, G.W., G.R. Nimmo, J.M. Bell, F. Huygens, F.G. O'Brien, M.J. Malkowski, J.C. Pearson, A.J. Stephens, P.M. Giffard, and Australian Group for Antimicrobiall Resistance. 2004. Genetic diversity among community methicillin-resistant Staphy/ococcus aureus strains causing outpatient infections in Australia. J. Clin. Microbiol. 42:4735-4743. 
7. Daum, R.S., T. Ito, K. Hiramatsu, F. Hussain, K. Mongkolrattanothai M. Jamklang, and S. Boyle-Vavra. 2002. A novel methicillin-resistance cassette in community-acquired mehicilin-resistant Staphylococcus auneus isolates of diverse genetic backgrounds. J. Infect. Dis. 186:1344-1347

8. Denis, O., A. Dieplano, C. Nonhoff, R. De Ryck, R. de Mendonca, S. Rattiers, R. Vanhoof, and $M J$. Struelens. 2004. National surveillance of methicillin-resistarit Staphylococcus aureus in Belgilan hospitals indicates rapid diversification of epidemic clones. Antimicrob. Agents Chemother. 48:3625-3629.

9. Deurenberg, R.H., C. Vink, C. Driessen, M. Bes, N. London, J. Etienne, and E.E. Stobbreringh. 2004. Rapid detection of Panton-Valentine leukocidin from clinical isolates of Staphylococcus aureus strains by real-time PCR , FEMS Microbiol. Lett. 240:225-228

10. Enright, M.C., N.P. Day, C.E. Davies, S.J. Peacock, and B.G. Spratt. 2000. Multilocus sequence typing for characterization of methicillin-resistant and methicillin-susceptible clones of Staphylococcus aureus. J. Clin. Microbiol. 38:1008-1015.

11. Enright, M.C.., D.A. Robinson, G. Randle, E.J. Feil, H. Grundmann, and B.G. Spratt. 2002. The evolutionary history of methicillin-resistant Staphylococous aureus (MRSA). Proc. Natl. Acad. Sci. USA. 99:7687-7692

12. Hansisen, A.M., G. Kjeldsen, and J.U. Ericson Sollid. 2004. Local variants of staphylococcal cassette chromosome mec in sporadic methicillin-resistant Staphylococcus aureus and methicillin-resistant caagulase-negative staphylococci: evidence of horizontal gene transfer? Antimicrob. Agents Chemother. 48:285-296

13. Hiramatsu, K., L. Cuî, M. Kuroda, and T. Ito. 2001. The emergence and evolution of methicillin-resistant Staphylocaccus aureus. Trends Microbiol. 9:486-493.

14. Ito, T., Y. Katayama, K. Asada, N. Mori, K. Tsutsumimoto, C. Tiensasitorn, and K. Hiramatsu. 2001. Structural comparison of three types of staphylococcal cassette chromosome mec integrated in the chromosome in methicillin-resistant Staphylococcus: aureus. Antimicrob. Agents Chemother. 45:1323-1336.

15. Ito, T., K. Okuma, X.X. Ma, H. Yuzawa, and K. Hiramatsu. 2003. Insights on antibiolic resistance of Staphylococcus aureus from its whole genome: genomic island SCC. Drug Resist. Updat. 6:41-52.

16. Ito, T., X. Ma, F. Takeuchi, K. Okuma, H. Yuzawa, and K. Hiramatsu. 2004. Novell type $\checkmark$ staphylocaccal cassette chromosome mec driven by a novel cassette chromosome recombinase, corc. Antimicrob. Agents Chemother. 48:2637-2651.

17. Jensen, L.B., N. Frimodt-Moller, and F.M. Aarestrup. 1999. Presence of erm gene classes in Gram-positive bacteria of animal and human origin in Denmark. FEMS Microbiol. Lett. 170:151-158

18. Kotetishvili, M, O.C. Stine, Y. Chen, A. Kreger, A. Sulakvelidze, S. Sozhamannan, and J.G. Morris Jr. 2003. Multilocus sequence typing has better discriminatory ability for typing Vibrio cholerae than does pulsed-field gel electrophoresis and provides a measure of phylogenetic relatedness. J. Clin. Microbial. 41:2191-2196. 
19. Kotetishvili, M, O.C. Stine, A. Kreger, J.G. Morris Jr, and A, Sulakvelldze. 2002 Multiocus sequence typing for characterization of clinical and envionmental salimonella strains. J. Clin. Microbiol 40:1626-1635:

20. Lindsay, J.A. and M.T. Holden. 2004 Staphylocoocus aureus. superbug, super genome? Trends Microbiol: 12.378-385

21. Lowy, F.D. 1998. Staphylococcus aureus infections. N. Engl J. Med, 339:520-532.

22. Mongkolrattanothal, K., S. Boyle, M.D. Kahana, and R.S, Daum, 2003. Severe Staphylococcus aureus infections caused by clonally related community-acquired methicillin-susceptible and methicilini-resistant isolates. Clin. Infect Dis 37:1050-1058.

23. National Commitee for Clinical Laboratory Standards. 1999 performance standards for antimicrobial susceptibility testing; ninth informational supplement M100-S9; Wayne, Pa.

24. Oliveira, D.C., and H. de Lencastre. 2002. Multiplex PCR strategy for rapid identification of structural types and variants of the mec element in methicillin-resistant Staphytococcus aureus. Antimicrob. Agents Chemother, 462155-2161.

25. Oliveira, D.C., A. Tomasz, and H. de Lencastre. 2001. The evolution of pandemic clones of methicillin-resistant Staphylococcus aureus: identification of two ancestral genetic backgrounds and the associated mec elements. Microb. Drug. Resist. 7:349-361.

26. Perez-Roth, E., F. Lorenzo-Diaz, N. Batista, A. Moreno, and S. Mendez-Alvarez. 2004. Tracking methicillin-resistant Staphylococcus aureus clones during a $5 \times y e a r$ period (1998 to 2002) in a Spanish hospital. J. Clin. Microbiol. 42:4649-4656.

27. Predari, S.C., M. Ligozzi, and R. Fontana. 1991. Genotypic identification of methicillinresistant coagulase-negative staphylococci by polymerase chain reaction. Antimicrob. Agents Chemother. 35:2568-2573.

28. Prevost, G., P. Couppie, P. Prevost, S. Gayet ${ }_{1}$ P. Petiau, B Cribier, H. Monteill, and Y. Piemont. 1995. Epidemiological diata on Staphylococcus aurews strains producing synergohymenotropic toxins. J. Med, Microbiol. 42:237-245.

29. Revazishvili, T, M. Kotetishvili, O.C. Stine, A.S. Kreger, J.G. Morris Jir, and A. Sulakwelidze. 2004. Comparative analysis of multilocus sequence typing and pulsed-field gel electrophoresis for characterizing Listeria monocytogenes strains isolated from environmental and clinical sources. \&. Clin. Microbiol 42:276-285.

30. Shukla, S.K., M.E. Stemper, S.V. Ramaswamy, J.M. Conradt, R. Reich, E.A. Graviss, and K.D. Reed. 2004. Molecular characteristics of nosocomial and Native American community-associated methicillin-resistant Staphylococcus aureus clones from rural Misconsin. J. Clin. Micrabiol. 42:3752-3757.

31. Tenover, F.C., R.D. Arbeit, R.V. Goering, P.A. Mickelsen, B.E. Murray, D.H. Persing, and B. Swaminathan. 1995. Interpreting chromosomal DNA restriction patterns produced by pulsed-field gel electrophoresis: criteria for bacterial strain typing. J. Clin. Microbiol. 33:2233-2239. 


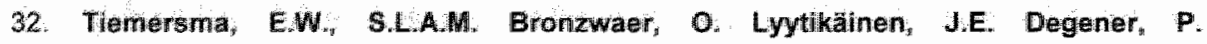
Schrijnemakers, N. Bruinsma, J. Monen, W. Witte, H. Grundmann and European Antimicrobial Resistance Surveillance System Participants. 2004. Methicillin-resistant. Staphylococcus aureus in Europe, 1999-2002. Emerg: Infect: Dis: 10:1637-1634.

33. Vandenesch, F., T. Naimi, M.C. Enright, G. Lina, G.R. Nimmo, H. Heffernan, N. Lassine, M. Bes, T. Greenland, M.E. Reverdy, and J. Etienne. 2003, Communilyacquired methichlin-resistant Staphylococcus aureus carrying Panton-Valentine leukocidin genes: worldwide emergence. Emerg. Infect Dis. 9978-984.

34. Wannet, W.J., E. Spalburg, M.E. Heck, G.N. Pluister, R.J. Willems, and A.J. De Nealing. 2004. Widespread dissemination in The Netherlands of the epidemic Berlin methicillin-resistant Staphylococcus aureus clone with low-level resistance to oxacillin. $J$. Clin. Microbial. 42:3077-3082.

35. Westh, H., D.M. Hougaard, J. Vuust, and V.T. Rosdahl. 1995. Prevalence of erm gene classes in erythromycin-resistant Staphylococcus aureus strains isolated between 1959 and 1988. Antimicrob. Agents Chemother. 39:369-373.

36. Witte, W. 2004. International dissemination of antibiotic resistant strains of bacterial pathogens. Infect. Genet. Evol. 4:187-191. 


\section{CHAPTER 5}

The prevalence of the Staphylococcus aureus tst gene among community- and hospital-acquired strains and isolates from Wegener's Granulomatosis patients

Ruud H. Deurenberg, Rutger F. Nieuwenhuis, Christel Driessen, Nancy London, Frank R. Stassen, Frank H. van Tiel, Ellen E. Stobberingh and Cornelis Vink

FEMS Microbiolagy Letters. 2005. 245:185-189 


\section{ABSTRACT}

To allow rapid identification of toxic shock syndrome toxin-1 (TSST-1)-producing Staphylococcus aureus strains, a realtime PCR assay for the detection of the tst gene, which encodes TSST-1, was developed. The assay was applied to $S$. aureus isolates from patients with Wegener's Granulomatosis (WG), as well as isolates that were classified as either community- (CA) or hospital-acquired (HA). No significant difference in the percentage of tst-positive strains was observed between isolates from WG pattients and CA isolates (24\% and $25 \%$, respectively). In contrast, only $14 \%$ of the $\mathrm{HA}$ isolates were tst-positive $(p<0.05)$. Investigation of the clonal relationship between tst-positive $C A$ and HA strains could indicated the recent emergence of a virulent $S$. aureus clone in the community.

\section{INTRODUCTION}

The pathogenicity of Staphylococcus aureus can in part be attributed to the production of pyrogenic toxins. Because secretion of these toxins causes excessive stimulation of T-lymphocyles, they are called superantigens (SAgs) (13). To date, fifteen different SAgs have been identified in S. aureus, i.e. staphylococcal enterotoxins (SE) $A$ to $E$ and $G$ to $M$, exfolliative loxins (ET) $A$ and $B$, and toxic shock syndrome toxin-1 (TSST-1) $(1,10,16)$.

TSST-1 is a $29,1-\mathrm{kDa}$ protein that is encoded by the $S$. aureus $t$ st gene $(7,11)$. The release of TSST-1 into the bloodstream may give rise to a variety of severe clinical conditions, such as toxic shock syndrome (TSS), sudden infant death syndrome (SIDS), and Kawasaki syndrome. The tst gene is present in up to $70 \%$ of the S aureus strains isolated from patients with TSS. TSS is characterized by high fever, erythematous rash formation, hypotension and major oxygen involvement. which may lead to multi organ failure. Without appropriate therapy, a lethal shock may develop within 24 hours after the onset of symptoms $(6,7,12,13)$. Although most cases (two thirds) of TSS are associated with tampon USe, an increasing number of cases are related to localized infections, surgical complications and insect bites (12). Musser at al. showed that the majorily of female patients affected with TSS had a single clone af S. aureus that was well adapted to colonization in the genital tract (15). TSS is usually treated with proper drainage of surgical wounds, a high dose of a flactam antibiotic and W-globulin (2) Nevertheless, TSS still has a lethality rate of aboul $30 \%(7)$

The potency of TSST-1 lies in its ability to efficiently induce T-cell proliferation and activation (10,000-fold more efficiently than other antigens). This is due to bridging 
the antigen-presenting cells (APC) and T-lymphocytes through binding the major histocompatibility complex (MHC) class II on APCs and specific variable regions on the B-chain of both CD4 and CD8 antigen receptors. Consequently, a T-helper 1 type response is mounted. which results in the massive release of interleukins and cylokines (6). It has previously been suggested that TSST-1 as well as other SAgs may play a role in patients suffering from Wegener's Granulomatosis (WG), a disease in which organs are damaged through inflammation of blood vessels. This finding was based on the observation of an increased incidence of nasal carriage of $S$ aureus in combination with chronic activation of circulating T-cells in WG patients (17).

In order to both controi and monitor the spread of $S$. aureus strains producing TSST-1 in the community as well as in the hospital it is important to be able to rapidly identify these strains. Therefore, a real-time PCR (TagMan) assay for the detection of the S. aureus ist gene was developed. The assay was used to determine the prevalence of tst-positive strains among community-acquired (CA) and haspitalacquired (HA) $S$. aureus bloodstream isolates, and among isolates from nasal swabs from WG patients. Finally, the clonal relation between the TSST-1-positive CA and HA strains as well as all $S$. aureus isolates from WG patients was investigated using Pulsed-Field Gel Electrophoresis (PFGE).

\section{MATERIALS AND METHODS}

Bacterial isolates

One-hundred and six S. aureus strains consisting of 55 TSST-1-negative and 51 TSST-1-positive $S$. aureus isolates, which were previously characterized using a conventional tst-specific PCR method $(9,10)$, were used to investigate the characteristics of the tst real-time PCR assay. To test for potential cross-reactivity with other staphylococcal species, clinical isolates of Staphylococcus epidermidis $(n=14), S$. capitis $(n=3)$. S. haemolyticus $(n=4), S$. chromogenes $(n=1), S$. cohnil $(n=1)$, S. hominis $(n=1)$. S. sciuri $(n=1)$ and $S$. warneri $(n=1)$ were subjected to the TSST-1 real-time PCR. The strains were identified with the API Staph identification system (Biomérieux, Boxtel, The Netherlands).

A random selection of 86 methicillin-susceptible S. aureus (MSSA) bloodstream isolates from individual patients in our hospital, a tertiary 680-bed university hospital, was investigated for the presence of the tst gene. These strains, isolated between 1999 and 2003 , included $51 \mathrm{CA} \mathrm{S.} \mathrm{aureus} \mathrm{isolates} \mathrm{(isolated} \mathrm{within} 48$ hours after patient admission to the hospital) and $36 \mathrm{HA} \mathrm{S}$ aureus isolates (isolated after 72 hours of 
admission). In addition, 165 aureus strains, isolated from nasal swabs in 2004 , from WG patients were investigated. Each of these strains was found to be catalase and coagulase positive, confirming the identification of these isolates as $S$. aureus.

Primer and probe design

Primers (Sigma-Genosys, Haverhill, United Kingdom) and TaqMan ${ }^{\text {-pprobes }}$ (Applied Biosystems [ABI], Nieuwerkerk ald ljssel, The Netherlands) were designed based on the published sequences of the S. aureus-specific tst and femA genes (Table 1), using the computer programme Primer Express $2.0(\mathrm{AB})$, Nieuwerkerk a/d ljssel, The Netherlands). The specificity of the primer and probe sequences was confirmed by screening sequence databases using BLAST (http:/www.ncbi.n/m.nih.gov/blast).

\section{TaqMan assay for femA and TSST-1}

A PCR specific for the S. aureus femA gene was developed to serve as a positive controll for the tst-specific PCR. Assay conditions, such as primer and probe concentrations, were optimized according to the guidelines from both the Primer Express 2.0 software programme and the manual (Protocol) of the TaqMan Universal PCR Master Mix (ABI, Nieuwerkerk ald ljssel, The Netherlands). The following reaction conditions were used in the TaqMan ${ }^{*}$ assay: $0.3 \mu$ M of femA_FP or TSST-1_FP, 0.3 $\mu \mathrm{M}$ of femA_RP or TSST-1_RP, $100 \mathrm{nM}$ of femA-PR or TSST-1_PR, $1 \times$ TaqMan Universal PCR Master Mix (ABI, Nieuwerkerk ald lissel, The Netherlands) and $20 \mu \mathrm{l}$ of purified genomic DNA (isolated from a 1 McFarland $\left(3 \times 10^{\theta}\right.$ colony forming units [CFU]/ml) suspension using the Wizard(Q) Genomic DNA Purification Kit (Promega, Leiden, The Netherlands) (15)) or $20 \mu \mathrm{l}$ of a 1:100 diluted 1 McFarland suspension in a total volume of reaction mixture of $50 \mu$ l. Amplification was performed on the $A B \mid$ PRISM 7000 Sequence Detection System using the following programme: 2 min at $50^{\circ} \mathrm{C}, 10 \mathrm{~min}$ at $95^{\circ} \mathrm{C}$, followed by 42 cycles of $15 \mathrm{sec}$ at $95^{\circ} \mathrm{C}$ and $60 \mathrm{sec}$ at $60^{\circ} \mathrm{C}$.

\section{Pulsed-Field Gel Electrophoresis (PFGE)}

PFGE analyses was carried out by digestion of the $S$. aureus chromosomal DNA with Smal (Invitrogen, Breda, The Netherlands) essentially as described previously (8). The PFGE patterns were analyzed with Dice comparison and unweighted pair group matching analysis (UPGMA) settings with GelCompar II 3.5 


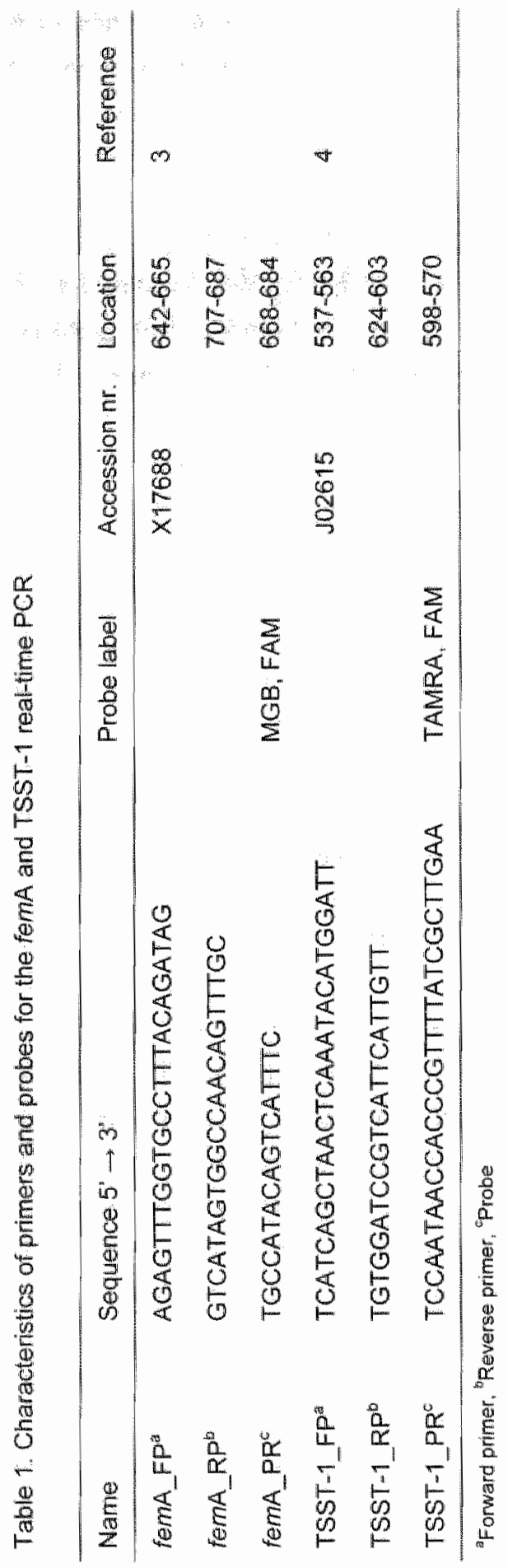


(Applied Maths, Sint-Martens-Latem, Belgium) according to the scheme of Tenover et al (1B). The position tolerance was set at $2.0 \%$ and isotates with a simikrity index of 0.80 or more were classified as a clonal group.

\section{RESULTS AND DISCUSSION}

Determination of the detection limit of the tst real-time PCR assay

Initially, the tst TaqMan assay was tested using both purified bacterial DNA as well as bacterial suspensions as input material. Since the assay performed similarly using both types of material (data not shown), the assay was optimized by adding bacterial suspensions directly to the reaction mixtures.

To assess the detection limit of the assay, five ten-fold dilutions were made of a 1 McFarland suspension of a tst-positive $S$ aureus strain (HT.2004.0349). The number of CFUs in each dilution was determined with an Eddy Jet automatic spiral platter (IUL. Instruments, Barcelona, Spain). Then, the bacterial suspensions were tested directly in the real-time PCR assay in three independent runs. As shown in Figure 1(a), the different bacterial suspensions generated mean $C t$ values ranging from 19.96 to 37.36 . The lower detection limit of the assay was approximately $60 \mathrm{CFU}$ per reaction, which corresponded to approximately $3 \mathrm{CFU} / \mu \|_{\text {, }}$ i.e. a $10^{-5}$ dillution of a 1 McFarland suspension. The standard curve derived from the amplification plat (Figure 1(b)) showed a near optimal slope of -3.4 , indlicating a near optimal reaction efficiency. Furthermore, the standard curve showed that the assay had a broad dynamic range.

\section{Sensitivity and specificity of the assay}

To determine the sensitivity and specificity of the assay, known tst-positive $(n=51)$ and $t s t$-megative $(n=55) S$. aurews isolates were tested. The tst-positive strains produced $\mathrm{Ct}$ values between 23.34 and 31.83 (mean=26.51, $S D=1.37$ ), which was in the range of the ist-positive control strain. All tst-negative strains did not generate detectable signals (data not shown). As a control for potential inhibition of PCR reactions, all isolates were also tested for the presence of the $S$. aureus-specific femA gene by real-time PCR. As expected, each of these isolates was positive in this assay, with $\mathrm{Ct}$ values ranging from 26.01 to 30.05 (mean $=27.98, \mathrm{SD}=0.94$ ) (data not shown).

The tst PCR assay was investigated further by testing a panel $(n=26)$ of staphylococcal species other than $S$. aureus. None of these strains generated positive 
results (data not shown) indicating that there was no cross-reactivity with other staphylococcal species.
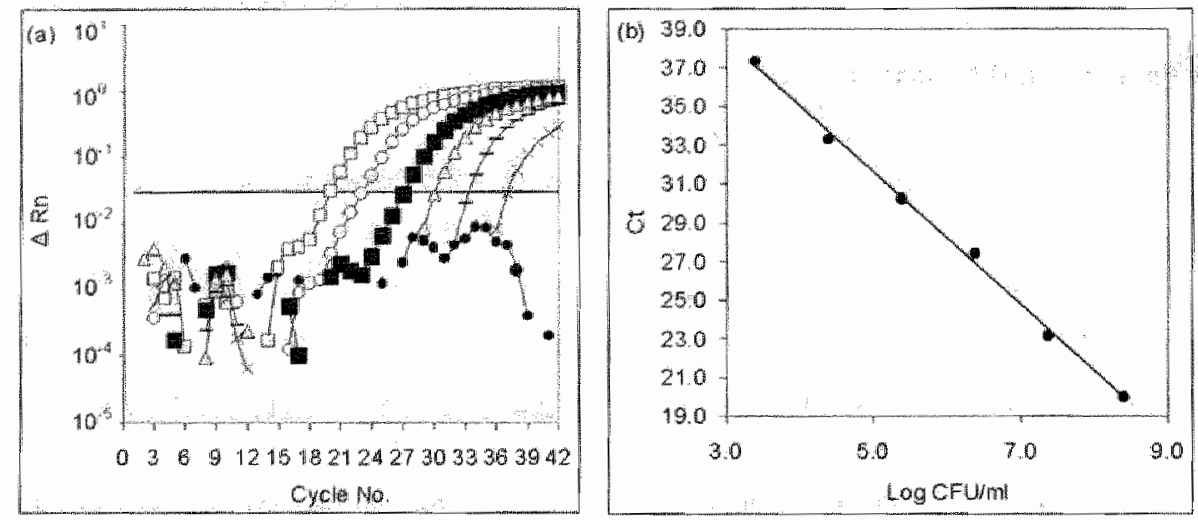

Figure 1. (a) PCR amplification curves of serial dilutions a tst-positive S. aureus strain (HT.2004,0349). The strengths of the suspensions ranged from $3 \times 10^{3}$ to $3 \times 10^{8}$ CFU/ml (1 McFarland). $\triangle \mathrm{Rn}$ indicates the normalized fluorescent reporter value, subtracted from the background value. $3 \times 10^{8} \mathrm{CFU} / \mathrm{ml}(-0-) ; 3 \times 10^{7} \mathrm{CFU} / \mathrm{mi}(-\mathrm{O}-) ; 3 \times$ $10^{6} \mathrm{CFU} / \mathrm{ml}(-\mathrm{m}) ; 3 \times 10^{5} \mathrm{CFU} / \mathrm{ml}(-\Delta-) ; 3 \times 10^{4} \mathrm{CFU} / \mathrm{ml}(-2) ; 3 \times 10^{3} \mathrm{CFU} / \mathrm{ml}(-\mathrm{x}-)_{0}$ ) NTC, no template control $(-\bullet)$; threshold $(--)$. (b) Standard curve generated with the $C$ t values from the amplification plots shown in (a).

Reproducibility of the assay

The reproducibility of the assay was tested with four tst-positive $S$. aureus strains in five independent runs. In these PCR runs, mean $\mathrm{Ct}$ values were found of $24.59(S D=0.45), 26.57(S D=0.23), 29.37(S D=0.02)$ and $26.05 \quad(S D=0.20)$, respectively. This indicated that the real-time tst $P C R$ was highly reproducible.

Prevalence of the tst gene in clinical isolates

Twelve of the $51(24 \%)$ CA S aureus isolates were positive for the tst gene and generated $C t$ values between 25.13 and 34.40 (mean=28.73, SD=3.56). In contrast, only five of $36(14 \%)$ of the HA S. aureus isolates were tst positive and generated $\mathrm{Ct}$ values between 27.02 and 32.11 (mean=29.41, $\mathrm{SD}=2.17$ ). Four of the $16(25 \%) \mathrm{S}$. aureus strains isolated from patients with WG were tst positive and generated $\mathrm{Ct}$ values between 25.23 and 28.81 (mean=27.08, $\mathrm{SD}=1.65$ ). This percentage 
corresponded to that reported in a previous study. in which a percentage of $19 \%$ among WG patients was described (17).

Clonal relationship of tst-positive CA and HA S. aureus and WG olinical isolates

The clonal relationship between the tst-positive CA and HA S. aureus isolates was studied by PFGE. From the different PFGE patterns a dendrogram was constructed (Figure 2). Six clonal groups ( $A$ to $F$ ) were found, and the majority ( 9 out of 17) of the TSST-1-positive S. aureus isolates were grouped within major clonal group A. Interestingly, most of these isolates were obtained in 2002 and 2003, and had a CA origin. The other 8 isolates were grouped within five minor clonal groups ( $B$ to $F$ ). These strains were isolated between 1999 and 2001, and had either a CA or HA origin. The majority of the tst-positive CA and HA S. atureus strains was resistant to amoxicillin and/or penicillin, but a common resistant phenotype was not found among the CA $S$. aureus strains. In addition, none of the tst-positive $S$. aureus strains was positive for PVL (5).

A link between the patients carrying the CAS. aureus strains was not found. Some of the patients had been hospitalized during a period of 12 months prior to isolation of the CA S. aureus strain. In addition, several patients suffered from different disorders, such as Chronic Obstructive Pulmonary Disease (COPD) and diabetes. Taken together, these data might suggest that during the period 1999-2003, tst-positive strains from a single clonal group have become predominant in the community.

The clonal relationship between the $S_{n}$ aureus strains isolated from WG patients was investigated with PFGE. One of the strains could not be typed, due to repeated failure to digest DNA with Smal. Seven clonal groups ( $G$ to $M$ ) were found among the remaining 15 strains. The 4 tst-positive $S$. aureus strains were equally distributed between clonal group $H$ and L. However, a relation between clonal groups of tst $^{\text {t }}$ positive and tst-negative $S$. aureus strains was not found (datla not shown). Furthermore, the dendrogram showed that only 2 of the strains isolated from WG patients had a clonal relationship with the emerging CA strains (clonal group A). It is assumed that these 2 strains were acquired by the WG patients outside the hospital.

The classification of the tst-positive strains from $1999-2003$ within 6 different clonal groups is in contrast to the results from Musser ef al., who only identified one single clonal group among TSST-1-producing $S$, aureus isolates thall caused urogenital TSS [9]. Although the latter strains were typed by multillocus enzyme electrophoresis (MLEE) rather than PFGE, these data may indicate that while clonally unrelated tst- 
postive strains may be disseminated in the community, a specific disease, such as TSS, may only be caused by specific clonal groups of $S$. aurews.

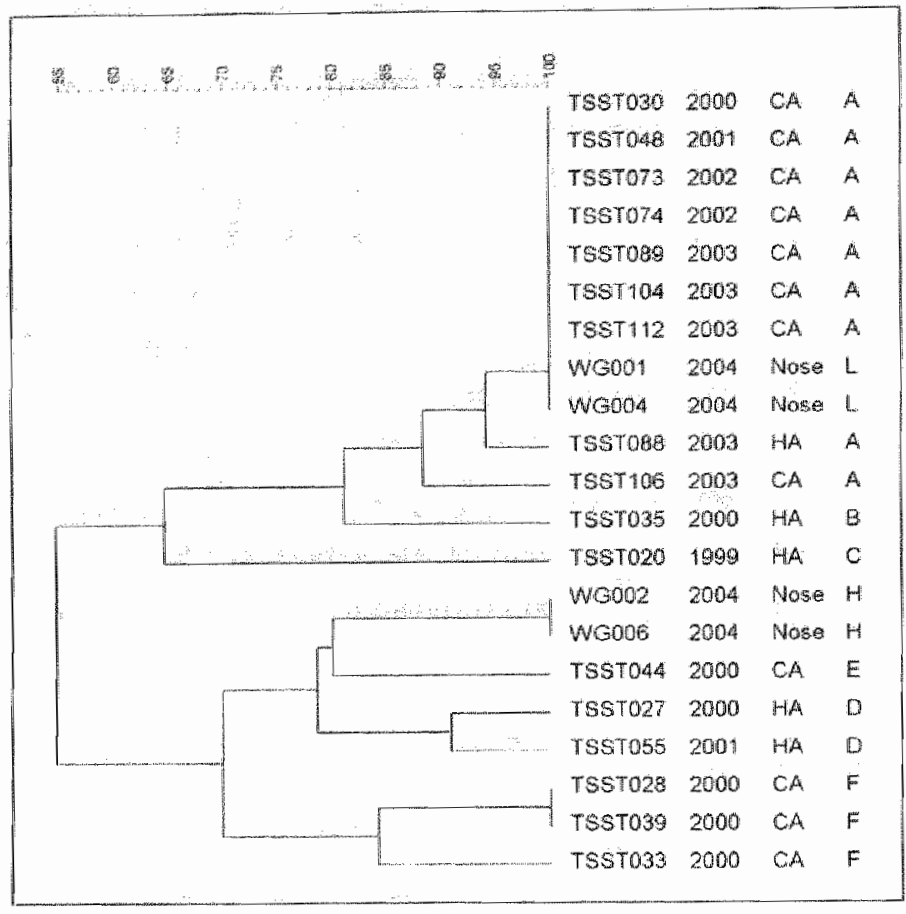

Figure 2. Dendrogram of $S$, aureus isolates (CA, HA and WG) carrying the tst gene. The four columns on the right represent isolate code, year of isolation, origin and clonal group; respectively. Community-acquired (CA); hospital-acquired (HA); Wegener's Granulomatosis (WG).

\section{CONCLusion}

A real-time PCR assay was developed for the detection of the $S$. aureus tst gene. This assay generated results in less than two hours and was, therefore, significantly faster than conventional PCR methods (9 10). The assay was very convenient, since it could be applied directly on diluted bacterial suspensions and previous DNA purification is not required. Furthermore, the assay was found to be highiy reproducible, specific as well as robust. The percentage of tst-positive strains among $S$ : aureus isolates from WG patients was similar to that among isolates from the community. The tst-positive $C A$ and $H A S$ aureus strains were grouped in one major (A) and five minor cilonal groups (B to F). Since most of the isolates from the major 
clonal group were isolated during the later years of the sample period, these isolates may have a more virulent phenotype than isolates which belong to other clonal groups. Furthermore, no relation was found between ctonal groups of tst-positive and tstnegative $S$. aureus strains isolated from WG patients. Since wrulent $S$ aurous strains pose an increasing problem worldwide, both in the hospital and in the community, the availability of a rapid, real-time PCR assay for the identification of tst-harbouring $S$. aureus strains may contribute to the control of the spread of virulent clones of $S$. aureus.

\section{ACKNOWLEDGEMENTS}

J. Etienne, M. Bes (INSERM, Lyon, France) and W. Manson (University of Groningen. The Netherlands) are thanked for the collection and characterization of TSST-1-negative and TSST-1-positive S. aureus strains.

\section{REFERENCES}

1. Banks, M.C., N.S. Kamel, J.B. Zabriskie, D.H. Larone, D. Ursea, arid D.N. Posnett. 2003. Staphylococcus aureus express unique superantigens depending on the tissue source. J. Infect. Dis. 187:77-86.

2. Barry, W., L. Hudgins, S.T. Donta, and E.L. Pesanti. 1992. Intravenous immunoglobulin therapy for toxic shock syndrome. JAMA. 267:3315-3316.

3. Berger-Bachi, B., L. Barberis-Maino, A. Strassle, and F.H. Kayserr. 1989. FonA, a host-mediated factor essential for methicillin resistance in Staphylococcus aureus: molecular cloning and characterization. Mol. Gen. Genet. 219:263-269.

4. Blomster-Hautamaa, D.A. B.N. Kreiswirth, J.S. Komblum, R.P. Nowick, and P.M. Schlievert. 1986. The nucleotide and partial amino acid sequence of toxic shock syndrome toxin-1. J. Biol. Chem. 261:15783-15786.

5. Deurenberg, R.H., C. Vink, C. Driessen, M. Bes, N. London, J. Etienne, and E.E. Stobberingh. 2004. Rapid detection of Panton-Valentine leukocidin from clinical isolates of Staphylococcus aureus strains by real-time PCR. FEMS Microbiol. Lett. 240:225-228.

6. Dinges, M.M., P.M. Orwin, and P.M. Schllevert. 2000. Exotoxins of Staphylococcus aurous. Clin. Microbiol Rev. 13:16-34.

7. Fraser, J., V. Arcus, P. Kong, E. Baker, and T. Proft. 2002. Superantigens - powerful modifiers of the immune system. Mol. Med. Today. 6:125-132.

8. Hanssen, A.M., G. Kjeldsen, and J.U. Ericson Sollid. 2004. Local varianits of staphylococcal cassette chromasome mec in sporadic methicillin-resistant Staphylococcus aureus and methicillin-resistant coagulase-negative staphylococci: evidence of horizontal gene transfer? Antimicrob. Agents Chemother, 48:285-296. 
9. Jarraud, 5 , C. Motgel, J. Thioulouse, G. Lina, H. Meugnier, F. Forey, X. Nesme, J. Etienne, and F. Vandenesch. 2002. Relationships between Staphylococcus aureus genetic background, virulence factors, agr groups (alleles), and human disease. Infect. Immun. 70:631-641

10. Johnson, W.M., S.D. Tyler, E.P. Ewan, F.E. Ashton, D. Pollard, and K.R. Rozee. 1991. Detection of genes for enterotoxins, exioliative toxins "and toxic shock syndrome toxin 1 in Staphylococcus aureus by the polymerase chain reaction. J. Clin. Microbiol 29:426-430

11. Llewelyn, $\mathbf{M}_{s}$, and $J$. Cohen. 2002. Superantigens: microbial agents that corrupt immunity. Lancet Infect. Dis. 2:156-162.

12. Lowy, F.D. 1998 Staphylococcus aureus infections. N. Engl. J. Med. 339:520-532.

13. Marrack, $\mathbf{P}_{\text {.; }}$ and J. Kappler. 9990. The staphylococcal enterotoxins and their relatives. Science. 248:705-711.

14. Miller, S.A., D.D. Dykes, and H.F. Polesky. 1988. A simple salting out procedure for extracting DNA from human nucleated cells. Nucleic Acids Res. 16:1215.

15. Musser, J.M., P.M. Schlievert, A.W. Chow, P. Ewan, B.N. Kreiswirth, V.T. Rosdaht, A.S. Naidu, W. Witte, and R.K. Selander. 1990. A single clone of Staphylococcus awreus causes the majority of cases of toxic shock syndrome. Proc. Natl. Acad. Sci. USA 87:225229.

16. Petersson, K, G. Forsberg, and B. Walse. 2004. Interplay between superantigens and immunoreceptors. Scand. J. Immunol, 59:345-355.

17. Popa, E.R., and J.W. Tervaert. 2003. The relation between Staphylococcus aureus and Wegener's granullomatosis: current: knowledge and future directions. Intern. Med. 42:771780 .

18. Tenover, F.C., R.D. Arbeit, R.V. Goering, P.A. Mickelsen, B.E. Murray, D.H. Persing, and B. Swaminathan. 1995. Interpreting chromosomal DNA restriction patterns produced by pulsed-field gel electrophoresis: criteria for bacterial strain typing. J. Clin. Microbiol. $33: 2233-2239$ 


\section{CHAPTER 6}

\section{Molecular characterisation of methicillin-resistant Staphylococcus aureus bloodstream isolates from Croatia}

Ana Budimir, Ruud H. Deurenberg, Vanda Plecko, Cornelis Vink, Smilja Kalenic and Ellen $\mathrm{E}$. Stobberingh

Journal of Antimicrobial Chemotherapy. 2005. Submitted 


\section{ABSTRACT}

A total of 82 hospitall-acquired methicillin-resistant Staphylococcus aureus (HA-MRSA) bloodstream isolates, collected in 2001 and 2002 in Croatia, were characterised by Pulsed-Field Gel Electrophoresis (PFGE), SCCmec typing and Multilocus Sequence Typing (MLST). Furthermore, the presence of the Panton-Valentine leukocidin (PVL) and toxic shock toxin (tst) genes was investigated by real-time PCR. All strains were multiresistant and were distributed among 19 different clonal groups (A to S) as determined by PFGE. Two of the groups, group $H$ and $K_{s}$ harboured the majority of the MRSA strains with $52 \%$ and $12 \%$, respectively. The predominant SCCmec type that was found among the isolates was type $1(\mathbf{8 9} \%)$. Eleven percent of the strains harboured a modified SCCmec type III, which, in contrast to the regular type III, contained an additional locus D (dcs region). One strain harboured a novel sccmec typa, a type $V$ like, due to the presence of the ccrC gene and locus $E_{3}$ in combination with three additional loci $\mid C_{n}, D$ and F). MLST showed the presence of ST111-MRSA-I and ST247-MRSA-I among Croatian MRSA isolates. All isolates were negative for both PVL and TSST-1.

\section{INTRODUCTION}

Staphylococcus aureus is recognized as a significant pathogen in posloperative wound infections, pneumonia and urinary tract infections. S. aureus has a remarkable ability to rapidly adlapt to antibiotic pressure which "over the years, has narrowed the choice of antimicrobial drugs effective against $S$. aureus. Soon after the introduction of methicillin for the treatment of staphylococcal infections, the first methicillin-resistant $S$. aureus (MRSA) strain was isolated in 1961 in the United Kingdom. Since then, a number of MRSA clones have arisen and spread worldwide. MRSA, which was initially a typical nosocomilal pathogen, has recently started to appear in the community. It appears that novel strains of MRSA in the community are genetically distinct from MRSA strains originating in the hospital. In some community seltings, communityacquired MRSA (CA-MRSA) has become the prevalent form of $S$ aureus isolated from cutaneous infections, especially among children. In some hospitals, CA-MRSA is replacing the classic, hospital-acquired MRSA (HA-MRSA) $(2,9,13,17,21)$.

The resistance of staphylococci to methicillin and all other $\beta$-lactam antibiotics is associated with the expression of penicillin-binding protein 2a (PBP2a), which is not present in susceptible staphylococci. This protein is encoded by the mecA gene, which is situated on a mobile genetic element, Staphylococcal Cassette Chromosome mec (SCCmec). SCCmec is a genomic island that is inserted at the $3^{\prime}$ end of onf and is located near the replication origin of S. aureus. Five different SCCmec types have so 
far been found in MRSA strains. SCCmec types I, II and III are found in strains isolated from in-patients, from people with a history of prior hospitalisation , or health care workers (HA-MRSA), while SCCmec types IV and $V$ are mainly associated with CAMRSA. SCCmec contains the mec complex (mecA and its regulators) and the cor gene complex, which encodes site-specific recombinases, responsible for the mobility of SCCmec. Several different cor genes have currently been identified: ccrA1 and CcrB1 In SCCmec type 1, ccrA2 and ccrB2 in SCCmec type $\| 1$ and $N_{1}$ ccrA3 and ccrB3 in SCCmec type III, and corC in SCCmec type $V(12,13,14,21)$.

S. aureus can possess a number of virulence factors. Panton-Valentin leukocidin (PVL) is a potential virulence factor and is predominantly associated with furunculosis, cutaneous abscesses and severe necrotic skin infections (15). PVL, together with SCCmec type IV, could be a marker for CA-MRSA (27), although PVL was not found in Australian CA-MRSA strains harbouring SCCmec type IV (20). TSST1 is a $29.1-\mathrm{kDa}$ superantigen (SAg) that is encoded by the $S$. aureus tst gene. The release of TSST-1 into the bloodstream may give rise to a variety of severe clinical conditions, such as toxic shock syndrome (TSS), sudden infant death syndrome (SIDS), and Kawasaki syndrome. TSST-1 is one of the most potent of the SAgs and has probably been responsible for an innumerable number of human deaths in the past. TSST-1 is produced by many MRSA strains, particularly in Japanese hospitals $(1016)$

Croatia has a MRSA prevalence of $36.7 \%$ among bloodstream isolates (26). Information on the clonal distribution of MRSA in Croatia, however, is not available. Furthermore, nothing is currently known about the prevalence of PVL and TSST-1 among Croatian MSRA isolates. Therefore, the aim of this study was to determine the clonal distribution of MRSA among bloodstream isolates in Croatia isolated in 2001 and 2002 using Pulsed-Field Gel Electrophoresis (PFGE), SCCmec typing and Muttilocus Sequence Typing (MLST), and to determine the presence of the potential virulence factors PVL and TSST-1.

\section{MATERIALs AND METHODS}

\section{Chinical isolates}

A total of 82 MRSA bloodstream isolates were collected from 11 hospitals in 8 Croatian cities during 2001 and 2002 as part of the European Antimicrobial Resistance Surveillance System (EARSS) project. All strains were hospital-acquired, i.e. isolated $\geq 72$ hours after patient admission to the hospital. Reference strains $S$. aureus 
ATCC 25923 for PFGE, MRSA COL (SCCmec 1), BK2464 (SCCmeG II). ANS46 (SCCmec III), HDE288 (SCCmec IV) and WIS (SCCmec V) for SCCmec typing were used. MRSA Cluster 28 was used as a reference strain for PVL and $S$. aureus HT.2004.0349 as the reference strain for TSST-1. All strains were identified as $S$ aureus by catalase, coagulase and DNAse production.

\section{Susceptibility testing}

The MIC of oxacillin was determined by the broth micro-dilution method, according to the guidelines of the National Committee for Clinical Laboratory Standards (NCCLS) (19). Susceptibility testing of the other agents was performed by the disc diffusion on Mueller-Hinton agar plates, according to the NCCLS guidelines (19). The following antimicrobial drugs were tested: penicillin, clindamycin, erythromycin, azithromycin, gentamicin, vancomycin, rifampicin, ciprofloxacin, norfloxacin, trimethoprim, tetracycline, linezolid, chloramphenicol, trimethoprim-sulfamatoxazole and nitrofurantoin (Becton Dickinson, France).

\section{SCCmec typing}

SCCmec typing was essentially carried out as described by Oliveira et al (22) in which mecA and six different loci on SCCmec were amplified by PCR with the following modifications. PCR amplification of mecA sequences was carried out with primers mecA1 and mecA2 (Sigma Genosys, The Netherlands), resulting in a PCR product of 527 bp instead of 162 bp (24). PCR was performed in a volume of $50 \mu$ l containing 10 $\mu$ i of a 0.5 McFarland suspension $\left(1.5 \times 10^{3} \mathrm{CFU} / \mathrm{ml}\right)$ of the MRSA strain, $0.2 \mathrm{mM}$ of each dNTP (Amersham Biosciences, The Netherlands), $1 \times$ PCR reaction buffer (Qiagen, The Netherlands), 1.25 U HotStarTaq (Qiegen, The Netherlands) and primers. The primer concentrations used were similar as previously described (22), except for those of the mecA primers, which were $0.6 \mu \mathrm{M}$ for both mecA 1 and mecA2. The amplifications were performed on a GeneAmp PCR System Model 9600 (Applied Biosystems, The Netherlands) with the following programme: $15 \mathrm{~min}$ at $94^{\circ} \mathrm{C}$, followed by 30 cycles of 30 sec at $94^{\circ} \mathrm{C}, 30$ sec at $53^{\circ} \mathrm{C}$ and $60 \mathrm{sec}$ at $72^{\circ} \mathrm{C}$, followed by a postextension step of $10 \mathrm{~min}$ at $72^{\circ} \mathrm{C}$. The PCR products were separated on $2 \%$ agarose gels in Tris-Acetate-EDTA (TAE) buffer, stained with ethidium bromide and visulalized with UV light using a FluorChem ${ }^{\text {TM }}$ Imaging System (Alpha Innotech Corporation. The Netherlands). 
PCF for corABs and cenc

Most of the primers used for amplification of ccrAB3 and ccr were as described previously $(11,14)$. Primer $\beta 2$, however, was replaced by a primer with the following sequence: 5-ATTGCCTTGATAATAGCCTCT 3 (primer $\beta 2 a$ ). The following reaction conditions were used: either $1.2 \mu \mathrm{M}$ of forward primer $\beta 2 \mathrm{a}$ or $0.4 \mu \mathrm{M}$ of fonward primer yF respectively, $0.4 \mu \mathrm{M}$ of either reverse primer $a 4$, or $y R, 0.2 \mathrm{mM}$ of each dNTP, $1 \times$ PCR reaction buffer, $2.5 \mathrm{U}$ of HotStarTaq DNA Polymerase and $10 \mu$ ll of a 0.5 to 1 McFariand suspension $\left(1.5\right.$ to $\left.3 \times 10^{8} \mathrm{CFU} / \mathrm{ml}\right)$ in a total wolume of $50 \mu \mathrm{l}$. Amplification was performed on the GeneAmp PCR System Model 9600 using the following programme: 15 min at $95^{\circ} \mathrm{C}$, followed by 35 cycles of 1 min at $95^{\circ} \mathrm{C}, 1 \mathrm{~min}$ at $55^{\circ} \mathrm{C}$ and $1 \mathrm{~min}$ at $72^{\circ} \mathrm{C}$, followed by an extension step of $10 \mathrm{~min}$ at $72^{\circ} \mathrm{C}$. PCR products were analyzed by electrophoresis through $1 \%$ agarose gels as described above.

PFGE analyses

PFGE was essentially performed as previously described (11). Whole bacterial DNA was prepared and digested in agarose plugs with Smal. Restriction fragments were resolved using CHEF DR II apparatus (Bio-Rad Labioratories, Hemel Hempstead. UK) with the following settings: voltage $6 \mathrm{~V} / \mathrm{cm}$, temperature $14 \%$, initial time $5 \mathrm{sec}$, final time $40 \mathrm{sec}$ and duration 20 hours. The relatedness of the strains was determined with GelCompar II 3.5 (Applied Maths, Belgium) according to the scheme of Tenover et al (25). Isolates with a similarity index of 0.80 or more were classified as a clonal graup $(3,23)$.

Muthlocus Sequence Typing (MLST)

Two representative strains from the major clonal groups as obtained through PFGE $(3,5,23)$ were used for MLST (8). The primers used for MLST were identical to those described previously (8). with the exception of primers glpF-Dn and gmk-Up, which were replaced by primers g/pF-Dna (5-TGGTAAAATCGCATGTGCAATTC-3') gmk-Upa (5-ATCGTTTTATCAGGACCATC-3'), respectively. The PCR praducts were sequenced using an ALFexpress II automatic sequencer (Amersham Biosciences, The Netherlands). Finally, the sequence type (ST) was determined using the MLST database (http://www mist.net). 
Detection of PVL and TSST-1

The presence of PVL and TSST-1 was investigated with real-time PCR as described previously $(6,7)$.

\section{RESULTS}

Susceptibility patterns

The 82 MRSA isolates had MIC values for oxacillin of $\geq 128 \mu \mathrm{g} / \mathrm{mi}$. All strains were resistant to gentamicin and ciprofloxacin and were susceptible to vancomycin. linezolid and nitrofurantoin. Most of the strains $(96 \%)$ were resistant to clindamycin, erythromycin and azithromycin. In addition, $36 \%$ percent of the strains were resistant to rifampicin, $32 \%$ was resistant to tetracycline, $9 \%$ was resistant to chloramphenicol and $0.2 \%$ was resistant to trimethoprim-sulfamatoxazole.

\section{SCCmec typing}

A total of 73 of the $82(89 \%)$ MRSA strains were found to contain SCCmec type 1. From $9(11 \%)$ strains, the SCCmec type was not typeable with the method of Oliveira et al. (22). The SCCmec of each of these strains was found to harbour mecA and loci $C, D, E$ and $F$. Therefore, these cassettes only differ from SCCmec type III in the presence of locus $D$. To investigate the nature of these cassettes in more detail, the $\mathrm{ccr}$ genes of these strains were characterised. In 8 of the 9 MRSA strains, the ccr gene was identified as corAB3. Consequently, these strains were classified as harbouring SCCmec type III. The other non-typeable MRSA strain (79) harboured ccrC, which is normally only carried on SCCmec type $\mathrm{V}$.

\section{PFGE analyses}

PFGE analyses were performed on the MRSA strains and a dendrogram was constructed (Figure 1). Three of the 82 MRSA isolates could not be typed, either due to difficulties with the lyses of the bacteria or the subsequent digestion of the DNA. A total of 19 clonal groups ( $A$ to $S$ ) were found and wo of these groups. $H$ and $K$, were classified as major clonal groups. Clonal group $H$ harboured 43 of the $82(52 \%)$ MRSA 


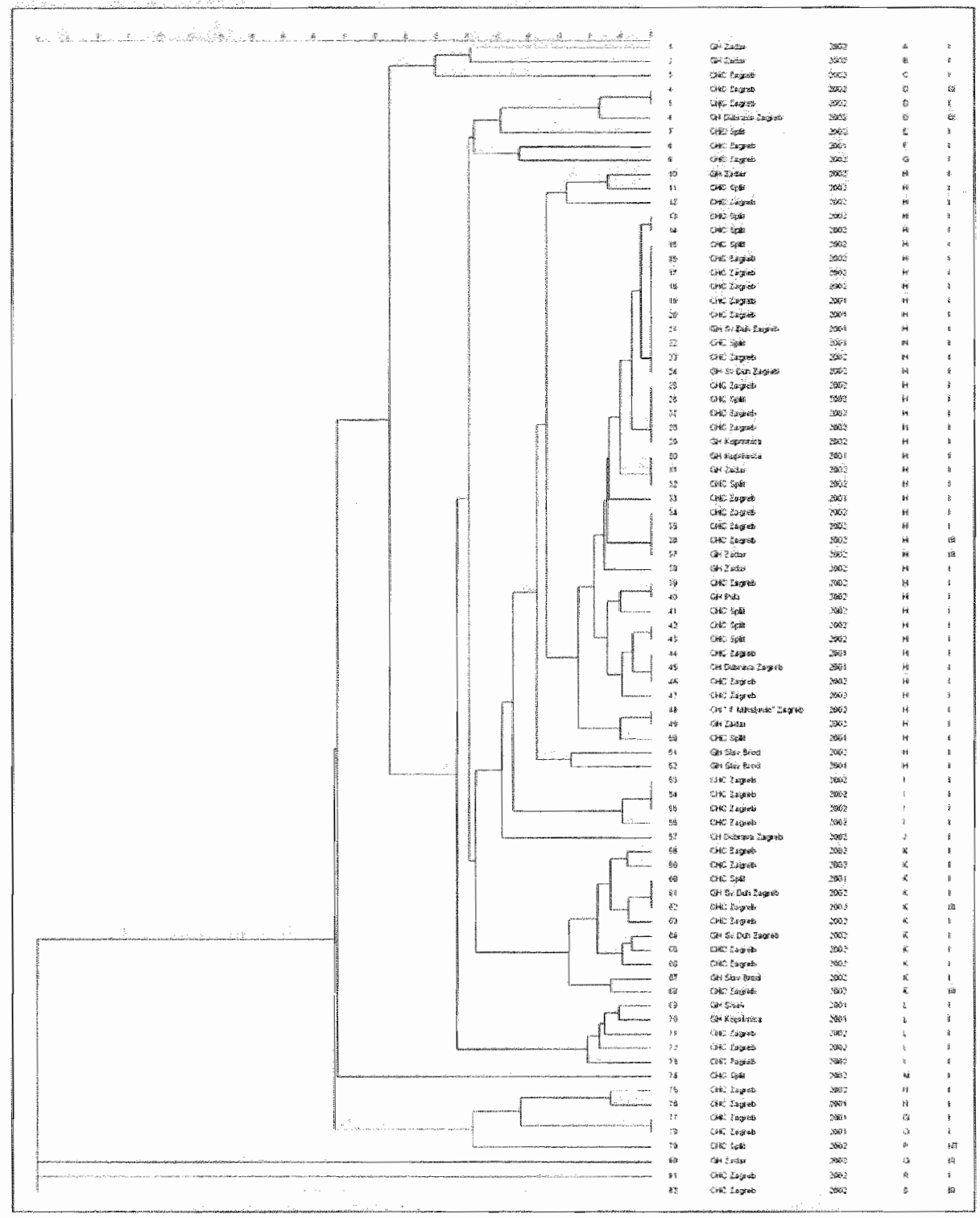

Figure 1. Dendrogram of the 82 MRSA isolates. The five columns on the right represent MRSA isolate code, center, year of isolation, clonal group and SCCmec type, respectively. NT. Not typeable. 
isolates, whereas clonal group K harboured 11 of the $82(13 \%)$ of the MRSA isolates: In both group $\mathrm{H}$ and group $\mathrm{K}$, SCCmec type / was predominant at $95 \%$ and $82 \%$, respectively: Furthermore, the MRSA strains from groups $H$ and $K$ had a different susceptibility pattern. The majority $(91 \%)$ of the strains from group $\mathrm{H}$ were resistant to rifampicin and tetracycline, while the majority of the strains from group $K$ were susceptible to these antibiotics (84\% and $91 \%$, respectively). Strains harbouring SCCmec type III were classified in various clonal groups, ie group D (2). $H(2), K(2)$, $Q(1)$ and $S$ (1). The results from the SCCmec typing and the PFGE analyses indicated that the distribution of particular MRSA genotypes is not restricted to specific hospitals or cities in Croatia.

\section{MLST analyses}

Two representative strains from the major clonal groups $H$ and $K$ were characterised by MLST. As shown in Table 1, both strains from group $\mathrm{H}$ were identified as ST111, a single locus variant (SLV) of ST228 at the pta locus, whereas both strains from group $K$ were classified as ST247.

Table 1. MLST typing results of major clonal group $\mathrm{H}$ and $\mathrm{K}$

\begin{tabular}{lllll}
\hline Code & Major clonal group & SCCmec type & MLST profile & ST $^{\text {a }}$ \\
\hline 13 & $H$ & 1 & $1-4-1-4-46-24-29$ & 111 \\
46 & $H$ & 1 & $1-4-1-4-46-24-29$ & 111 \\
63 & $K$ & 1 & $3-3-1-12-4-4-16$ & 247 \\
65 & $K$ & 1 & $3-3-1-12-4-4-16$ & 247
\end{tabular}

\footnotetext{
${ }^{a}$ Sequence type
}

PVL and TSST-1 analyses

All 82 MRSA strains were negative for both PVL and the tst gene.

\section{DIScussion}

In this study, the clonal distribution of MRSA isolates in Croatia was described. The collection of strains studied was uniform, since it contains only bloodstream 
isolates. Most of the isolates $(89 \%)$ were found to possess SCCmec type 1. Eight of the nine strains that did not contain SCCmec type I, carried a modified SCCmec type III. In contrast to a normal type lll cassette, the cassette of these strains harboured locus $D$, which is usually only found in SCCmec type I, II and IV (22). An MRSA strain with a similar SCCmeo element (HSA10) has previously also been described by Ares de Sousa and cowworkers (1).

The single remaining 'non-SCCmec type I" strain from this study (strain 79) was found to harbour corC, together with loci $\mathrm{C}$ (med, normally found in SCCmec II and III), D, E (alocus between pl258 and Tn554, which is specific for SCCmec type III) and F (a locus between Th554 and or $\mathrm{X}$, which is specific for SCCmec type 1HI) (22). Since ccrC is usually only found in combination with locus $E$ in SCCmec type $V$. MRSA strain 79 is likely to harbour a novel SCCmec element. Further investigation into the exact structure of this element is required. Evidence for transmission of methicillin resistance between different: $S$, aureus strains during therapy suggests that SCCmec may be transferable in vivo between different strains (28). An encounter of two S, aureus strains harbouring different SCCmec cassettes could have led to formation of a novel, not previously described, SCCmec type, probably through homologues recombination (12).

Typing of the MRSA strains by PFGE revealed 19 clonal groups (A to $S$ ), two of

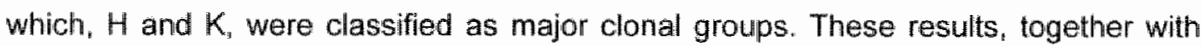
the SCCmec typing, indicated that the distribution of particular MRSA genotypes was not restricted to specific hospitals or cities in Croatia. A total of $52 \%$ of the MRSA strains were classified within major clonal group $\mathrm{H}$ and $95 \%$ of these strains harboured SCCmec type I. Two representative strains from group $H$ were typed by MLST, and were both classified as ST111-MRSA-I, a SLV of ST228 at the pla locus. Previously, only two MRSA isolates were typed as ST111: (1) a strain with an unknown SCCmec type (AB-903627102) from Nowway (http:/Www mlst.net), and (ii) a strain harbouring SCCmec type Ifrom the Czech Republic (18). The notion that ST111.MRSA-1 is found in different European countries and not in other parts of the world might indicate that this type is disseminating in Europe.

The second major clonal group group $K$, contained $13 \%$ of the MRSA isolates; $82 \%$ of the strains from this group harboured $\mathrm{SCC}$ mec type I. Two representative clones from group $K$ were both classified by MLST as ST247-MRSA-I, which is idlentical to the sequence type of the Iberian clone. This is one of the major MRSA clones currently isolated in European countries, such as the Czech Republic, Germany. ltally, Poland, Slovenia and Switzerland. ST247 is classified in clonal complex (CC) 8 $(2,9)$. 
The S aureus tsi gene and PVL were not detected in any of the isolates investigated. Similarly, a previous study reported anly a single PVL-positive isolate among 86 bloodstream isolates (4). These resutts supported the observation that $P V L$ is especially found among strains carrying SCCmec type IV causing severe skin infections (27). Furthermore, the absence of these genes suggested that they are not related to bloodstream infections in Croatia.

\section{ACKNOWLEDGMENTS}

We thank Prof. H. De Lencastre and Dr. D.C. Oliweira from The Rockefeller University, New York, USA for providing the reference strains for SCCmectyping. Dr. T. Uto from the Juntendo University, Tokyo, Japan, for providing the reference strain (WIS) for SCCmec V and Dr. W. Wannet from the National Institute of Public Health and Environment (RIVM) in Bilthoven, The Netherlands for MRSA Cluster 28 strain and Dr. J Etienne and Dr. M. Bes from INSERM, Lyon, France are thanked for reference strain HT.2004.0349. Christel Driessen is thanked for excellent performing the MLST analyses.

\section{REFERENCES}

1. Aires de Sousa, M., and $H_{\text {. }}$ de Lencastre. 2003. Evolution of sporadic isolates of methicillin-resistant Staphylococous aureus (MRSA) in hospitals and their similarities to isolates of community-acquired MRSA. J. Cilin. Microbiol 41:3806-3815.

2. Aires de Sousa, M., and $H$. de Lencastre. 2004. Bridges from hospitals to the laboratory: genetic portraits of methicillin-resistant Staphylococcus aureus clones. FEMS Immunol. Med. Microbiol. 40:101-111.

3. Coombs, G.W., G.R. Nimmo, J.M. Bell, F. Huygens, F. G. O'Brien, M.J. Malkowski, J.C. Pearson, A.J. Stephens, P.M. Giffard, and Australian Group for Antimicrobial Resistance. 2004. Genetic diversity among community methicillin-resistant Staphylococcus aureus strains causing outpatient infections in Australia. d. Clin. Microbiol. 42:4735-4743.

4. Couppie, P., B. Cribier, P. Prevost, E. Grosshans, and Y. Piemont, 1994. Leucocidin from Staphylococcus aureus and cutaneous infections: an epidemiologic study. Arch. Dermatol. 130:1208-1209.

5. Denis, O., A. Deplana, C. Nonhoff, R. De Rycik, R. de Mendonca, S. Rottiers, R. Vanhoof, and M.J. Struelens. 2004. National survellance of methicillin-resistant Staphylococcus aureus in Belgian hospitals indlicates rapid diversification of epidamic clones. Antimicrob. Agents Chemother, 48:3625-3629. 
6. Deurenberg, R.H., C. Vink, C. Driessen, M. Bes, N. London, J. Etienne, and E.E. Stobberingh. 2004. Rapid detection of Panton-Valentine leukocidin from clinical isolates of Staphylococcus aureus strains by real-time PCR, FEMS Microbiol. Lett. 240:225-228

7. Deurenberg, R.H., R.F. Nieuwenhuis, C. Driessen, N. London, F.R. Stassen, F.H. van Tiel, E.E. Stobberingh, and C. Vink. 2005. The prevalence of the Staphylococcus aureus ist gene among community- and hospital-acquired strains and isolates from Wegener's Granulomatosis patients. FEMS Microbiol. Lett. 245:185-189

8. Enright, M.C., N.P. Day, C.E. Davies, S.J. Peacock, and B.G. Spratt. 2000. Multilocus sequence typing for characterization of methicillin-resistant and methicillin-susceptible clomes of Staphylococcus aureus. J. Clin. Microbiol. 38:1008-1015.

9. Enright, M.C., D.A. Robinson, G. Randle, E.J. Feil, H. Grundmann, and B.G. Spratt. 2002. The evolutionary history of methicillin resistant Staphylococcus aureus (MRSA). Proc. Nati. Acad Sci. USA 99:7687-7692.

10. Furukawa, Y., Y. Segawa, K. Masuda, M. Takahashi, A. Ootsuka, K. Hirai, N. Takahashi, T. Aoki, F. Nagao, and J. Shimada. 1986. Clinical experience of 3 cases of toxic shocik syndrome caused by methicillin cephem-resistant Staphylococcus aureus (MRSA). Kansenshogaku Zasshi. 60:1147-1153.

11. Hanssen, A.M. G. Kjeldsen, and J.U. Ericson Sollid. 2004. Local variants of staphylococcal cassette chromosome mec in sporadic methicillin-resistant Staphylococcus aureus and methicillinwresistant coagulase-negative staphylococci: evidence of horizontal gene transfer? Antimicrob. Agents Chemother. 48:285-296.

12. Ito, T., Y. Katayama, K. Asada, N. Mori, K. Tsutsumimoto, C. Tiensasitorn, and K. Hiramatsu. 2001. Structural comparison of three types of staphylacoccal cassette chromosome mec integrated in the chromosome in methicillin-resistant Staphylococcus aureus. Antimicrob. Agents Chemother. 45:1323-1336.

13. Ito, T., K. Okuma, X.X. Ma, $H_{n}$ Yuzawa, and K. Hiramatsu. 2003, Insights on antibiotic resistance of Staphylococcus aureus from its whole genome: genomic island SCC. Drug Resist. Updat $6: 41-52$.

14. Ito, T., X. Ma, F. Takeuchi, K. Okuma, H. Yuzawa, and K. Hiramatsu. 2004. Novel type $V$ staphylococcal cassette chromosome mec driven by a novel cassette chromosome recombinase, ccrC. Antimicrob. Agents Chemother. 48:2637-2651.

15. Lina, G., Y. Piemont, F. Godail-Gamot, M. Bes, M.O. Peter, V. Gauduchon, F. Vandenesch, and J. Etienne. 1998. Involvement of Panton-Valentine leukocidinproducing Staphylococcus aureus in primary skin infections and pneumonia. Clin. Infect. Dis. $29: 1128-1132$.

16. Lltowelyn, M., and J. Cohen. 2002. Superantigens: microbial agents that corrupt immunity. Lancet Infect. Dis. 2:156-162.

17. Lowy, F.D. 1998. Staphy/ococcus aureus infections. N. Engl. J. Med. 339:520-532. 
18. Meller, O., M. Aires de Sousa, P. Urbaskova, V. Jakubu, H. Zemlickova, and H. de Lencastre. 2003. Update on the major elonal types of methicillin-resistant staphylococcus aureus in the Czech Republic. J. Clin. Microbiol. 41:4998-5005.

19. National Commitee for Clinical Laboratory Standards. 1999. Peiformance standards for antimicrobial susceptibility testing; ninth informational supplement M100-59, Wayne. $\mathrm{Pa}$.

20. O'Brien, F.G., T.T. Lim, F.N. Chong, G.W. Coombs, M.C. Enright, D.A. Robinson, A. Monk, B. Said-Salim, B.N. Kreiswirth, and W.B. Grubb. 2004. Diversity among community isolates of methicillin-resistant Staphylocioccus aureus in Australia. J. Clin. Microbiol. 42:3185-3190.

21. Okuma, K., K. Iwakawa, J.D. Turnidge, W.B. Grubb, J.M. Bell, F.G. O'Brien, G.W. Coombs, J.W. Pearman, F.C. Tenover, M. Kapi, C. Tiensasitorn, T. Ito, and K. Hiramatsu. 2002 Dissemination of new methicillin-resistant Staphylococcus aureus clones in the community, Clin. Microbiol 40:4289-4294.

22. Oliveira, D.C., and H. de Lencastre. 2002. Multiplex PCR strategy for rapid identification of structural types and variants of the mec element in methicillin-resistant Staphylococcus aureus. Antimicrab. Agents Chemother. 46:2155-2161.

23. Perez-Roth, E, F. Lorenzo-Diaz, N. Batista, A. Moreno, and S. Mendez-Alvarez. 2004. Tracking methicillin-resistant Staphylococcus aureus clones during a 54year period (1998 to 2002) in a Spanish thospital. J. Clin. Microbiol. 42 4649-4656.

24. Predari, S.C., M. Ligozzi, and R. Fontana. 1991. Gemotypic identification of methicillinm resistant coagulase-negative staphylococci by polymerase chain reaction. Antimicrob. Agents Chemother. 35:2568-2573.

25. Tenover, F.C., R.D. Arbeit, R.V. Goering, P.A. Mickelsen, B.E. Murray, D.H. Persing, and $B$. Swaminathan. 1995. Interpreting chromosomal DNA restriction patterns produced by pulsed-field gel electrophoresis: criteria for bacterial strain typing. J. Clin. Microbiol. 33:2233-2239

26. Tiemersma, E.W. S.L.A.M. Bronzwaer, O. Lyytikäinen, J.E. Degener, P. Schrijnemakers, N. Bruinsma, J. Monen, W. Witte, H. Grundmann, and European Antimicrobial Resistance Surveillance System Participants. 2004. Methicillih-resistant Staphylococcus aureus in Europe, 1999-2002. Emerg. Infect. Dis, 10:1637-1634.

27. Vandenesch, F, T. Naimi, M.C. Enright, G. Lina, G.R. Nimmo, H. Hefferman, N. Lilassine, M. Bes, T. Greenland, M.E. Reverdy, and J. Etienne. 2003. Communityacquired methicillin-resistant Staphylococcus aureus carrying Panton-Valentine leukocidin genes: worldwide emergence. Emerg. Infect. Dis. 9:978-984.

28. Wielders, C.L., M.R. Vriens, S. Brisse, L.A. de Graaf-Miltenburg, A. Troelstra, A. Fleer, F.J. Schmitz, J. Verhoef, and A.C. Fluit. 2001. Evidence for in-wivo transfer of mecA DNA between strains of Staphylococcus aureus. Lancet. 357:1674-1675. 


\section{CHAPTER 7}

Ciprofloxacin resistance is not a marker for methicillin-resistant Staphylococcus aureus in The Netherlands

Ruud H. Deurenberg, Cornelis Vink, Mieke A.A. Hoogkamp-Korstanje and Ellen E. Stobberingh

Journal of Clinical Microbiology. 2005. Submitted 


\section{ABstract}

The objective of this study was to investigate the relationship between ciprofloxacin resistance and methicillin resistance in $S$. aureus in The Netherlands. Of the $891 s$ aureus strains isolated from 14 Dutch hospitals between 1995 and 2005,133 isolates were found to be ciprofloxacin resistant. As only eight of these 133 isolates $(6 \%)$ were classified as methicillin-resistant $S$. aureus (MRSA) strains, ciprofioxacin resistance of $\mathbf{S}$. aureus is not a valuable predictive marker for methicillin resistance in the Netherlands. The MRSA strains harboured various SCCmec types and were classified into different clonal groups, indicating the presence of different MRSA clones.

\section{INTRODUCTION}

Staphylococcus aureus can cause various diseases. Since the introduction of methicillin in 1959 "methicillin-resistant S. aureus (MRSA) strains have been isolated in the United Kingdom in 1961 and thereafter in other parts of the world. This illustrated that $S$. aureus possesses a strong adaptive power to antibiotics (5). Resislance to methicillin is mediated through the mecA gene, which is situated on a mobile genetic element designated Staphylococcal Cassette Chromosome mec (SCCmec). To date, five different SCCmec types ( 1 to $V$ ) have been distinguished. Each SCCmec type contains genes that encode for resistance to $\beta$-lactam antibiotics, regulatory genes and the cassette chromosome recombinase (ccr) genes, which are required for chromosomal integration and excision of the cassettes. The cassettes of type II and III carry, in addition to $\beta$-lactarn antibiotics resistance genes, non- $\beta$-lactam antibiotics resistance genes on integrated plasmids and transposons $(5,6)$.

It has previously been shown that less than $5 \%$ of the methicillin-susceptible $S$ aureus (MSSA) strains and over 95\% of the MRSA strains are resistant to ciprofloxacin $(2,4,12)$. In addition, it was reported that exposure to ciprofloxacin is a significant risk factor for the isolation of MRSA, but not for the isolation of MSSA $(2,4,12)$. In $S$. aureus, ciprofloxacin resistance can be caused by either of three mechanisms: (i) mutations in the DNA topoisomerase IV genes ( $g r / \mathrm{A}$ and $g r \mathrm{~B}$ ), (ii) mutations in the DNA gyrase genes (gyrA and gyrB), and (iii) the presence of the NorA efflux pump (10). A limited number of drugs are currently available for the treatment of MRSA colonisation and infections. Mupirocin is commonly used as the drug of first choice for the eradication of MRSA colonisation. Nevertheless, both low- and high-level resistance against mupirocin have emerged among MRSA strains, caused respectively by a mutation in the chromosamal mup gene and the plasmid-borne iles-2 gene (1). 
The objective of this study was to investigate the predictive value of ciprofloxacin resistance of $S$. aureus for the isolation of MRSA in The Netherlands. Furthemore, since mupirocin is commonly used as the drug of first choice for the eradication of MRSA, the prevalence of high-level mupirocin resistance in $S$. aureus strains in The Netherlands was investigated.

\section{MATERIIALS AND METHODS}

\section{Clinical isolates and reference strains}

Between 1995 and 2005 , a total of $891 \mathrm{~S}$. aureus strains were isolated in 14 university and general hospitals in The Netherlands by the Susceptibility Surveillance Study Group. Of these strains, 133 were found to be resistant to ciprofloxacin. These, as well as 117 randomly selected ciprofloxacin-susceptible S. aureus strains, were included in this study. MRSA strains COL, BK2464, ANS46 and HDE288 were used as reference strains for SCCmec type I, II, III and IV, respectively (8). All strains were cultivated on $5 \%$ sheep blood agar and identified by catalase and coagulase tests.

\section{Susceptibility determinations}

MIC values for oxacillin were determined with the E-test (AB Biodisk, Sweden). Suspensions of $0.5 \mathrm{McF}$ arland $\left(1.5 \times 10^{8}\right.$ colony forming units [CFU]/mil) were plated on Mueller-Hinton agar plates and incubated for 18 hours at $37^{\circ} \mathrm{C}$. A MIC of $\geq 4 \mu \mathrm{g} / \mathrm{ml}$ was defined as resistant. Ciprofloxacin susceptibility was determined according to NCCLS guidelines and a MIC of $\geq 2 \mu \mathrm{g} / \mathrm{m} /$ was defined as resistant ( 7 ).

Identification of MRSA strains and SCCmec typing

Strains were identified as MRSA by using a multiplex PCR for the $g p$ (the 165 rRNA of Gram-positive bacteria), nuc (a $S$. aureus specific gene), HeS-2 (high-level mupirocin resistance) and mecA genes as described previously (1,3). SCCmec typing was performed by investigation of the presence of the cor and mecl genes using PCR as described previously (3). 
Pulsed-Field Gel Electrophoresis (PFGE)

PFGE analyses were carried out by digestion of the $S$. aureus chromosomal DNA with Smal essentially as described previously (3). The banding patters were visualized with UV light using a FluorChem ${ }^{\mathrm{rM}}$ Imaging System (Alpha Innotech Corporation, The Netherlands). Subsequently, the patterns were analysed according to the scheme of Tenover et al (11).

\section{REsults}

Prevalence of MRSA

To identify MRSA strains among the 117 ciprofloxacin-susceptible and all 133 ciprofloxacin-resistant $S$. aureus strains, a mecA gene-specific PCR was used. MRSA strains were only found among the ciprofloxacin resistant isolates. The number of MRSA strains identified, however, was rather low (8 out of $133[6 \%]$ ). The majority of the ciprofloxacin resistant isollates $(94 \%)$ as well as all ciprofloxacin-susceptible strains tested were MSSA strains. All 8 MRSA strains were isolated from ICU patients in 1995 . 1996 and 1998.

\section{SCCmec typing}

To assess the genetic relationship between the different MRSA isolates, SCCmec typing was performed. Four strains harboured SCCmec type 1, one harboured SCCmec type II, and three strains harboured SCCmec type IV. Interestingly, the MRSA strains harbouring SCCmec type I had an MIC for oxacillin of $>256 \mu \mathrm{g} / \mathrm{m}$, while the MRSA strains harbouring SCCmec type II or IV had a rather low MIC for oxacillin ( 8 or $32 \mu \mathrm{g} / \mathrm{ml}$ ) (Table 1 ).

Clonal relationship of MRSA isolates

To further investigate the relationship between the MRSA isolates, these strains were also typed by PFGE. The different PFGE patterns indicated that the MRSA strains could be classified into four different clonal groups (A to D). Strong similarity was only observed between strains MRSA 8,9 and 10 , which were classified as clonal 


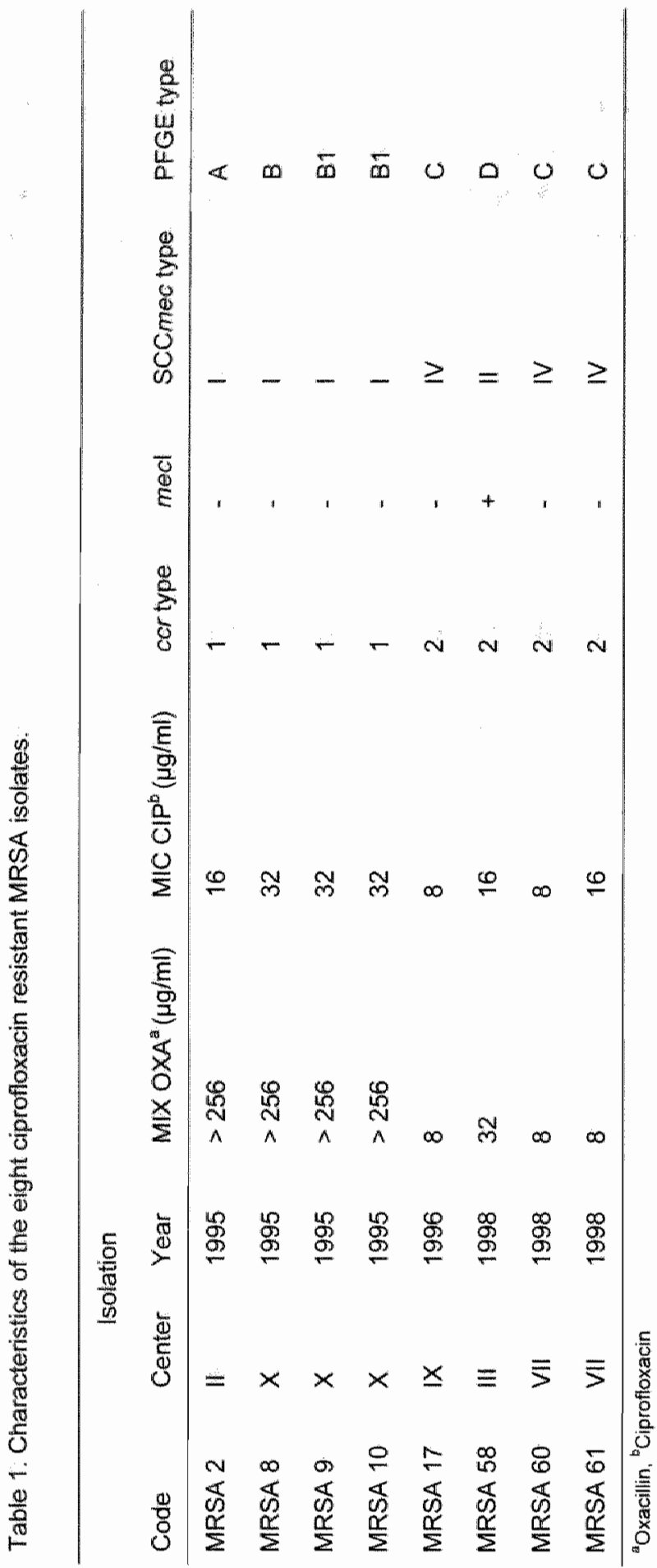


group B, and between strains MRSA 17,60 and 61, which were classiffed as clonal group $C$. The strains from clonal group $B$ were isolated in one hospital in 1995 and harboured SCCmec type 1, whereas the strains in clonal group D were isolated in two different hospitals in 1996 and 1998, respectively and harboured SCCmec type IV (Table 1).

\section{Prevalence of high-level mupirocin resistance}

The ileS-2 gene was found in only one ciprofloxacin-resistant MSSA strain, indicating that mupirocin can still be considered as the drug of choice for the eradication of MRSA in The Netherlands.

\section{DISCUSSION}

In this study, the prevalence of, and correlation between, methicillin and ciprofloxacin resistance among $891 \mathrm{~S}$. aureus isolates in The Netherlands was investigated. Only $15 \%$ of the S. aureus isolates in The Netherlands were classified as ciprofloxacin resistant strains. MRSA strains were found exclusively among the group of ciprofloxacin-resistant isolates, albeit that the percentage of mocA-positive strains in this group was only $6 \%$. These results imply that methicillin resistance may be considered as a predictive marker for ciprofloxacin resistance, whereas ciprofloxacin resistance is not a useful predictive marker for MRSA in The Netherlands. This is in contrast to the results of Schaefler, who investigated $2,833 \mathrm{~S}$. aureus strains from hospitals in New York and found that 149 strains (5.3\%) were ciprofloxacin resistant of which 140 were MRSA and 9 were MSSA (9). The relatively low percentage (0.9\%) of MRSA strains that was found among the total population of $891 \mathrm{~S}$. aureus isolates from The Netherlands was in accordance with a recent study by Tiemersma ef al, who reported an MRSA prevalence of $0.8 \%$ (12).

Among the MRSA isolates, two groups of genetically related strains were identified by PFGE. The three isolates that were classified within PFGE group $B$ were all isolated in the same year in a single hospital. The isolates from this group were also similar with regard to their SCCmec type (type 1), which corroborates the notion that these isolates are closely genetically related. The isolates from the other PFGE grroup (group C) were obtained from different hospitals in different years. The members from this group were also similar with respect to their SCCmec type (type IV), suggesting that these strains were CA-MRSA [1]. The other two MRSA isolates were classified 
within separate PFGE groups and these isolates were found to contain $8 \mathrm{CCmec}$ type I and If respectively. Interestingly, the average MIC values for both ciprofloxacin and oxacillin for MRSA strains harbouring SCCmec type I was higher than for MRSA strains harbouring SCCmec type IV. This indicates that a correlation may exist between the SCCmec type and the MIC values of oxacillin and ciprofloxacin. The notion that several clonal groups were found among the ciprofloxacin-resistant MRSA strains was in accordanice with an earlier study (2).

The mechanisms of resistance against fluoroquinolones on the one hand and methicillin on the other differ significantly. Fluoroquinolone resistance generally arises from spontaneous mutations in existing chromosomal genes (10), whereas methicillin resistance results from the acquisition of new genelic material, i.e. the SCCmec cassette (5). In light of this difference, the question arises as to why a large proportion of MRSA strains (100\% in this study) are ciprofloxacin resistant. A possible explanation is that the possession of a SCCmec cassette is accompanied by a higher mutation rate. Consequently, the mutations related to ciprofloxacin resistance could arise more efficiently. It is also possible thatt most MRSA strains are selected under conditions of multi-drug treatment, such that antibiotic pressure strongly favours the transmission of multimresistant $S$. aureus strains. Since point mutations can be acquired 'spontaneously', in contrast to the SCCmec cassette, it would be more obvious to find Imulti-drug resistance in strains that have previously acquired the mecA gene than in strains that do not contain this gene. Regardless of their exact nature, it is clear that both dissemination of antibiotic resistance and the relation between the different antibiotic resistance mechanisms will remain intriguing subjects of further study.

Finally, as no high-level resistance to mupirocin was found among the MRSA strains analysed, mupirocin can still be considered as the drug of choice for the eradication of MRSA in The Netherlands.

\section{ACKNOWLEDGEMENTS}

We are grateful to Prof. H. De Lencastre and Dr. D.C. Oliveira from The Rockefeller University "New York, USA for providing the reference strains for SCCmec typing. S. Nys (University Hospital Maastricht, The Netherlands) and the Susceptibility Surveillance Study Group for the collection of the $S$. aureus strains. The participating centres of the Susceptibility Surveillance Study Group include (geographically from north to south): Regional Laboratory for Public Health (G.A. Kampinga), Martini Hospital, Groningen (W. Vogels), Isala Clinic (P. Bloembergen), Regional Laboratory for Public Health, Enschede (M.G.R. Hendrix), Kennermer Gasthuis, Haarlem (E.P.F. ljzerman and A. Beunders), Onze Lieve Vrouwe Gasthuis. 
Amsterdam (P. Rietra), Bronovo Hospital. Den Haag (H. Bijlmer) Dlaconessenhuis Leiden (E.M. ter Meer-Veringla), Medical Centre Rijmmond-Zuid. Rotterdam (WD.H Handriks). University Medical Centre. Nijmegen (T. Schilin), St Antonius Hospital Niewwegein (A.d. Bartelds), St. Elisabeth Hospital. Tiburg (A.G.M. Buiting), St. Maartons Gasthuis. Venlo (W. Crombach), and Regional Laboratory for Public Health, Goes (L Sabbe),

\section{REFERENCES}

1. Anthony, R.M., A.M. Connor, E.G. Power, and G.L. French, 1999. Use of the polymerase chain reaction for rapid detection of high-level mupirocin resistance in staphylococci. Eur. J. Clin. Micrabiol. Infect. Dis. 18:30-34.

2. Blumberg, H.M., D. Rimland, D.J. Carroll, P. Terry, and I.K. Wachsmuth. 1991. Rapid development of ciprofloxacin resistance in methicillin-susceptible and resistant Staphylococcus aureus. J. Infect. Dis. 163:1279-1285.

3. Hanssen, A.M., G. Kjeldsen, and J.U. Ericson Sollid. 2004. Local variants of staphylococcal cassette chromosome mec in sporadic methilillin-resistant Staphylococcus aureus and methicillin-resistant coagulase-negative staphylococci: evidence of horizontal gene transfer? Antimicrob. Agents Chemother. 48:285-296.

4. Harbarth, S., N. Liassine, S. Dharan, P. Herrault, R. Auckenthaler, and D. Pittet. 2000 Risk factors for persistent carriage of methicillin-resistant Staphylococcus aureus. Clin. Infect. Dis. 31:1380-1385.

5. Ito, T., K. Okuma, X.X. Ma, H. Yuzawa, and K. Hiramatsu. 2003. Insights on antibiotic resistance of Staphylococcus aureus from its whole genome: genomic island SCC. Drug Resist. Updat. 6:41-52.

6. Ito, T., X. Ma, F. Takeuchi, K. Okuma, H. Yuzawa, and K. Hiramatsu. 2004. Novel type $V$ staphylococcal cassette chromosome mec driven by a novel cassette chromosome recombinase, ccrC. Antimicrob. Agents Chemother, 48:26372651.

7. National Committee for Clinicall Laboratory Standards. 1999. Performance standards for antimicrobial susceptibility testing: ninth informational supplement M100-\$9, Wayne, $\mathrm{Pa}$

8. Oliveira, D.C., and H. de Lencastre. 2002. Multiplex PCR strategly for rapid identification of structural types and variants of the mec element in methicillin-resistant Staphylococcus aureus. Antimicrob. Agents Chemother. 46:2155-2161.

9. Schaefler, S. 1989 . Methicillin-resistant strains of Staphylococcus aureus resistant to quinolones. J. Clin. Microbiol 27:335m336.

10. Schmitz, F.J., P.G. Higgins, S. Mayer, A.C. Fluit; and A. Dalhoff. 2002 Activity of quinolones against Gram-positive cocci: mechanisms of drug action and bacterial resistance. Eur. J. Clin. Microbiol. Infiect. Dis. 21:647-659.

11. Tenover, F.C., R.D. Arbeit, R.V. Goering, P.A. Mickelsen, B.E. Murray, D.H. Persing, and $B$. Swaminathan. 1995 . Interpreting chromosomal DNA restriction patterns produced 
by pulsed-field gel electrophoresis: criteria for bacterial strain fyping. J. Chin. Michobiol. $33: 2233-2239$

12. Tiemersma, EW. SLAM; Bronzwaer, O. Lyytikainen, JE. Degener, P. Schrijnemakers, N. Bruinsma, J. Monen, W. Witte, H. Grundmann, and European Antimicrobial Resistance Survellance System Participants, 2004. Methicillin-resistant Staphylococcus aureus in Europe, 1999-2002. Emerg. Infect. Dis. 10:1637-1634.

13. Weber, S.G., H.S. Gold, D.C. Hooper, A.W. Karchmer, and Y. Carmeli. 2003. Fluoroquinolones and the risk for methicillin-resistant Staphylacoccus aureus in hospltalized patients. Emerg. Infect. Dis. 9:1415-1422. 
CHAPTER 8

General discussion \& Summary

Algemene discussie \& Samenvatting 


\section{GENERAL DISCUSSION \& SUMMARY}

This thesis describes the molecular characterisation of Staphylococcus auneus isolates with respect to the resistance to methicillin and the detection of some virulence factors, lie. Panton-Valentine leukocidin (PVL) and toxic shock syndrome toxin-1 (TSST-1). In addition, the dissemination of methicillin-resistant $S$. aureus (MRSA) between several European countries and within one country was studied.

As community-acquired MRSA (CAMRSA) often harbour the genes encoding for PVL, a real-time PCR was developed and evaluated to identify PVL-harbouring $S$. aureus strains (Chapter 3 ). In addition; a real-time PCR method was developed and evaluated to detect the tst gene, encoding TSST-1, in S. aureus strains (Chapter 5). TSST-1 positive strains were found among Wegener's Granulomatosis (WG) patients, CA and hospital-acquired (HA) S. aureus isolates (24\%, $14 \%$ and $25 \%$, respectively). Investigation of the clonal relationship between tst-positive CA and HA sirains with Pulsed-Field Gel Electrophoresis (PFGE) might indicated the recent emergence of a virulent $S$. aureus clone in the community. Early detection of MRSA using ciprofloxacin resistance as a predictive marker was not useful on the collection of $S$. aureus strains tested (Chapter 7 ).

Using several typing techniques, such as PFGE, SCCmec typing and Multilocus Sequence Typing (MLST), as well as the real-time PCRs for PVL and TSST-1, MRSA isolates from different European countries, i.e. Belgium, Croatia, Germany and The Netherlands were investigated.

The Euregio Meuse-Rhine (EMR) is formed by the border regions of Belgium. Germany and The Netherlands (Chapter 4). PFGE analyses of MRSA isolates from the EMR ( $n=152)$ revealed four major clonal groups, $A, G, L$ and $Q$, suggesting dissemination of MRSA between and also within the countries forming the EMR Group A harboured mainly SCCmec type Ill and sequence types (STs) 239 and ST241. The majority of the strains from group $G$ harboured SCCmec type 1 and ST8 and ST247, whereas most strains from group $L$ carried either SCCmec type IV or I. Within group $L$, ST8 and ST228 were found, bellonging to clonal complexes (CC) 8 and 5 , respectively. Most strains from group $Q$ included SCCmoc type $1 /$ and were sequence typed as ST225. Both ST225-MRSA-II and ST241-MRSA-III were nowell findings in Germany. In addition, the SCCmec type of two isolates has not been described previously: one strain was classified as SCCmec type III, but harboured the pls gene and the dos region, while another strain was characterized as SCCmec type IV, but lacked the dcs region. Of the two isolates harbouring $P V L_{\text {, }}$ one harboured SCCmec type IV and the 


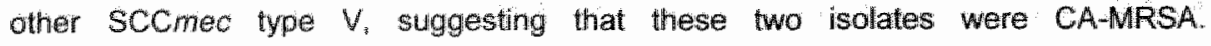
Furthermore, the SCCmec type was highly predictable (approximately $85 \%$ ) for the antibiotic susceptibility pattern, suggesting that rapid identification of the SCCmec type might be useful to predict the susceptibility pattern and guide the choice of antibiotics used for treatment. This could prevent unnecessary use of the "last resort antibiotic" vancomycin, which is then only needed in case of MRSA isolates harbouring SCCmec type II or III.

Chapter 6 describes the clonal distribution of 82 MRSA bloodstream isolates collected in 2001 and 2002 in Croatia. NO PVL and TSST-1 positive isolates were found: All strains were mult/resistant and were distributed among 19 clonal groups ( $A$ to S) as investigated by PFGE, two of which, $H$ and $K$, were major clonal groups. This suggests spread between Croatian hospitals. Group $H$ harboured $52 \%$, whereas group $K$ harboured $12 \%$ of the MRSA isolates. The majority $(89 \%)$ of the strains harboured SCCmec type I. A non-standard SCCmec type III was found in $11 \%$ of the isolates. One strain harboured, besides four loci, ccrC, which is normally only found in SCCmec type V. MLST analyses showed the presence of ST111-MRSA-I and ST247-MRSA-I, also found in the EMR and in other European countries.

Rapid and accurate molecular characterisation of MRSA, based on the SCCmec type and the investigation of the genetic background by MLST, is still a labour intensive task. Two methods are described in the literature to investiglate the type of SCCmec. The first method of Oliveira et al is a multiplex PCR method "where mecA and six different loci on SCCmec are amplified with PCR (8). The second method by Ito et al $(4,5)$ characterised the SCCmec type based on the combination of the mec complex and the cor genes. Most studies use the first method, whereas the method of Ito at al is now used when the SCCmec type cannot be determined with the method of Oliveira ef al. However, the two methods gave different results when typing SCCmec (10). A general and international agreement should be reached to define known and new SCCmec types, and one method should be developed and used in future studies. This method should be evaluated on all major MRSA clones as investigated by MLST (2). Since MLST is very labour intensive, a novel molecular typing method for the investigation of the dissemination of MRSA should be developed, that brings with it the speed of spa typing and the accuracy of MLST. This method should ideally be a combination of MLST, spa typing. SCCmec typing and should also include the determination of $S$. aureus specific genes, such as fem $A$, and several important virulence factors, like PVL and TSST-1. 
The worldwide emerge of CA-MRSA is a threat to both the community and the hospital environment, since these strains are known to be more virulent than HA-MRSA strains. Further studies should foremost focus on one clear definition of CA.MRSA, instead of the (at least) eight definitions that are now being used (6, 9). Furthemone, studies to investigate the prevalence of CA-MRSA, their genetic background, the presence of a larger panel of virulence factors in CA-MRSA strains and the risk factors for CA-MRSA colonisation should be started. MLST analyses are necessary to investigate if these strains have a ST1, ST30 or ST80 background, the common CAMRSA background found in the United States of America, Australlia and Europe respectively (11). Another question concerning CA-MRSA is the possible relation between SCCmec type IV (and V) and PVL, since reports are conflicting as to whether there is a relation between SCCmec type IV and PVL $(1,7,11)$. This should be performed with a real-time PCR assay, combining the $S$. aureus specific femA gene, the resistance gene mecA, ccrAB2, mecR1 (in combination specific for SCCmec type IV) and PVL. CA-MRSA strains with a different genetic background as investigated by MLST should be studied $(2,11)$.

There are still a number of questions unanswered concerning the molecular evalution of MRSA. One of the most intriguing questions is the origin of SCCmec. in this respect, it is noteworthy that Hanssen of al studied 39 methicillin-resistant coagulase-negative staphylococci (MRCNS), and 22 had a novel SCCmec type (3). These novel SCCmec types could give us more information about the possible transfer of SCCmec between CNS species and $S$. aureus. Moreover, other studies found novel SCCmec types, or SCC elements without mecA, which could be a reservoir for antibiotic resistance islands, in $S$. aureus. Further studies should also investigate the role of pets and farm animals in the transfer of SCCmec, i.e. is SCCmec formed in animals in MRCNS or MRSA and transferred to humans or are humans the source of CINS or S aureus strains carrying SCCmec?

It has been suggested that MRSA is more pathogenic than MSSA, but little evidence has been brought forward, except that CA-MRSA, harbouring SCCmec type IV and $P V L$, have caused necrotising pneumonia in young adults. However, a relation between resistance and virulence cannot be ruled out, since it has been shown that sub-inhibitory concentrations of antibiotics influence the expression of virulence factors.

Another question is why a large proportion of MRSA strains are ciprofloxacin resistant. The mechanisms of resistance against fluoroquinolones and methicillin differ significantly. Fluoroquinolone resistance generally arises from spontaneous mutations in existing chromosomal genes, whereas methicillin resistance results from the 
acquisition of new genetic material, ie: SCCneC. It is possible that most MRSA strains are selected under conditions of multi-drug treatment, and that antibiotic pressure strongly favours the transmisston of multi-resistant $S$. aureus strains. Regardless of the exact nature, it is clear that the dissemination of antibiotic resistance strains will remain an important subject of further studies.

\section{REFERENCES}

1. Chung, M, G. Dickinson, H. De Lencastre, and A. Tomasz. 2004. linternational clones of methicillin-resistant Staphwococcus aureus in two hospitals in Miami; Florida. J. Clin: Microbiol 42:542-547

2. Enright, M.C., D.A. Robinson, G. Randle, E.J. Feill, H. Grundmann, and B.G. Spratt. 2002. The evolutionary history of methicillin-resistant Staphylococcus aureus (MRSA). Proc. Natl Acad. Sci. USA. 99:7687-7692.

3. Hanssen, A.M., G. Kjeldsen, and J.U. Ericson Sollid. 2004. Local variants of staphylococcal cassette chromosome mec in sporadic methicillin-resistant Staphylococcus auraus and methicillin-resistant coagulase-negative staphylococci: evidence of horizontal gene transfer? Antimicrob. Agents Chemother. 48:285-296.

4. Ito, T., K. Okuma, X.X. Ma, H. Yuzawa, and K. Hiramatsu. 2003. Insights on antibiotic resistance of Staphyfococcus aureus from its whole genome: genomic island SCC. Drug Resist. Updat. 6:41-52.

5. Ito, T., X. Ma, F. Takeuchi, K. Okuma, H. Yuzawa, and K. Hiramatsu. 2004. Novel type $\checkmark$ staphylococcal cassette chromosome mec driven by a novel cassette chromosome recombinase, ccrC. Antimicrob. Agents Chemother, 48:2637-2651.

6. Naimi, T.S., K.H. LeDell, K. Como-Sabetti, S.M. Borchardt, D.J. Boxrud, J. Etienne, S.K. Johnson, F. Vandenesch, S. Fridkin, C. O'Boyle, R.N. Danila, and R. Lynfield. 2003. Comparison of community and health care-associated methicillin-resistant Staphylococcus aureus infection. JAMA 290:2976-2984.

7. O'Brlen, F.G., T.T. Lim, F.N. Chong, G.W. Coombs, M.C. Enright, D.A. Rabinson, A. Monk, B. Said-Salim, B.N. Kreiswirth, and W.B. Grubb. 2004. Diversity among community isolates of methicillin-resistant Staphylococcus aureus in Australia. J. Clin. Microbiol. 42:3185-3190.

8. Oliveira, D.C., and H. de Lencastre. 2002. Multiplex PCR strategy for rapid identification of structural types and variants of the mec element in methicillin-resistant Staphylococcus aureus. Antimicrob. Agents Chemother. 46:2155-2161.

9. Salgado, C.D., B.M. Farr, and D.P. Calfee. 2003. Community-acquired methicillinresistant Staphylococcus aureus: a meta-analysis of prevalence and risk factors. Clin. Infect. Dis. 36:131-139. 
10. Shore, A., A.S. Rosisney, C.T. Keane, M.C. Enright, and D.C. Coleman. 2005 Seven novel variants of the staphylococcal chromosomal cassette mec in methicillin-resistant Staphylocaccus aureus isolates from Ireland Antimicrob. Agents chemother 49:20702083.

11. Vandenesch, F., T. Naimi, M.C. Enright, G. Lina, G.R. Nimmo, H. Heffernan, N. Liassine, M. Bes, T. Greenland, M.E. Reverdy, and J. Etienne. 2003. Communityacquired methicillin-resistant Staphylococcus aurous carying Panton-Valentine leukocidin genes: worldwide emergence. Emerg. Infect. Dis. 9:978-984. 


\section{Algemene discussie \& SAMENVATTING}

Dit proefschrift beschrifft de moleculaire karakterisering van Staphylococcus aureus isolaten betreffende de resistentie voor methicilline en de detectie van de virulentie factoren Panton-Valentine leukocidine (PVL) en toxic shock symdrome toxin-"I (TSST-1). Verder is de verspreiding van methicilline-resistente $S$. aureus (MRSA) isolaten in en tussen verschillende Europese landen onderzocht.

Omdat community-acquired MRSA (CA-MRSA) stammen vaak de genen bezitten welke coderen voor het PVL werd een real-time PCR assay ontwikkeld en geëvalueerd voor de identificatie van PVL-producerende $S$. aureus isolaten (Hoofdstuk 3). Daarnaast werdi een real-time PCR ontwikkeld en geëvalueerd voor de detectie van het tst gen, dat codeert voor TSST-1, in S. aureus stammen (Hoofdstuk 5). TSST-1-pasitieve $S$. aureus stammen werden gevonden in patiënten met Wegener's Granulomatosis, CA en haspital-acquired (HA) S. aureus isolaten $(24 \%, 14$ $\%$ en $25 \%$, respectievelijk). De relatie tussen de tst-positieve CA isolaten werd met behulp van Pulsed-Field Gel Electrophoresis (PFGE) onderzocht. Deze resultaten suggereren de verspreiding van een virulente $S$. awreus kloon in de open populatie. Ciprofloxacine resistentie als een voorspellende marker voor de detectie van MRSA was niet bruikbaar op de collectie $S$, aureus stammen welke zijn bestudeerd (Hoofdstuk 7).

Om de verspreiding in België, Duitsland, Kroatiê en Nederland en tussen de landen onderling te onderzoeken werden MRSA isolaten gekarakteriseerd met behulp van PFGE en Multilocus Sequence Typing (MLST). Tevens werd het SCCmec type bepaald en werd de aanwezigheid van PVL en TSST-1 genen onderzocht.

De Euregio Maas-Rijn (EMR) wordt gevormd door de grensstreek van Belgide, Duitsland en Nederland (Hoofdlstuk 4). MRSA isolaten ( $n=152$ ) afkomstig uit deze regio werden getypeerd met behulp van PFGE. Vier grote klonale groepen, $A, G, L$ en Q. werden gevonden, hetgeen suggereent dat verschillende MRSA klonen zijn verspreid in de EMR. Groep A werd hoofdzakelijk gekenmerkt door de aanwezigheid van het SCCmec type III en sequence type (ST) 239 en ST241. SCCmec type I en ST8/ST247 waren aanwezig in de meerderheid van de stammen van groep $G$, terwijl de meeste stammen van groep L werden gekenmerkt door het SCCmec type IV of I. Binnen deze laatste groep werden ST8 en ST228 aangetoond, te onderscheiden in twee verschillende klonale komplexen (CC): CC8 en CC5. Het merendeel van de starnmen van groep Q werd gekenmerkt door het SCCmec type II en ST225. Zowel ST225-MRSA-II en ST241-MRSA-III zijn nieuwe MRSA typen in Duitsland. Verder 
werd in twee MRSA isolaten een nieuw SCCmec type gevonden. Eën stam bezat het SCCmec type III, met daamaast hel pls gen en de dos regio, terwill de tweede MRSA stam werd gekarateriseerd als het SCCmec type IV zonder de dcs regio. Een MRSA isolat met het SCCmec type $V$ was ook positief voor het PVL. Tenslotte werd een correlatie van ongeveer $85 \%$ gevonden tussen het SCCmec type en het antibiotica gevoeligheidspatroon van de MRSA stammen. Sinelle identificatie van hel SCCmec type lijkt brukbaar om het antibiotica gevoeligheidspatroon te voorspellen en zou gebruikt kunnen worden voor de keuze van de juiste antibiotica therapie. Dit kan leiden tot een reductie van het gebruik van vancomycine, dat alleen nodig is voor de behandeling van MRSA isolaten met het SCCmec type II of III.

Hoofdstuk 6 beschrijft een studie waarin de genetische achtergrond van 82 MRSA bloedkweek isolaten afkomstig uit Kroatië en geisoleerd in 2001 en 2002 werd onderzocht. De MRSA stammen waren PVL en TSST-1 negatief: Alle stammen waren multi-resistent en konden met behulp van PFGE worden verdeeld in 19 verschillende klonale groepen (A V/m S). Groep $H$ en $\mathrm{K}$ bevatten de meerderheid (52\% en $12 \%$. respectievelijk) van de MRSA stammen. Verspreiding van MRSA stammen tussen Kroatische ziekenhuizen lijkt dus waarschijnlijk. Het meest voorkomende SCCmec type bij deze isolaten was het type $\mid(89 \%)$, terwijl bij $11 \%$ van de stammen een nietstandaard SCCmec type III werd gevonden. Deze bezat een extra locus D vergeleken met het SCCmec type III prototype. Eén stam bezat een nieuw SCCmec type, welke werd gekenmerkt door het corC gen en locus $\mathrm{E}$, beide karakteristiek voor het SCCmec type $V_{*}$ in combinatie met drie extra loci $\left(C_{i} D\right.$ en $F$ ). Verder onderzoek met MLST onderscheidde twee STs, te weten ST111 en ST247.

Snelle en accurate moleculaire karakterisering van MRSA, gebaseerd op het SCCmec type en de genetische achtergrond zoals onderzocht met MLST, is nog steeds zeer arbeidsintensief. Twee methoden om het SCCmec type te bepalen zijn beschreven in de literatuur. De eerste methode, ontwikkeld door Oliveira et $a l_{v}$ is een multiplex PCR, walarbij het mecA gen en zes verschillende loci op het SCCmec worden gedetecteerd. De tweede methode, ontwikkeld door lto et al, karakteriseert het ScCmec type gebaseerd op de combinatie van het mec complex en de ccr genen. De meeste moleculair epidemiologische studies gebruiken de eerste methode en de methode van Ito et al wordt tegenwoordig gebruikt indien het SCCmec type met de methode van Oliveira et al niet kan worden bepaald. Deze twee methoden kunnen echter verschillendle resultaten geven bij Sccmec typering. Een algemene en internationale erkende definitie voor SCCmec dient te worden afgesproken en 
vervolgens zou een nieuwe methode ontwikkeld moeten worden woor de typering wan bekende en mieuwe SCCmec typen. Deze methode zou geevalueerd kunnen worden op alle bekende MRSA klonen, zoals onderzocht met MLST, en vervolgens kan deze methode in toekomstige studies gebruakt worden. Aangezien MLST een zeer arbeidsintensieve methode is ${ }$ is het ontwikkelen van een nieuwe moleculaire typeringsmethode voor onderzoek naar de verspreidng van MRSA ten zeerste gewenst. Deze methode dient de voordelen van spa typering (smeiheid) en MLST (accuratese) te combineren. Deze methode zou een combinatie kunnen zijn van MLST en SCCmec typering, alsmedie de detectie van een $S$. aureus specfieke gen, zoals femA, en een aantal virulentie factoren; zoals het PVL.

De wereldwijde toename van de prevalentie van CA-MRSA is een bedreiging binnen en buiten het ziekenhuis, omdat deze stammen wirulenter zijn dan HA-MRSA. stammen. Allereerst zal internationaal consensus bereikt moeten worden over de definitie van CA-MRSA. Vervolgens kunnen studies worden gestart om de prevalentie van CA-MRSA, de genetische achtergrond van CA-MRSA, de aanwezigheid van een groot aantal virulentie factoren in CA-MRSA stammen en de risicofactoren geassocieerd met CA-MRSA kolonisatie te onderzoeken. MLST analyses zijn bij deze studies noodzakelijk , om te onderzoeken of de stammen een ST1, ST30 of ST8O genetische achtergrond hebben, de typische CA-MRSA genetische achtergrond in respectievelijk de Verenigde Staten van Amerika, Australiè en Europa. Een andere vraag is de relatie tussen het SCCmec type IV (en $V$ ) en het $P V L$, want de verschillende studies geven geen duidelijk antwoord over de relatie tussen het SCCmec type IV en het PVL. Deze studie zou moeten worden verricht met behulp van een real-time PCR methode, welke het $S$. aureus specfiek gen fem $A_{\text {, }}$ het resistentie gen mecA. CCrAB2, $\triangle$ mecR1 (in combinatie specifiek voor het SCCmec type IV) en het PVL detecteert. Deze methode dient te worden geévalueerd met CA-MRSA stammen met een verschillende genetische achtergrond, zoals aangetoond met MLST.

Nog steeds zijn een aantal vragen onbeantwoord betreffende de möleculaire evolutie van MRSA. Eén van de meest interessante vragen is de herkomst van SCCmec. Het is opmerkelijk dat Hanssen et al 39 methicilline-resistente coagulasenegative staphylococcen (MRCNS) onderzochten, waarvan 22 stammen een onbekend SCCmec type thadden. Deze onbekende SCCmec typen kunnen ons meer informatie verschaffen over de mogelijke overdracht van SCCmec tussen CNS en $S$ aureus. Verder hebben andere studies ook onbekende SCCmec typen gewonden, of SCC elementen zonder mecA, welke een reservoir kunnen zijn voor antibiotica resistentie genen, in $S$. aureus. Tevens dient de rol van huisdieren en landbouwdieren te worden 
onderzocht als mogelijke bron voor het SCCmec. Ontstaat het SCCmec in dieren in MRCNS of MRSA en wordt vervolgens de mens besmet, of zijn mensen de bron van CNS en $S$, aureus stammen welke SCCmec bevatten?

Er wordt gesuggereerd dat MRSA meer pathogeen is dan MSSA, maar weinig situdies ziln uitgewoerd om dit te bewijzen. CA-MRSA, welke het SCCmec type IV en het PVL bevat, kan ernstige huidinfecties bij jonge volwassenen veroorzaken. Een relatie tussen resistentie en virulentie kan niet worden uitgesloten, omdat lage concentraties antibiotica de expressie van virultentiefactoren kunnen beïnvbeden.

Een andere vraag is waarom een groot percentage MRSA stammen resistent is voor ciprofloxacine. Het mechanisme van resistentie van fluoroquinolonen enerzijds en methicilline anderzijds is geheel verschillend. Fluoroquinolonen resistentie wordt hoofdzakelijk veroorzaakt door mutaties in het chromosoom, terwijl methicilline resistentie wordt veroorzaakt door SCCmec. Een mogelijkhaid is dat MRSA stammen worden geselecteerd tijdens antibioticatherapie en dat antibioticadruk de verspreiding van multi-resistente $S$. aureus stammen stimuleert.

Duidelijk is dat onderzoek naar verspreiding van antibioticaresistente bacterièn een belangrijk onderwerp is voor verdere studies. 


\section{DANKWOORD}

Aan het einde gekomen van mijn promotieonderzoek wil ik graag ledereen bedanken voor zijn/haar hulp en steun.

Ellen, een paar jaar geleden heb je me vit een zeer diep dal gehaald. De mogelijkheid tot een promotieonderzoek en de vrijheid die je me gaf om mede de richting van het onderzoek te bepalen hebben zeker bijgedragen aan mijn herstel. Dank je voor al je hulp, steun en soms corrigerende tik.

Kees, dank je voor je steun en bemoedigende woorden in de moeilijke begintijd, het verbeteren van de artikelen en voor de vele tips op het gebied van de moleculaire biologie.

Cathrien, dank je voor de mogelijkheid die je me hebt geboden om bij de afdeling Medische Microbiologie mijn promotieonderzoek te verrichten.

Christel, ongetwijfeld heb ik van jou het meeste geleerd op het gebied van de moleculaire biologie. Of we nu terug gaan naar mijn stage- en afstudieer periode, of tijdens mijn promotietijd, te vaak heb ik je vragen gesteld. Mijn speciale dank voor je hulp bij het opzetten van de TSST-1 TaqMan, de MLST bepalingen en dat je de rol van paranimf op je neemt. En stuur me a.u.b. een uitnodiging van jouw promotiel

Sita, mijn collega AlO, we hebben heel wat gebekvecht de afgelopen jaren. maar je kunt best aardig zijn als je wilt. Dank je voor al je hulp en steun speciaal bij milin hemden keuze.

Guy, samen zijn we eind 2003 met de SCCmec typering begonnen en wat waren we trots op onze eerste resultaten (nadat bij ons eerste experiment de negatieve controle positief was) en ons EMR stuk is, mede dankziij Jascha, uitgegroeid tot een prachtig stukje werk. Dank jullie voor jullie hulp! Ukki, ik bedoel Miranda, dank je voor al je hulp en raad, al dan niet op het gebied wan de wetenschap 9.

Ana, it was three weeks of hard working for our paper about MRSA in Croatia, but we got a nice paper. Thank you for all your help and support.

Monique, dank je voor al die keren dat ik bij je kon komen als ik vragen had over de bacteriologisch kant van het verhaal. Je was een goede steun als itk weer eens een stam niet kon identificeren. Daisy, bedankt voor al je hulp en steun, welke ik zeker eind 2003 nodig had. Erik, dank je voor al je hulp en steun bij de moleculaire biologie.

De mensen met wie ik het genoegen had elke dag per trein van en naar Maastricht te reizen. Jo, Wendy, Maarten, John, Jacqueline, Eric, Brenda, Kees en Trix, dank voor jullie steun met de "DNA profielen". 
Mama \& May papa \& Mabel, Rob \&own, oma en Loes, dank woor jullie hulp en geduld. Julle waren een fantastische steunl Loes, bedankt dat je paranimf will zijn en oolt hoop ik die rol woor jou op me te nemen!

Lieve Beer, dank je voor je steun de afgelopen 35 jaar. We weten nu eindelink dat je een vrouwtjes beer bent!

Rusud 


\section{CURRICULUM VITAE}

Ruud Deurenberg werd op 15 mei 1970 gebonen in Heerlen, Nederland. Van 1986 tot 1991 studeerde hij chemie aan het Middelbaar Laboratorium Onderwijs (MLO) te Sittard. Na afloop besloot hij verder te studeren aam het Hoger Laboratorium Onderwijs (HLO), alwaar hij biochemie studeerde. Na voltooling van zijn stago-en afstudeeropdracht bij de afdeling Medische Microbiologie van het academisch ziekenhuis Maastricht (azM) in 1995, werkte hij van 1995 tot 1998 als research analist bij deze afdeling. Van oktober 1998 tot juni 2000 was hij werkzaam als hoofdanalist bij de afdeling Biotechnologie van de Stichting Sanquin te Amsterdam. In juli 2000 begon hij te werken als research analist en laboratorium manager bij de afdeling Radiotherapie van het azM en sinds juni 2003 is hij werkzaam als assistent in opleiding (A.O) bij de afdeling Medische Microbiologie van het azM alwaar hij zijn promotieonderzoek verrichtte. 
b $\quad \cdots$

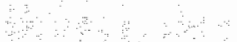




\section{Publications}

\section{Abstracts}

1. W. Landuyt, L. Lutgens, B. Ahmed, J. Theys, S. Nuyts, R. Deurenberg, A. Griffioen, W. Van den Bagaert, A. vam Oosterom and P. Lambin. The beneficial role of vascular targeting as a partner in anti-cancer therapy: some pre-dinical evaluations discussed. $1^{\text {st }}$ ESTRO Workshop on Bilology in Radiation Oncology. Fuglsø. Aarhus, Denmark. 10 to 12 June 2001.

2. W. Landuyt, L. Lutgens, B. Ahmed, R. Deurenberg, A. Giffioen, J. Theys, S. Nuyts, W. Van den Bogaert, A. van Oosterom and P. Lambin. An approach of the potential therapeutic windows in combinations of vascular targeting with radiotherapy. European Radiation Research Meeting. Dresden, Germany. 1 to 7 September 2001.

3. G. Oudhuis, R. Deurenberg, C. Vink and E. Stobberingh. Prevalence of SCCmec type in clinical methicillin-resistant Staphylococcus aureus (MRSA) isolates from three hospitals in The Netherlands, Belgium and Germany. $8^{\text {th }}$ Maastricht Medical Students Research Conference (MMSRC), Maastricht, The Netherlands. 17 March 2004.

4. Ruud H. Deurenberg, Guy J Oudhuis, Jascha E. Mooij, Cornelis Vink and Ellen E. Stobberingh. Prevalence of SCCmec type in methicillin-resistant Staphylococcus aureus (MRSA) isolates from the Euregio Meuse-Rhine. World Conference on Dosing of Antiinfectives, Nürnberg, Germany. 9 to 11 September 2004 .

5. R.H. Deurenberg, G.J. Oudhuis, J.E. Mooij, C. Vink and E.E. Stobberingh. Prevalence of SCCmec type in methicillin-resistant Staphylococcus aureus (MRSA) isolates from the Euregio Meuse-Rhine. Joint Scientific Meeting on Infectious Diseases and Microbiology NVMMNIZ/SBIMC-BVIKM 2004, Amsterdam, The Netherlands. 18 to 19 November 2004.

6. Ruud H. Deurenberg. Guy J. Oudhuis, Jascha E. Mooij, Cornelis Vink and Ellen E. Stobberingh. Prevalerice of SCCmec type in methicillin-resistant Staphylococcus aureus (MRSA) isolates from the Euregio Meuse-Rhine, Bioforum 2004, Liege, Belgium. 7 December 2004.

7. Miranda E. Niessen, Ruud $H$. Deurenberg, Cornelis Wink and Ellen E Stobberingh. Dissemination of Methicillin-Resistant Staphylocaccus aureus Clones in the Euregio Meuse-Rhine. PAC-Symposium, Leiden. The Netherlands. 3 March 2005.

8. R.H. Deurenberg, C. Vink, J. Hoogkamp-Korstanje and E.E. Stobberingh, Is ciprofloxacin resistance in Staphylococous aureus a biological marker for methicillin-resistant Staphylococcus aurews in The Netherlands? Wetenschappelijke Voorjaarswergadering NVMM/NVMM 2005, Arnhem. The Netherlands. 11 to 13 April 2005.

9. R.H. Deurenberg, G.J. Oudhuis, J.E. Mooij, C. Driessen, C. Vink and E.E. Stobberingh. Dissemination of methicillin-resistant Staphylocaccus aurous clones in the Euregio Meuse-Rhine. Wetenschappelijke Voorjaarsvergadering NVMM/NWM 2005, Arnhem. The Netherlands. 11 to 13 April 2005. 
10. RH. Deurenberg G.J. Oudhuis, JE. Mooij, C. Diessen, C. Vink and EE Stobberingh Dissemination of methicillin-resistant Staphwococcus aureus clones: in the Euregio Meuse-Rhine. $105^{\text {th }}$ General Meeting of the American Society for Microbiology (ASM). Atlanta, United States of America. 5 to 9 June 2005.

\section{Pear-reviewed papers}

1. Ruud H. Deurenberg. Cornelis Vink, Christel Driessen, Michèle Bes, Nancy London, Jerome Etienme and Ellen E. Stobberingh. 2004. Rapid detection of Panton-Valentine leukacidin from clinical isolates of Staphylocaccus aureus strains by real-time PCR. FEMS Microbiology Letters. 240:225-228.

2. Ruud H. Deurenberg, Rutger $F$. Nieuwenhuis, Christel Driessen, Nancy London, Frank R. Stassen, Frank $H_{\text {. }}$ van Tiel, Ellen Stobberingh and Cornelis Vink. 2005. The prevalence of the Staphylococcus aureus tst gene among community- and hospitalacquired strains and isolates from Wegener's Granulomatosis patients. FEMIS Micrabiology Letters. 245:185-189.

3. Ruud H. Deurenberg, Cornelis Vink, Guy J. Oudhuis, Jascha E. Mooij, Christel Driessen, Guy Coppens, Jos Craeghs, Els De Brauwer, Sebastian Lemmen, Hans Wagenvoort, Alexander W. Friedrich, Jacques Scheres and Ellen E. Stobberingh. 2005. Different clonal complexes of methicillin-resistant Staphylococcus aureus are disseminated in the Euregio Meuse-Rhine. Antimicrobial Agents and Chemotherapy. Submitted.

4. A. Budimir, R.H. Deurenberg, V. Plecko, C. Vink, S. Kalenic and E.E. Stobberingh 2005. Molecular characterisation of methicillin-resistant Staphylococcus aureus bloodstream isolates from Croatia. Journal of Antimicrobial Chemotherapy. Submitted.

5. Ruud H. Deurenberg, Comelis Vink, Mieke A.A. Hoogkamp-Korstanje and Ellen E. Stobberingh. 2005. Ciprofloxacin Resistance is not a Marker for Methicillin-Resistant Staphylococcus aureus in The Netherlands. Journal of Clinical Microbiology. Submitted.

6. R.H. Deurenberg, C. Vink, S. Kalenic, A.W. Friedrich, C.A. Bruggeman and E.E. Stobberingh, 2005. The molecular evolution of methicillin-resistant Staphylococcus aureus, Journal of Antimicrobial Chemotherapy. In preparation. 
Finding the treasures that lay hidden in my lonely cave...

(Kayak - Marfin) 